\title{
La recuperación del palacio primitivo del Alcázar de Sevilla*
}

\author{
Recovery of the primitive palace of the Alcázar of Seville
}

Cristina Vargas Lorenzo ${ }^{1}$

Trífora Arqueología y Patrimonio S. L.

\begin{abstract}
RESUMEN
El conjunto monumental del Alcázar de Sevilla encierra aún hoy tras dos décadas de estudios arqueológicos innumerables incógnitas por resolver, si bien es cierto que las trazas fundamentales de su evolución y transformación han sido en lo sustancial localizadas. En el contexto de su investigación, el primer recinto, con su amurallamiento inicial y su primer gran palacio, ha concitado la mayor parte de nuestras investigaciones recientes, ya presentadas en diversos foros. Este trabajo es el fruto de un complejo proceso de análisis y rescate que durante 5 años se ha centrado en la recuperación del edificio fundacional del Alcázar, fechado en el siglo XI y oculto entre los restos de 9 viviendas que en la actualidad ocupan su antiguo espacio. Por un lado, mostramos aquí por vez primera el resultado de nuestras labores de recuperación de un palacio único, prototípico y hasta ahora oculto $y$, por otro, ponemos de manifiesto u na vez $\mathrm{m}$ ás la coherencia d el p rocedimiento de análisis, habitual en nuestro equipo, tanto en sus trazas estratégicas fundamentales como en la adecuada interacción arqueología-arquitectura, imprescindible para tal fin.
\end{abstract}

Palabras clave: Alcázar de Sevilla; arqueología; arquitectura; rehabilitación; análisis arqueológico de edificios; estratigrafía; cronotipología; proceso metodológico; siglo XI.

\begin{abstract}
The monumental complex of the Alcázar of Seville is still home to many unknowns after two decades of archaeological surveys, while it is true that the essential traces of its evolution and transformation have been discovered. In the context of its survey, much of our work, already presented in different forums, has focused on the first enclosure within its first wall and its first great palace. This work is the result of a complex process of analysis and rescue, which for five years has aimed to rec over the the Alcazar's main building, dating to from the 11 th century and hidden amongst the remains of 9 houses that currently occupy its former area. On one hand, we show for the first time the result of the works carried out to recover a unique prototypical palace, hitherto hidden. On the other hand, we demonstrate once again the coherence of the process of analysis, common in our team, both at its key strategic traces and the adequate archaeology-architecture interaction, indispensable to this end.
\end{abstract}

Key words: Alcázar of Seville; archaeology; architecture; refurbishment; building archaeological analysis; stratigraphy; chronotipology; methodological processes; $11^{\text {th }}$ century.

Recibido: 31-01-2019. Aceptado: 22-04-2019. Publicado online: 20-09-2019

Cómo citar este artículo / Citation

Vargas Lorenzo, C. 2019: "La recuperación del palacio primitivo del Alcázar de Sevilla", Arqueología de la Arquitectura, 16: e089. https://doi. org/10.3989/arq.arqt.2019.011

Copyright: (c) CSIC, 2019. (C) UPV/EHU Press, 2019. Este es un artículo de acceso abierto distribuido bajo los términos de la licencia de uso y distribución Creative Commons Reconocimiento 4.0 Internacional (CC BY 4.0).

\footnotetext{
* Este trabajo forma parte del Proyecto de Excelencia del Plan Nacional I+D+I denominado "Sistematización cronológica del Real Alcázar de Sevilla. Dataciones absolutas y gestión de la información mediante SIG y BIM” (HAR 2017-85182-P) financiado por el Ministerio de Economía, Industria y Competitividad, cuyo investigador principal es Miguel Ángel Tabales Rodríguez.

1 triforas1@gmail.com / ORCID iD: https://orcid.org/0000-0002-5872-6416
} 


\section{ANTECEDENTES}

La revisión y posterior reformulación de la cronología del primer Alcázar de Sevilla ha sido un hecho difícil de asumir, máxime cuando la historiografía tradicional que abogaba por una datación emiral sigue contando con cierto respaldo por parte de expertos medievalistas. Tras varios Proyectos Generales de Investigación ${ }^{2}$ y un Proyecto de Excelencia Autonómico ${ }^{3}$ con numerosos análisis arqueológicos, dataciones absolutas, excavaciones, estudios de materiales, topográficos y paleogeográficos, la fecha de su construcción no debería continuar en cuestionamiento, pues queda constatada entre mediados y finales del s. XI.

La resolución de esta problemática de primer orden fue clave para dar respuesta a numerosas preguntas tales como la configuración urbana del sector y su desarrollo antes de su implantación, el conocimiento de sus fases constructivas, formato original y posteriores transformaciones. En este sentido los resultados derivados de las últimas campañas arqueológicas realizadas en el Patio de Banderas (Tabales 2015) arrojaron una horquilla evolutiva cuyo inicio lo situamos en el s. IX a. C., continuando sin demasiadas interrupciones hasta época contemporánea, momento en el que se reorganiza su interior edificando casas adosadas a los diferentes lienzos conservados y dejando libre su espacio central para la colocación de una fuente. Relevante en la secuencia resulta el origen de la ocupación humana en esta parte de la ciudad, mucho antes de lo esperado y materializada en el hallazgo de varias oquedades vinculadas a usos domésticos, así como la extraordinaria transformación del entorno desde su primitiva fundación, pasando de ser un terreno elevado y flanqueado por los cauces del río Guadalquivir y Tagarete a una explanada regular y alejada de cursos fluviales. Tras un largo periodo de inactividad el sector volvió a ocuparse a finales del s. II a. C., pero no será hasta mediados del s. I a. C. cuando experimente un crecimiento sustancial con la formalización de un urbanismo tardorrepublicano, consistente en un gran

\footnotetext{
2 "Proyecto General de Investigación Análisis Arqueológico del Real Alcázar de Sevilla 1 (2000-2005)", "Proyecto General de Investigación Análisis Arqueológico del Alcázar de Sevilla 2, Patio de Banderas (2009-2013)" y actualmente en curso: "Proyecto General de Investigación Análisis Arqueológico del Alcázar de Sevilla 3, el origen del Alcázar (2017-2019)", financiados por el Patronato del Real Alcázar y Casa Consistorial de Sevilla.

3 "Análisis Estratigráfico y Cronotipológico de los Recintos Fortificados del Alcázar de Sevilla. Procedimientos, Sistemas y Aplicaciones desde su Vertiente Constructiva" (P12-TEP-1843), financiado por la Consejería de Economía, Innovación y Ciencia de la Junta de Andalucía.
}

edificio de carácter público usado posiblemente como almacén de grano. Dicho urbanismo quedaría anulado por un fenómeno natural de carácter violento fechado mediante Carbono 14 entre finales del s. II y principios del III d. C. (Tabales 2015: 184). El análisis arqueológico en combinación con los estudios geoarqueólogicos y paleobiológicos atribuyen la responsabilidad de tal destrucción a un Evento de Alta Energía; solo de ese modo puede explicarse un nivel de derrumbe de tal magnitud, mezclándose los restos con capas de limo provistas de componentes fluvio-marinos ${ }^{4}$. Como consecuencia de ello, la zona no se recuperó, constructiva y ocupacionalmente hablando, hasta finales del s. V-principios del VI d. C., momento en el que se documentan nuevos restos constructivos vinculados a un edificio de dimensiones notables. Su funcionalidad no está constatada, aunque la hipótesis que se baraja es la de un conjunto monacal dado su emplazamiento, cronología y dimensiones (Tabales 2015: 232).

La actividad islámica tuvo lugar durante el s. XI y supuso la última fase ocupacional previa a la implantación del primer recinto amurallado del Alcázar. Nos referimos a un urbanismo taifa extramuros de carácter doméstico que se extiende por el Patio de Banderas y su entorno. Su construcción, previa explanación del terreno y expolio mediante fosas de elementos constructivos previos, está bien documentada en el primer caso, identificándose un total de 6 casas articuladas en torno a calles estrechas e irregulares, planificadas alrededor de un pequeño patio central con jardín deprimido y dotadas de todos los servicios para garantizar un cierto nivel de comodidad: habitaciones pequeñas pero suficientes, cocinas, letrinas y estancias perimetrales con sus alcobas. Dichas casas estuvieron en uso el tiempo necesario como para requerir reformas; es el caso de los pavimentos de dess, cuyas reparaciones son visibles, la transformación de parterres rehundidos en suelos de cal, el repinte de algunas estancias con zócalos con lacería roja sobre fondo blanco, o la sustitución del sistema de evacuación de pozos negros por una moderna red de saneamiento público que vierte sus aguas a una alcantarilla central ubicada en una de las calles principales.

El barrio taifa, al menos en el lugar que nos ocupa, quedó anulado por la implantación del primer recinto amurallado del Alcázar. La revisión y puesta en común

\footnotetext{
4 Una consecuencia indiscutible del episodio de inundación fue la subida de cotas, situándose en algunos puntos hasta tres metros por encima de los niveles anteriores.
} 
de todas las intervenciones donde se documentó su sistema de cimentación (Tabales e. p.) posibilitó el conocimiento con altos niveles de certeza de su proceso constructivo, operación hecha al unísono, pero no por ello carente de particularidades ante la necesidad de adaptarse a la irregularidad del terreno, condicionado por un declive topográfico en sentido norte-sur. Asimismo, la revisión de los análisis de paramentos fruto del trabajo derivado de los proyectos concedidos ha proporcionado nuevas propuestas metodológicas para definir cronotipos fiables y completar el estudio de su técnica constructiva (Vargas 2013).

En este punto de la investigación, y descartada ya su datación emiral, quedaba por matizar su adscripción tardotaifa o bien almorávide inicial, difícil de detectar en los restos materiales recuperados dado el breve margen de tiempo existente entre ambos periodos históricos. Asimismo, seguíamos sin poder responder cuestiones fundamentales para la comprensión del funcionamiento del primer Alcázar. Para ello era necesario seguir completando la secuencia estratigráfica relativa a costa de incorporar nuevos análisis de estructuras susceptibles de ser estudiadas con el método arqueológico.

La coyuntura la proporcionó la posibilidad de analizar el inmueble n. ${ }^{\circ}$ 7-8 del Patio de Banderas como consecuencia de una Inspección Técnica de Edificios, que por normativa municipal es obligatorio realizar a todas aquellas casas que tengan una antigüedad superior a 100 años, criterio que cumple esta vivienda, levantada por el marqués de Irún en el sector occidental del Alcázar fundacional en 1874. La primera inspección reveló tal deterioro estructural que hubo que actuar de urgencia, efectuando operaciones de apuntalamiento de muros y forjados. No obstante, el Proyecto de Consolidación Estructural que debía redactarse para acometer la obra cuanto antes estaba sujeto a la ejecución de una intervención arqueológica previa cuyos resultados pudieran condicionar su futura redacción (Figs. 1 y 2).

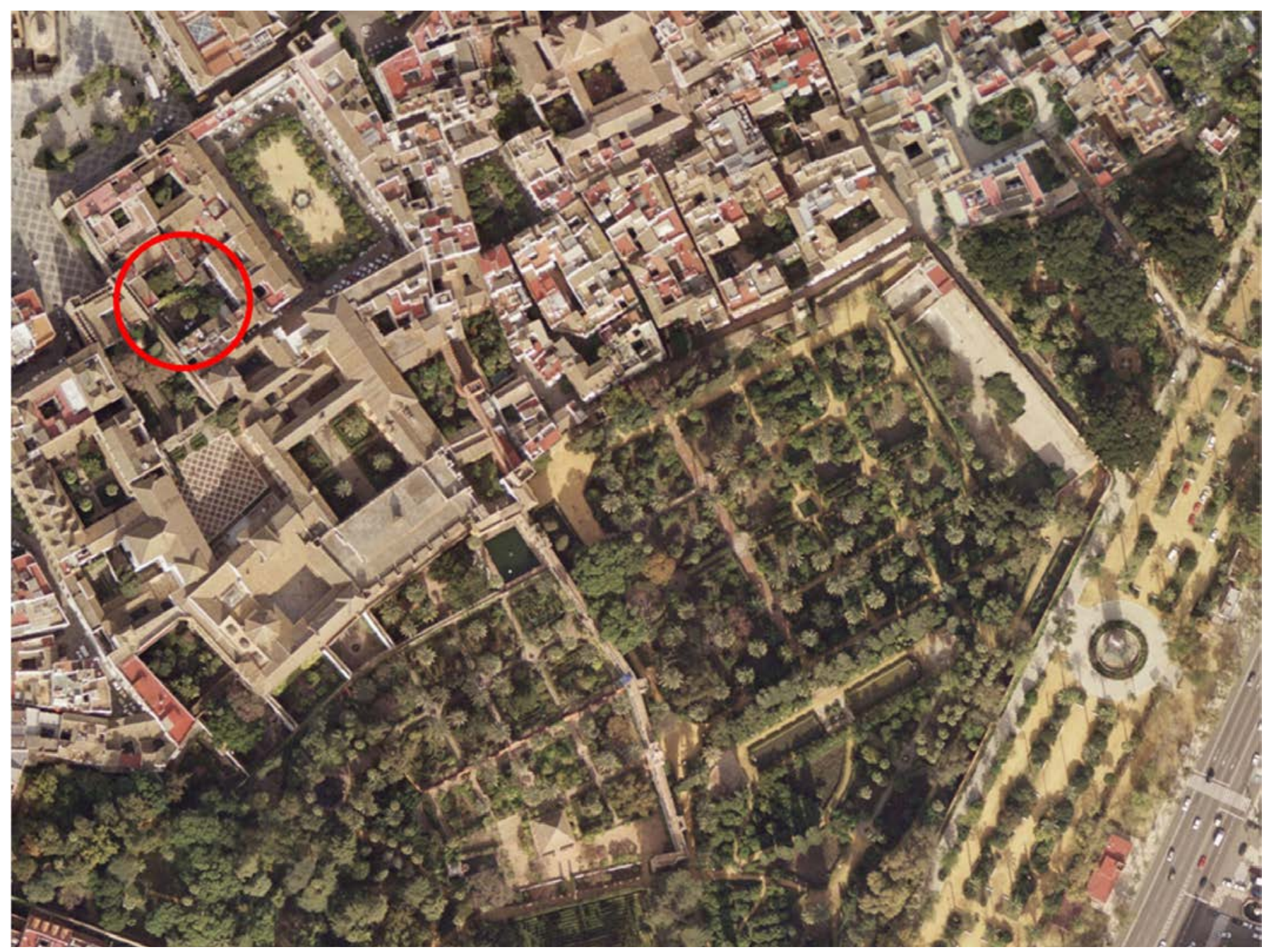

Figura 1. Localización de la parcela en el conjunto urbano del Alcázar de Sevilla (Google Earth). 


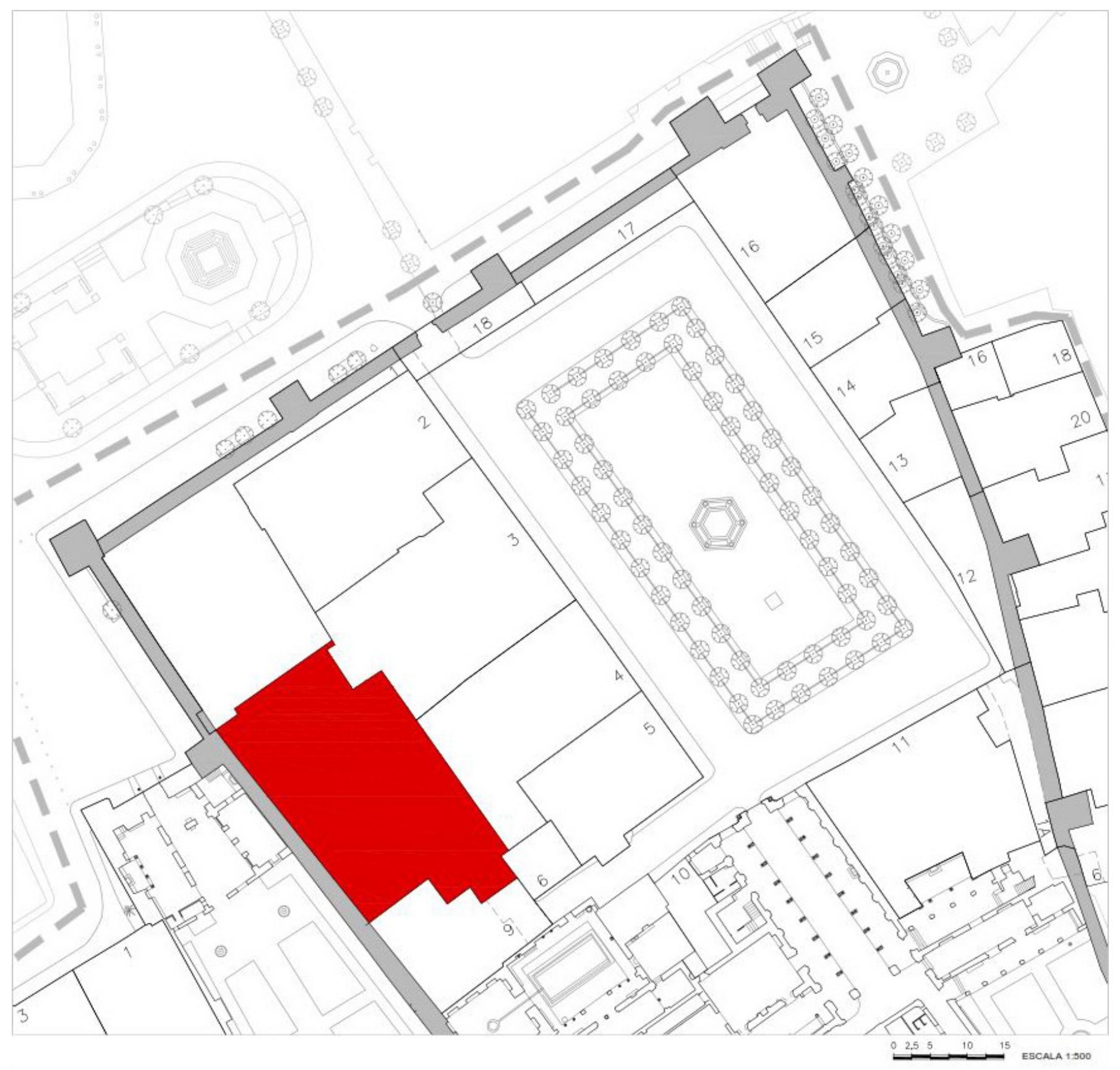

Figura 2. Plano actual de las casas del Patio de Banderas. Escala 1/500.

Los estudios arqueológicos previos a la obra han sido tres, a saber, una actividad preventiva de excavación y muestreos paramentales (año 2013) que reveló los restos del palacio fundacional, seguida de otra en la que se efectuaron sondeos y análisis de paramentos (años 2013-2014), dentro de la cual se contempló la recuperación y consolidación de los revestimientos pictóricos de un arco geminado perteneciente al citado palacio (año 2014). Finalmente se llevó a cabo el control arqueológico de obras, cuyas tareas se efectuaron entre mediados de 2016 y 2018. En concreto, estos dos últimos años han sido providenciales, pues la investigación de este punto del Alcázar ha resuelto, por extensión, dos problemas esenciales para seguir avanzando en la comprensión del primer recinto: por un lado, la morfología de las torres y sus sistemas de acceso a los adarves de la muralla y, por otro, la reducción del intervalo de incertidumbre respecto de su fecha fundacional, situando su construcción con altos niveles de certeza entre mediados-finales del siglo XI. A esta realidad incorporamos ahora la constatación 
de un palacio construido al abrigo de sus murallas, pieza clave en la secuencia evolutiva del Alcázar generada hasta el momento.

\section{PROCESO DE INTERVENCIÓN ARQUEOLÓGICA}

Ya no resulta necesario, y menos en este foro, justificar la validez de la aplicación del método arqueológico en el análisis de edificios históricos. La última década del siglo XX y sobre todo la primera del XXI fueron cruciales para definir a través de las intervenciones italianas y españolas una disciplina capaz de analizar las construcciones históricas desde una perspectiva diacrónica (Francovich y Parenti 1988; VV. AA. 2002). Tras innumerables esfuerzos de reflexión fruto del intercambio de experiencias y propuestas de nuevas herramientas, pasando por el análisis del marco legal, o la propia relación entre profesionales, se consiguió consensuar una denominación mayoritariamente aceptada por todos los agentes implicados en el patrimonio edificado: la Arqueología de la Arquitectura.

Desde ese momento, la labor de arquitectos y arqueólogos especialistas en la disciplina ha ido enfocada fundamentalmente a optimizar el método de estudio con la introducción de nuevas herramientas gráficas y analíticas, que han permitido una mejor comprensión del comportamiento del edificio en todas sus dimensiones.

No obstante, como es lógico, el método debe ser flexible, pues no todos los edificios históricos comportan las mismas problemáticas $\mathrm{y}$, por tanto, las mismas necesidades. En este sentido, el inmueble n. ${ }^{0}$ 7-8 presentaba tres cuestiones cuya resolución era prioritaria para afrontar en un segundo momento su rehabilitación, a saber:

1. Planteamiento de una hipótesis evolutiva inicial.

2. Obtención de una secuencia evolutiva completa, así como constatación (y en su caso, análisis) de la continuación de un palacio islámico cuyas estructuras, conservadas en alzado en la casa . $^{\circ} 2$, ya eran conocidas desde, al menos, el siglo XIX.

3. Valoración de la entidad de los restos arqueológicos hallados durante el proceso de investigación con el objeto de plasmar una posible propuesta de recuperación y puesta en valor de los mismos en el contexto de la rehabilitación del edificio.
Para dar respuesta a estas tres cuestiones era urgente diseñar un programa que cumpliera con los objetivos planteados.

El proceso de documentación previo a la realización de los primeros trabajos arqueológicos resultó esencial, ya que facilitó la planificación y diseño de la estrategia de intervención. Para ello se elaboró un estudio histórico preliminar donde quedaron recogidos todos los datos disponibles acerca del inmueble y su entorno, procedentes de la consulta de distintas fuentes de información. El análisis de la planimetría histórica demostró la existencia en el sector de espacios habitacionales vinculados, al menos desde principios del siglo XVII, a la figura del alcaide del Alcázar, tal y como queda consignado en uno de los planos $^{5}$. No obstante, en el entorno ya se conocía desde antiguo la existencia de estructuras islámicas en alzado atribuibles a un edificio de cierta prestancia en la casa n. ${ }^{\circ} 2$ del Patio de Banderas, contigua a la n. ${ }^{\circ}$ 7-8. José Gestoso, en 1889, publica una extensa descripción de una cúpula de nervaduras en la casa . $^{\circ} 3$ del Patio de Banderas (actual n. ${ }^{\circ}$ 2, Gestoso 1889: 324-325). Su interpretación lo lleva a adjudicarle una cronología almohade, integrándola en el contexto del Palacio del Yeso, ubicado más al sur, en el interior del conjunto monumental. Unos años más tarde volvería a referirse a ella en una nueva publicación, asegurando que el palacio al que perteneció la cúpula "fue engrandecido por los africanos considerablemente, en el siglo XI, y continuó siéndolo durante el periodo de los reyes de Taifa" (Gestoso 1897: 71) (Figs. 3 y 4).

El descubrimiento dado a conocer por dicho autor tuvo cierta repercusión. Tal es así que treinta años más tarde, en 1931, el alcalde y el director-conservador del Alcázar tramitaron formalmente una petición al Ministro de Hacienda con el objetivo de reclamar la propiedad de una serie de fincas, entre ellas, la n..$^{\circ} 3$, identificada por ellos como "cúpula almohade", así como los inmuebles 6-10 por ser, según ellos, la continuidad del "Palacio Almohade" (Fernández et al. 2017: 136).

Torres Balbás también hace mención a la cúpula, entendiéndola, al igual que Gestoso, como una pieza importante de los Cuartos Yeso-Montería. Asimismo, da por hecho que se trata de una construcción almohade, aunque sus similitudes con la que se encuentra precediendo el mihrab de la mezquita mayor de Tremecén le hicieron dudar, planteando la posibilidad de una adscripción almorávide (Torres 1949: 31).

\footnotetext{
Plano atribuido a Vermondo Resta y fechado en el año de 1608 (Archivo General de Simancas).
} 


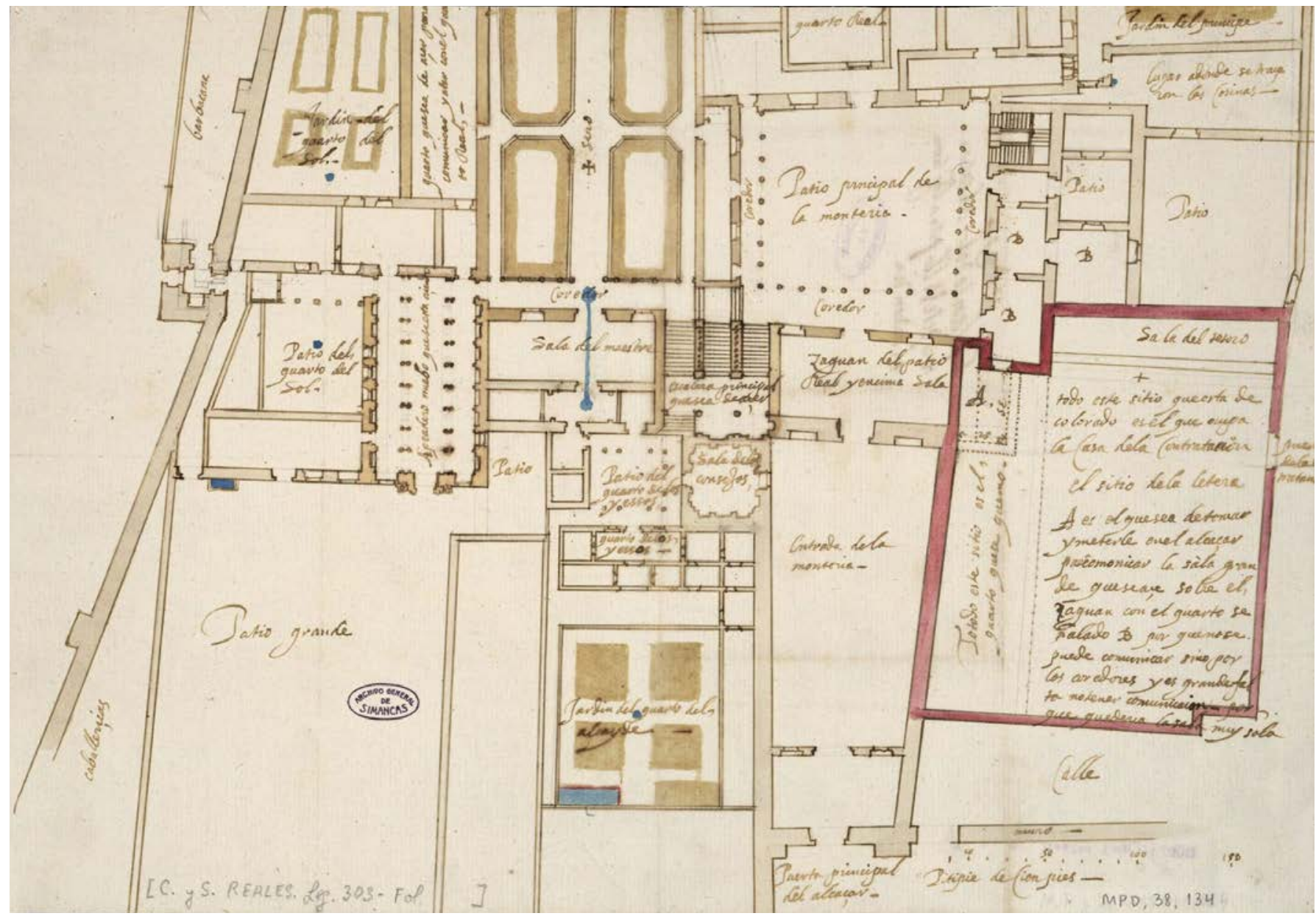

Figura 3. Plano atribuido a Vermondo Resta (Archivo General de Simancas).

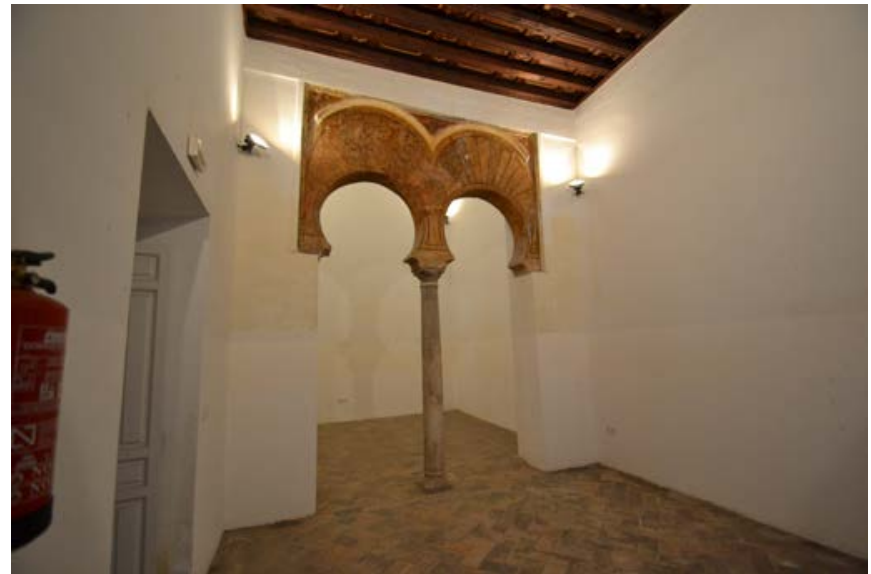

Figura 4. Arcos geminados conservados en el inmueble no 2 del Patio de Banderas.

Publicaciones más recientes, como las de Rafael Manzano no solo proporcionan referencias a la cúpula sino también a otros restos correspondientes al antiguo palacio integrados y visibles en el interior de los inmuebles 2 y 7-8, respectivamente. En este sentido, habla de una inspección visual realizada en 1963 en la que reconoce que la alcoba con su cúpula de nervaduras de tradición cordobesa pertenecería a una estancia alargada provista de otra alcoba de idéntica factura colocada en el extremo opuesto, esto es, el extremo occidental de la casa n. ${ }^{0} 7-8$, desaparecida por reformas posteriores fruto de la segregación que sufrió el palacio. Asimismo, hace referencia a la techumbre provista de canes decorados que originalmente cubriría la estancia central de la nave, encontrándose en la casa n. ${ }^{\circ} 2$ en su formato original, mientras que en la 7-8 estaría transformada por reformas del siglo XX. Aunque interpreta como almohade dichos restos, advierte, al igual que los investigadores precedentes, las muchas similitudes que la bóveda presenta con la que se conserva en la Mezquita Mayor de Tremecén (Manzano 1995: 117).

Antonio Almagro en 2011 publica un artículo en el que establece una comparativa entre el sistema constructivo de la bóveda de la casa 7-8 y la del alminar de la Mezquita Kutubiya, en Marraquech. La similitud que 
presenta el espacio con otros palacios almohades de Alcázar de Sevilla, como el Yeso, Contratación, o Crucero, así como sus características técnicas, hacen que se incline por una cronología almohade tardía (Almagro 2011: 49-50). En 2015, ya en paralelo a nuestro análisis arqueológico, vuelve a revisar la bóveda del inmueble a propósito del análisis que efectúa de la Mezquita Mayor de Tremecén. Sus doce arcos entrecruzados forman una cúpula de perfil hemisférico rematada con un cupulín central de mocárabes que guardan mucha relación con la que nos ocupa a diferencia de sus plementos, calados y ricamente decorados en la de Tremecén, permitiendo de ese modo el paso de la luz a través de unos huecos abiertos en su trasdós. Asimismo, analiza la cubierta de la nave central, situada en el espacio anexo a la bóveda calada, cuyos tirantes de madera se apoyan en canes con una decoración y disposición semejantes a los del alfarje que cubre la nave central del palacio islámico del Alcázar. Por todo lo expuesto, concluye planteando una revisión de la datación almohade inicialmente adjudicada, pues podrían atribuirse también al periodo almorávide (Almagro 2015a: 13).

La diversidad de enfoques con los que fueron realizados estos análisis proporcionaron una base sólida sobre la que comenzar a trabajar. En este sentido, asumidas las conclusiones de los estudios de Torres Balbás y Gestoso desde su perspectiva estilística, así como las de Manzano y Almagro en su condición de arquitectos, incorporamos la herramienta de la Arqueología de la Arquitectura con la intención de resolver las tres cuestiones planteadas en líneas previas.

La obtención de una hipótesis evolutiva como punto de partida se resolvió gracias a la ejecución de una primera fase de estudios previos (año 2013) con una estrategia encaminada a tal finalidad. Para ello se contó en primer lugar con un levantamiento planimétrico del edificio en el que se identificaron los paramentos-guía y sus contactos a través de una batería de 38 muestreos paramentales de $1 \mathrm{~m}^{2}$ aproximadamente. Con este ejercicio tan simple como eficaz pudo constatarse el carácter plurifásico del edificio, además de establecer las relaciones de anteroposterioridad entre sus elementos, así como su ordenación constructiva, reconocible a través de una simbología creada para tal finalidad (Tabales 2002a: 8182). Asimismo, los picados de revestimientos realizados para hacer los muestreos sirvieron para generar otro plano con la identificación y posterior clasificación de los cronotipos más relevantes para la secuencia evolutiva, tomando como base las tablas cronotipológicas confeccionadas en el Alcázar y su entorno desde el año 1999.

Este primer reconocimiento del edificio fue completado con la ejecución de 7 sondeos prospectivos que revelaron el momento inicial de ocupación de la parcela en época tardía y su desarrollo hasta la actualidad, dejando patente la complejidad de su evolución histórica, así como la diversidad constructiva presente en el edificio. Los muestreos paramentales mostraron evidencias más que suficientes como para suponer la presencia de restos de entidad del palacio islámico perteneciente al recinto primitivo del Alcázar. Los cortes arqueológicos, aunque superficiales y sin agotar registro, confirmaron la ocupación y continuidad de este espacio desde mucho antes de la implantación islámica, esto es, s. IV de nuestra Era.

Por todo ello, a esta primera aproximación le siguió una intervención arqueológica resultado de ampliar los estudios previos a la obra durante los años 2013 y 2014. El objeto era resolver la segunda problemática planteada inicialmente, consistente en, por un lado, la obtención de la secuencia evolutiva de la parcela $\mathrm{y}$, por otro, la certificación de la existencia del palacio. Continuando, por tanto, con el segundo nivel en la estrategia de intervención, se eliminaron al completo los revestimientos murarios de las estancias principales del palacio mediante picado arqueológico para someterlos a análisis estratigráficos, cronotipológicos y constructivos, previo levantamiento ortofotográfico de dibujo en CAD. Especial atención en este proceso tuvo la elaboración del plano base del que partiría la representación gráfica de las tres lecturas, realizándose dibujos exactos de los contornos de las unidades principales y simplificando las secundarias. Los grosores de las líneas determinaron la naturaleza y significado de cada una de ellas, distinguiendo las discontinuidades detectadas con una línea discontinua, los despieces estructurales o solerías con una línea de grosor fino, los contornos internos a diferentes planos e interfacies con una línea de grosor medio y los estructurales con otra de máximo grosor (Tabales 2002a: 140, 202).

El siguiente paso fue el análisis estratigráfico, con la plasmación de las distintas Unidades Estratigráficas asociadas a cada fase detectada, empleando para ello colores sólidos pero lo suficientemente transparentes como para permitir la visualización de fábricas, discontinuidades, números de unidad, etc. Ni qué decir tiene la importancia de las unidades interfaciales tanto en representación gráfica como en la propia interpretación, pues 
su valor como indicadores cronológicos resulta incuestionable. En cambio, todas las unidades que formaban parte de un mismo grupo coetáneo y, por tanto, homogéneo, se sometieron a un proceso de simplificación, suprimiendo las relaciones intermedias y reduciendo a una sola las complejas (Caballero 1996: 69). A su vez, en aquellos paramentos con una complicación estratigráfica mayor, las unidades fueron agrupadas en actividades, generando una interpretación basada en la comprensión de los distintos procesos constructivos documentados.

El análisis cronotipológico permitió hacer una caracterización de las técnicas constructivas, reconociendo un total de 12 tipos de aparejos, 4 de vanos, 4 de cubiertas, 5 de pavimentos y 6 de enlucidos. El proceso de clasificación se formalizó en función de una serie de "variables diagnóstico" que permitieron una completa identificación para su posterior determinación y encuadre cronológico. Las variables seleccionadas fueron tres, a saber, funcionales, materiales y técnicas. Asimismo, a través del uso de analíticas específicas como Carbono 14 , termoluminiscencia y mensiocronología fue posible establecer al menos las cronologías absolutas de las fábricas principales de la muralla del recinto I y de las estancias mejor conservadas del palacio. Los resultados fueron plasmados gráficamente en planos cronotipológicos en los que cada fábrica, forjado y elemento susceptible de ser clasificado recibió un color representativo de una tipología concreta vinculada exclusivamente a una fase determinada.

El análisis constructivo, anteriormente denominado estructural (Tabales 2002a: 195), se acometió con el objeto de recabar datos sobre las patologías visibles en estructuras, generadas por defectos en la propia ejecución de la obra, por el paso del tiempo, o por la acción humana como respuesta a una reforma o alteración de la estructura original. De todas ellas, la tercera categoría es fundamental, pues incide en la interpretación arqueológica general y estratigráfica en particular. A partir de la detección de eventos tales como adosamientos murarios (con o sin encastre), rupturas superficiales, grietas, taponamientos, desplomes, etc., y su representación gráfica, fue posible determinar la naturaleza de dichos eventos, su alcance y, lo más importante, las relaciones de anteroposterioridad con las estructuras adyacentes, enriqueciendo así el examen estratigráfico.

En paralelo a este análisis paramental tripartito, se llevaron a cabo nuevos sondeos con el objeto de conocer algunos aspectos no analizados en profundidad en la primera intervención. Se hicieron tres cortes en el patio meridional para completar el conocimiento sobre la configuración del ajardinamiento islámico perteneciente al palacio primitivo y sus transformaciones hasta la actualidad. Con el mismo fin se excavaron otros dos en el jardín más septentrional, centrando especialmente la atención en la localización y encuadre cronológico de una alberca y un parterre ajardinado representados en la planimetría histórica ${ }^{6} \mathrm{y}$ enfrentados a un gran patio. Ya en el interior de la vivienda se ampliaron tanto en anchura como en profundidad los sondeos realizados en la primera fase con la intención de conocer más en profundidad las cotas y sistemas de cimentación del palacio islámico. Finalmente, en el sótano se hizo una cata junto a la torre oriental de la gran Portada del León a fin de identificar posibles preexistencias (Figs. 5, 6, 7, 8 y 9).

\footnotetext{
6 Planos de Vermondo Resta y Sebastián de Van Der Borcht (Archivo General de Simancas y Archivo General de Palacio).
}

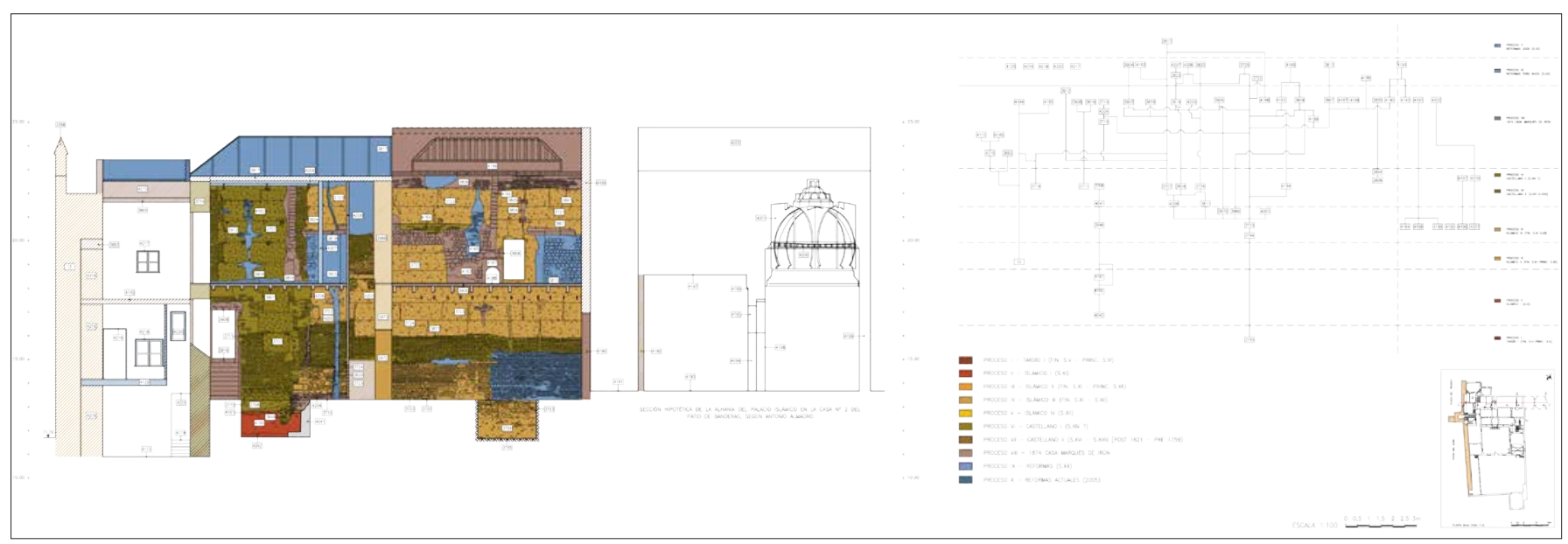

Figura 5. Análisis de paramentos. Sección oeste-este de la nave principal. Estudio estratigráfico. Escala 1/100 (Tabales y Vargas 2014). 


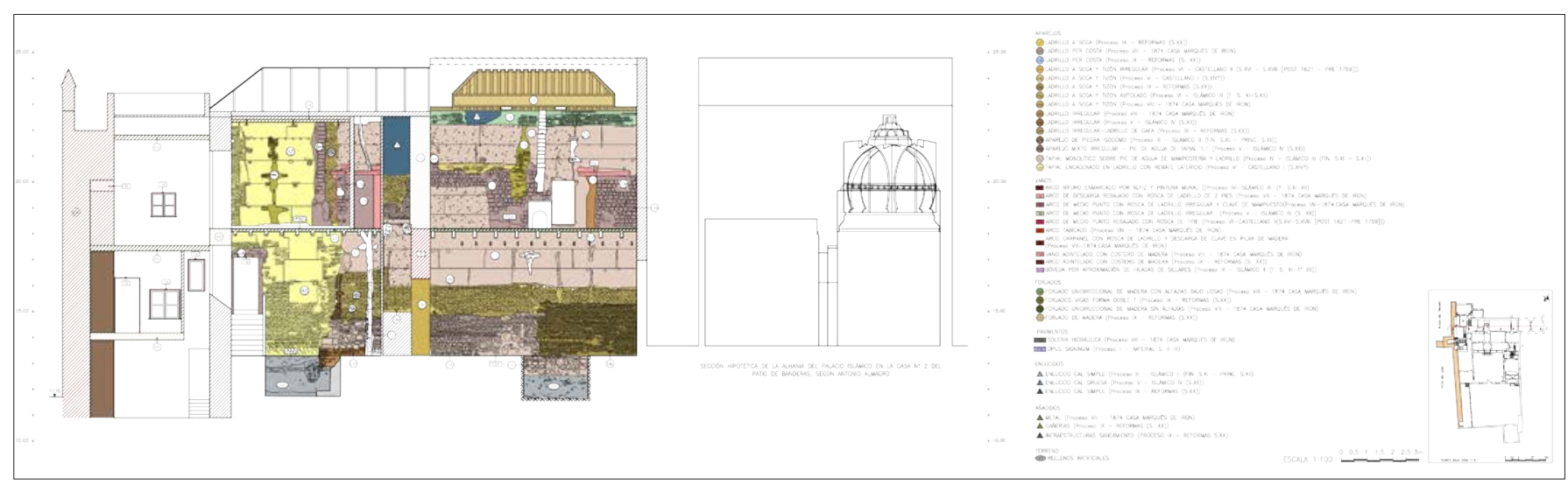

Figura 6. Análisis de paramentos. Sección oeste-este de la nave principal. Estudio tipológico. Escala 1/100 (Tabales y Vargas 2014).

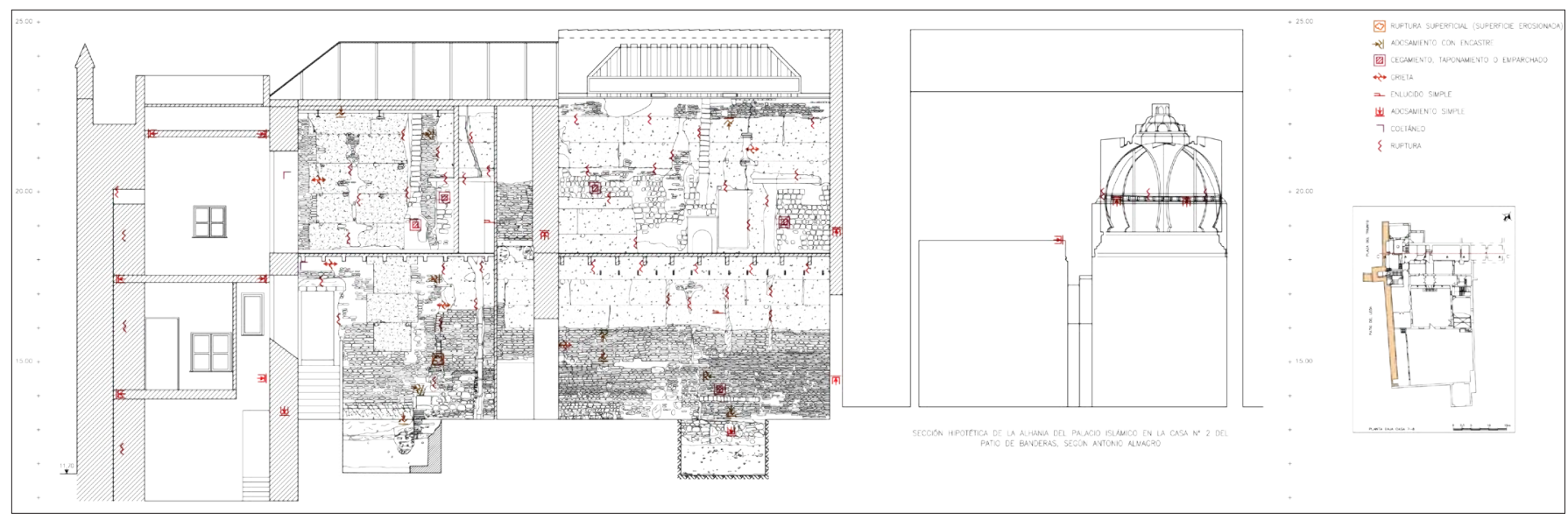

Figura 7. Análisis de paramentos. Sección oeste-este de la nave principal. Estudio constructivo. Escala 1/100 (Tabales y Vargas 2014).

Los resultados de ambas fases depararon una secuencia ocupacional íntimamente relacionada con los restos arqueológicos hallados en las excavaciones del Patio de Banderas y Patio del León, dada su cercanía. En el subsuelo del inmueble 7-8 no se llegó al nivel de ese primer momento de ocupación, pero la secuencia sí resultó coincidente en fases posteriores, esto es, a partir del s. II-III d. C. Las estructuras documentadas en los sondeos XXIV y XXX definieron un urbanismo bajoimperial cuyas cotas permitieron articularlas con los restos del Patio de Banderas, de funcionalidad industrial. Asimismo, pudimos constatar cómo en este punto del sector sucede el mismo fenómeno de declive topográfico en sentido norte-sur, con una diferencia máxima de $2,34 \mathrm{~m}^{7}$.

\footnotetext{
7 Los pavimentos del SE-XXX (+7.26 m al sur ) se sitúan a más de dos metros de diferencia del suelo de opus signinum del SE-XXIV $(+9.60 \mathrm{~m}$ al norte). Esta elevación queda enquistada hasta el día de hoy en el cuadrante noroccidental del primer recinto mediante la urbanización de estructuras aterrazadas en periodos posteriores (Tabales y Vargas 2014: 13).
}

El episodio de inundación expuesto en líneas precedentes y documentado bajo la plaza del Patio de Banderas se detecta también en los cortes XXIV y XXX, colmatando los espacios previamente abandonados y elevando el terreno, situándose en algunos puntos hasta en tres metros por encima de los niveles anteriores.

A finales del s. V y principios del VI d. C. se datan nuevos restos constructivos realizados con sillares alcorizos, uno de ellos perteneciente a la dovela de un gran arco adintelado junto a un pavimento de cerámica de machaqueo que permiten efectuar el mismo ejercicio de correspondencia con el Patio de Banderas, en este caso, situando dichos restos en el entorno de un edificio monumental.

El urbanismo de época taifa descubierto bajo la plaza del Patio de Banderas también alcanzó el sector más occidental del futuro primer Alcázar, pues en el sondeo XXIX se reconocieron muros y pavimentos 


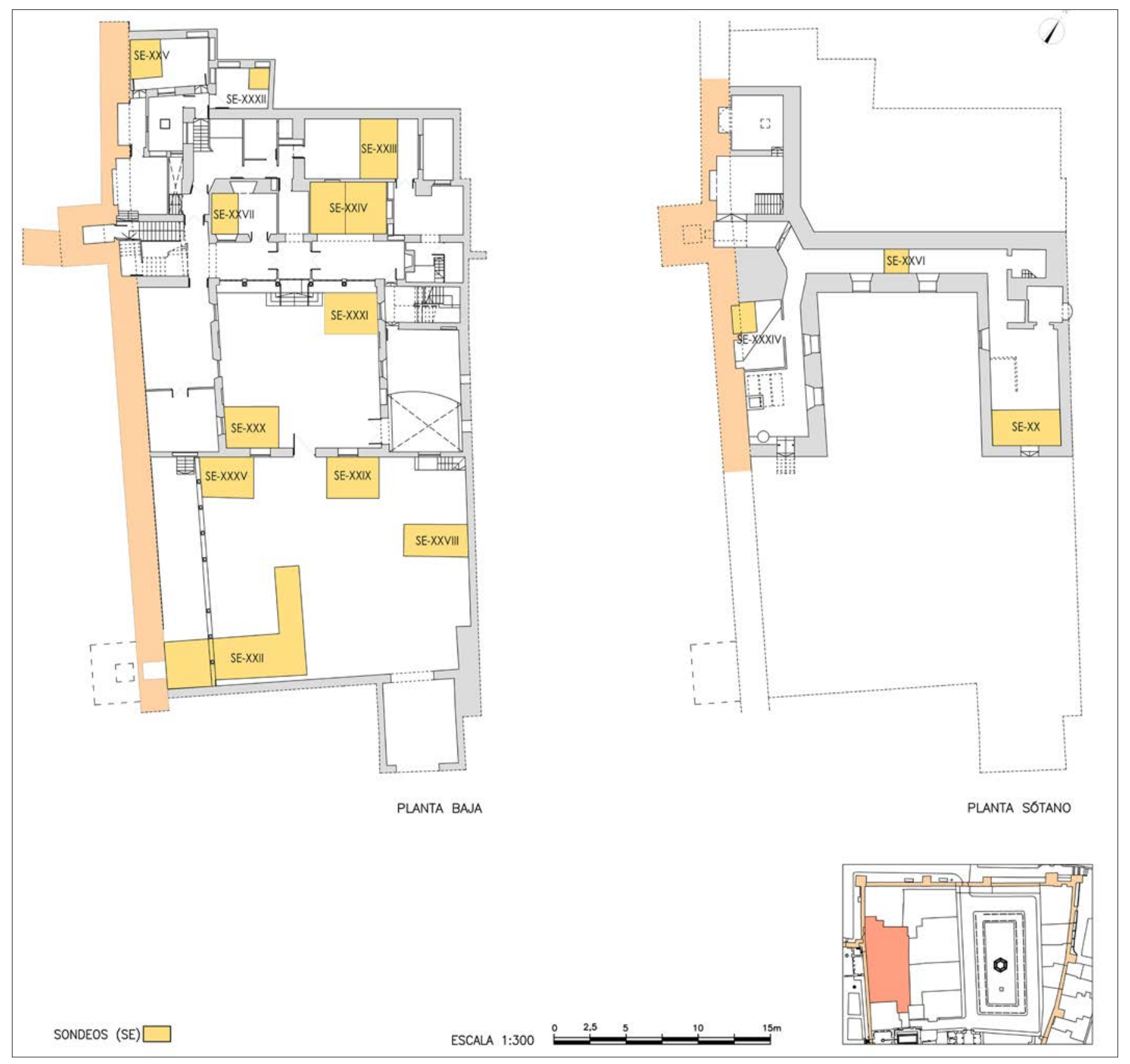

Figura 8. Localización de los sondeos estratigráficos. Escala 1/300 (Tabales y Vargas 2014).

cuyas características responden a esa misma fase de ocupación. Asimismo, también quedaron documentadas reformas fruto del uso continuado de las viviendas; es el caso de una estancia delimitada por dos muros de mampostería y pavimentada originalmente con un suelo de dess que quedó amortizado por otro pavimento de cal más humilde, además de la introducción de un pozo de abastecimiento adosado a uno de los muros.
El barrio taifa, al menos en la parcela del inmueble 7-8, quedó anulado por la construcción del primer amurallamiento del Alcázar. La prueba material se obtuvo del sondeo XXII, efectuado en la esquina suroeste del patio principal del inmueble, a los pies de la muralla. Nos referimos a un muro de mampostería conservado a nivel de cimentación con orientación este-oeste que quedó amortizado por la fosa de cimentación del paño oeste de la muralla, de orientación norte-sur. 


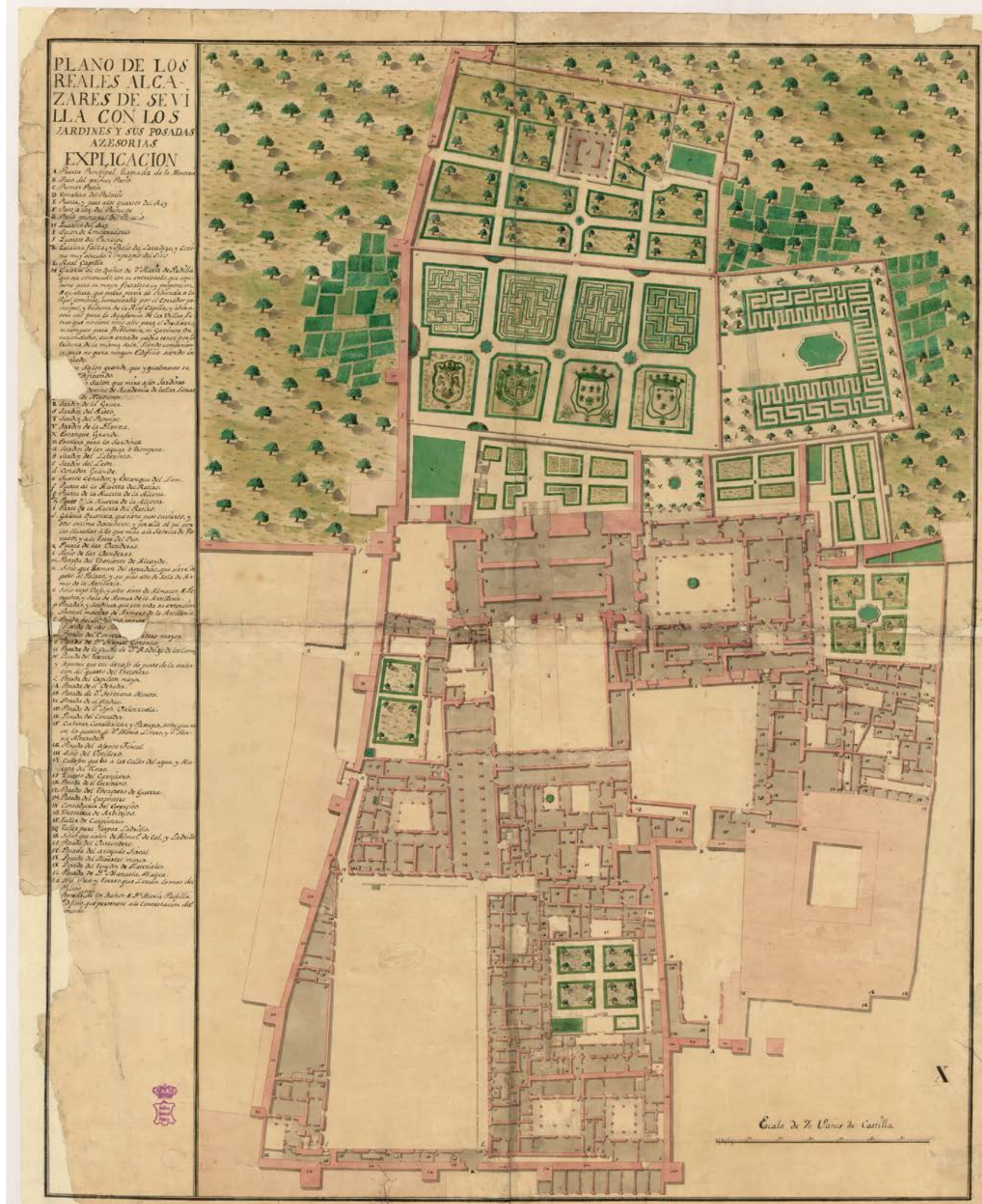

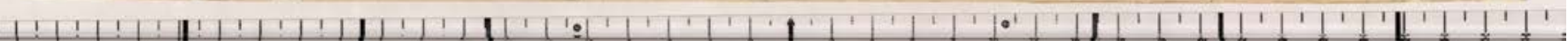

Figura 9. Plano de Sebastián Van der Borcht (Archivo General de Palacio). 
Este mismo corte también nos permitió documentar el proceso de construcción de la muralla ${ }^{8}$ en este punto y cotejarlo con los datos obtenidos hasta el momento, los cuales se han matizado, combinado y completado, determinando que la construcción de este primer recinto fundacional se hizo al unísono pero no por ello carente de particularidades para adaptarse a la irregularidad topográfica. La preparación del terreno fue la primera tarea a realizar, operación con un alto nivel de complejidad al tratarse de un sector de la ciudad ocupado por un urbanismo taifa en pleno funcionamiento. Una vez definido el trazado de la muralla, hubo que derribar hasta nivel de cimientos aquellas viviendas que ocupaban el ámbito de actuación, incluyendo especialmente las del sector occidental, emplazamiento elegido para el palacio. Dichas demoliciones estuvieron acompañadas de sendas zanjas de expolio con el objeto de reaprovechar materiales constructivos de edificios previos, procediendo con posterioridad a explanar el terreno con tierras seleccionadas y evacuar los escombros. Esta tarea podría haber sido más rápida si simplemente hubieran apisonado los desechos. Sin embargo, de no haberse acondicionado el terreno, la cota de uso hubiera subido varios metros, haciendo incompatible la vida en las casas que circundaban los terrenos anexos al futuro recinto amurallado, que continuaron con su actividad ${ }^{9}$.

La segunda operación consistió en trazar las zanjas de cimentación, cuyas dimensiones variaron dependiendo del sector. En este sentido, la zanja del lado norte se trazó en forma de $\mathrm{V}$ con base plana, alcanzando los 3 $\mathrm{m}$ de profundidad y más de 5 de espesor, mientras que en el lado occidental hubo que profundizar algo más, si bien el espesor no sobrepasó los $4 \mathrm{~m}$. Esta irregularidad viene motivada por la necesidad de adaptarse a la topografía del terreno, ya que mientras la zanja del lado norte discurría en sentido paralelo al declive topográfico, al oeste lo hacía en sentido transversal. Dicha cuestión afecta de la misma manera al cimiento y caña de la muralla: en el lado norte, se efectuó un vertido de tierra mejorada con cal hasta alcanzar los $2 \mathrm{~m}$, colocándose a continuación y a eje respecto de la fosa dos sillares que servirían de base para la ubicación de la caña de la muralla, retranqueada de modo que generaba una pequeña

\footnotetext{
8 Solo quedan en pie los lienzos norte y oeste (el meridional fue eliminado por la ampliación del recinto amurallado a inicios del s. XII y el oriental fue drásticamente sustituido por otro hecho en tapial como consecuencia de la citada ampliación).

9 El acondicionamiento del terreno se hizo a la cota $12 \mathrm{~m} \mathrm{~s}$. n. m. a excepción de la esquina noreste, donde se construiría el palacio. En este caso la cota no se rebajó, permitiendo así que el conjunto palacial quedara en alto.
}

zapata de no más de $2 \mathrm{~cm}$. Asimismo, la estructura de piedra tanto a nivel de cimientos como en alzado estaba compuesta por tres hojas, las dos exteriores de piedra y la interior conformada por un relleno de tierra y cascotes, alcanzando un espesor total de 1,95 m aprox. El lado oeste presenta una técnica similar, si bien se observa un acusado desajuste en la cimentación y caña de la muralla respecto de la zanja, ya que mientras que en el interior la fosa tan solo cuenta con apenas $15 \mathrm{~cm}$ de espesor, al exterior alcanza los $2 \mathrm{~m}$. Por otro lado, las dos hiladas pétreas que quedan bajo la superficie no están a plomo como en el lado norte, sino que la segunda se retranquea respecto de la primera, generando una zapata que viene a sumarse a la de la caña de la muralla, conformando dos zapatas o escarpas sobresalientes en total.

La cimentación de las torres muestra el mismo sistema de zanja corrida si bien, como es lógico, adquieren las dimensiones necesarias para introducir el cubo de sillares de cada una de ellas. Solo se ha podido analizar en su totalidad la torre suroccidental, arrasada hasta prácticamente sus cimientos y visible desde el Patio de la Montería. En este punto se pudo observar que el cimiento de la torre era más profundo que el lienzo occidental, permitiendo la colocación de una hilada más. Asimismo, la irregularidad topográfica existente también en este sector fue corregida en este caso mediante la introducción de una pequeña losa de no más de $20 \mathrm{~cm}$ sobre la que se dispusieron cuatro hiladas de sillares formando una pirámide escalonada de $2 \mathrm{~m}$ de altura, base de la caña del lienzo de muralla. La cota de uso estaba situada de modo que tan solo dos hiladas pétreas quedaban soterradas, quedando las otras dos sobre la superficie.

Tras el proceso de cimentación se acometió finalmente el alzado de lienzos y torres del primer recinto. Sus muros fueron levantados en sillería isódoma de acarreo, procedente muy probablemente de la muralla romana a juzgar por las huellas descontextualizadas de izado y acople que se observan en la práctica totalidad de los sillares. Dicha fábrica pétrea se combina a partir de la línea de adarve con fábricas mixtas hechas mediante ladrillo fino y mampostería de mediano calibre; es el caso de parapetos, merlones y cámaras de las torres. El análisis de estas últimas ha deparado interesantes novedades, pues la dificultad para acceder a su interior había hecho imposible plantear algo más que una hipótesis basada en fundamentos analógicos, según los cuales, al menos hasta el s. XII, eran macizas hasta su adarve. Sin embargo, el análisis de la torre oriental del León, inserta en el espacio del inmueble 7-8, deparó una realidad 
diferente, constatando una morfología hasta el momento única en la arquitectura islámica de este periodo. En este sentido, las torres presentan en su base un pequeño acceso hacia su interior, el cual estaría hueco. Dicho hueco experimentaría una disminución en sentido longitudinal logrado mediante la aproximación por hiladas de sillares de piedra idénticos a los de la muralla, conformando una bóveda que quedaría situada por debajo del nivel de suelo de cada una de las cámaras. La bóveda, dejaría un espacio abierto en su coronación para permitir el acarreo de material defensivo, mientras que el ingreso humano se efectuaba a través de una puerta abierta en la cara oriental de la cámara, conectando palacio y paseo de ronda mediante un puente levadizo o sabat, solución frecuentemente empleada para salvar tránsitos elevados ${ }^{10}$. El hecho de que las tres únicas torres originales investigadas dispongan de accesos como el antes descrito, y de que dos de ellas evidencien un sistema de paso en voladizo, podría hacernos pensar que el resto respondería al mismo esquema, pero no es descartable que alguna de ellas, allí donde no existieran edificios contiguos, pudiera disponer de alguna escalera transversal, como la de Mérida $^{11}$, o tal vez, lateral (Figs. 10 y 11).

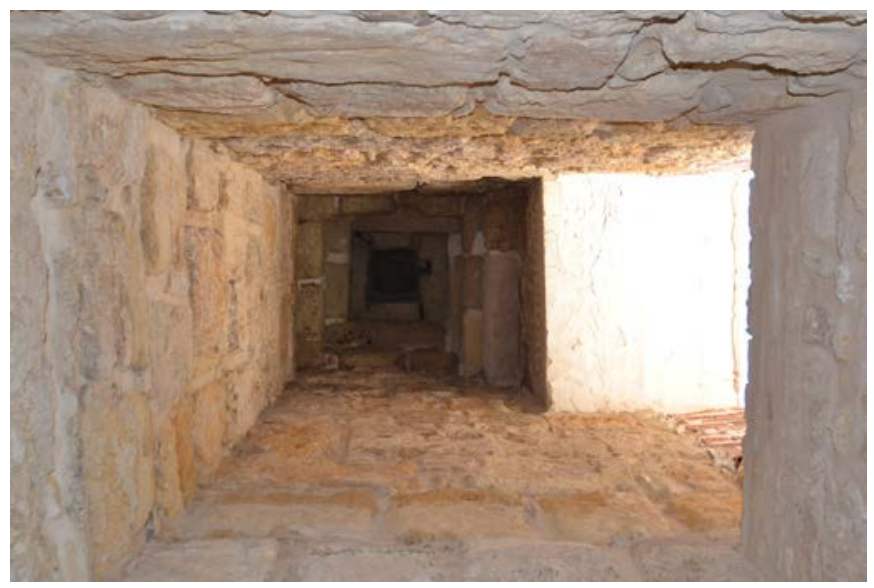

Figura 10. Bóveda por aproximación de hiladas vista desde el interior de la torre occidental de la Puerta del León (recinto primero).

\footnotetext{
10 Nuestra hipótesis inicial se basaba en las investigaciones de la casa $\mathrm{n} .^{\circ}$ 16 del Patio de Banderas (Tabales 2002b), donde se hallaron los restos de la antigua puerta de ingreso al interior del primer recinto, flanqueada por sendas torres. Por aquel entonces, planteamos que estas, además de servir de vigilancia, serían las únicas responsables de ofrecer comunicación con los adarves de la muralla primitiva.

11 Lo más lógico sería pensar en la presencia de peldaños embutidos en paralelo a la muralla, pero lo cierto es que no se conservan huellas en ningún punto de la misma. Por otro lado, pensar en escaleras en sentido perpendicular a los lienzos sería irracional, dado que haría falta disponer de, al menos, casi $17 \mathrm{~m}$ de desarrollo para poder ascender los $12 \mathrm{~m}$ de altura existentes desde su base hasta el adarve defensivo. No obstante, el caso de Mérida representa el único paralelo similar conocido.
}

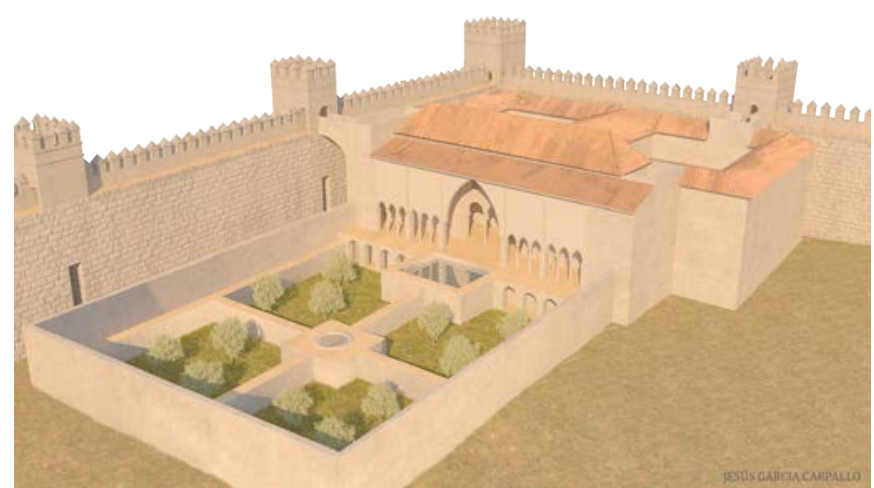

Figura 11. Reconstrucción hipotética de la comunicación entre el palacio islámico y las torres del primer recinto del Alcázar. Reconstrucción virtual de Jesús García Carpallo a partir de Miguel Ángel Tabales Rodríguez y Cristina Vargas Lorenzo.

Continuando con la secuencia evolutiva, el siguiente paso tras la construcción de la muralla fue la planificación del palacio islámico. De los 14 sondeos realizados, fueron 6 los que depararon estructuras cuyas características permitieron dibujar la planta de un edificio de corte palacial. Así, en los sondeos estratigráficos XXVIII y XXXI (ubicados en los patios de la vivienda actual) se documentaron restos de estructuras hidráulicas vinculadas a la configuración de su ajardinamiento, mientras que en el XXVI (sótano) pudo analizarse el muro principal de contención concebido para sustentar el edificio y, a su vez, salvar el desnivel topográfico existente, manteniendo el palacio en una posición elevada y dominante. Los sondeos XXIII, XXIV y XXVII, ubicados en el interior de la segunda y tercera crujía de la vivienda, permitieron determinar la construcción del palacio a nivel de cimientos, precisando con ello las trazas, compartimentaciones y dimensiones del mismo.

El estudio de paramentos al que antes hemos aludido certificó que los muros norte y sur de la tercera crujía así como los tabiques de compartimentación de las estancias occidentales pertenecían al momento de construcción del palacio, todos ellos (aunque con reformas) conservados en muy buen estado y prácticamente hasta su coronación, algo extraordinario dado el uso continuado del edificio, así como los eventos de naturaleza catastrófica sufridos en la ciudad de Sevilla, como los terremotos de los años 1356 y 1755 , respectivamente.

De la totalidad de hallazgos documentados en el proceso de intervención destacan dos, a saber, el descubrimiento de la alcoba oeste perteneciente a la nave norte del palacio, con sus arcos geminados de acceso 
en alzado ricamente policromados, en buen estado de conservación y simétricos a la alcoba incluida en la casa n. ${ }^{\circ} 2$, así como la exploración de la techumbre de la estancia central de la nave norte, cuyo análisis resolvió la existencia de piezas antiguas vinculadas al antiguo alfarje del palacio y conservado íntegramente en una de las estancias de la casa $n .^{\circ} 2$, como bien avanzaba Rafael Manzano (1995: 117) (Figs. 12, 13 y 14).

Las conclusiones de esta segunda intervención pusieron de manifiesto la necesidad urgente de iniciar cuanto antes la consolidación de los arcos geminados recién descubiertos, así como la concepción de una serie de propuestas de conservación que redundaran en la redacción del Proyecto Arquitectónico. Esas recomendaciones incluían, entre otras, operaciones tan evidentes como la recuperación y puesta en valor de los tramos de muralla islámica insertos en el interior de la vivienda a modo de muro medianero con el Patio del León del
Alcázar, la consolidación y conservación de las fábricas originales del palacio, así como la valoración de algunos de los restos hallados en los sondeos arqueológicos como detalle de la estratigrafía subyacente.

Dichas operaciones se efectuaron en el transcurso de la obra de consolidación del edificio entre los años 2016 y mediados de 2018, cumpliendo así el último objetivo planteado en la estrategia inicial: incidir en la rehabilitación del edificio mediante propuestas surgidas no solo de los hallazgos de las dos intervenciones previas, sino de los que pudieran salir a la luz como consecuencia de la propia obra. En este punto del proceso, la relación entre arqueólogo y arquitecto fue fundamental para la obtención de un buen resultado final, pues en este caso el arquitecto aceptó la implicación del arqueólogo en su proyecto, entendiendo su papel como "investigador del edificio" o, dicho de otro modo, como una figura susceptible de obtener en una obra de

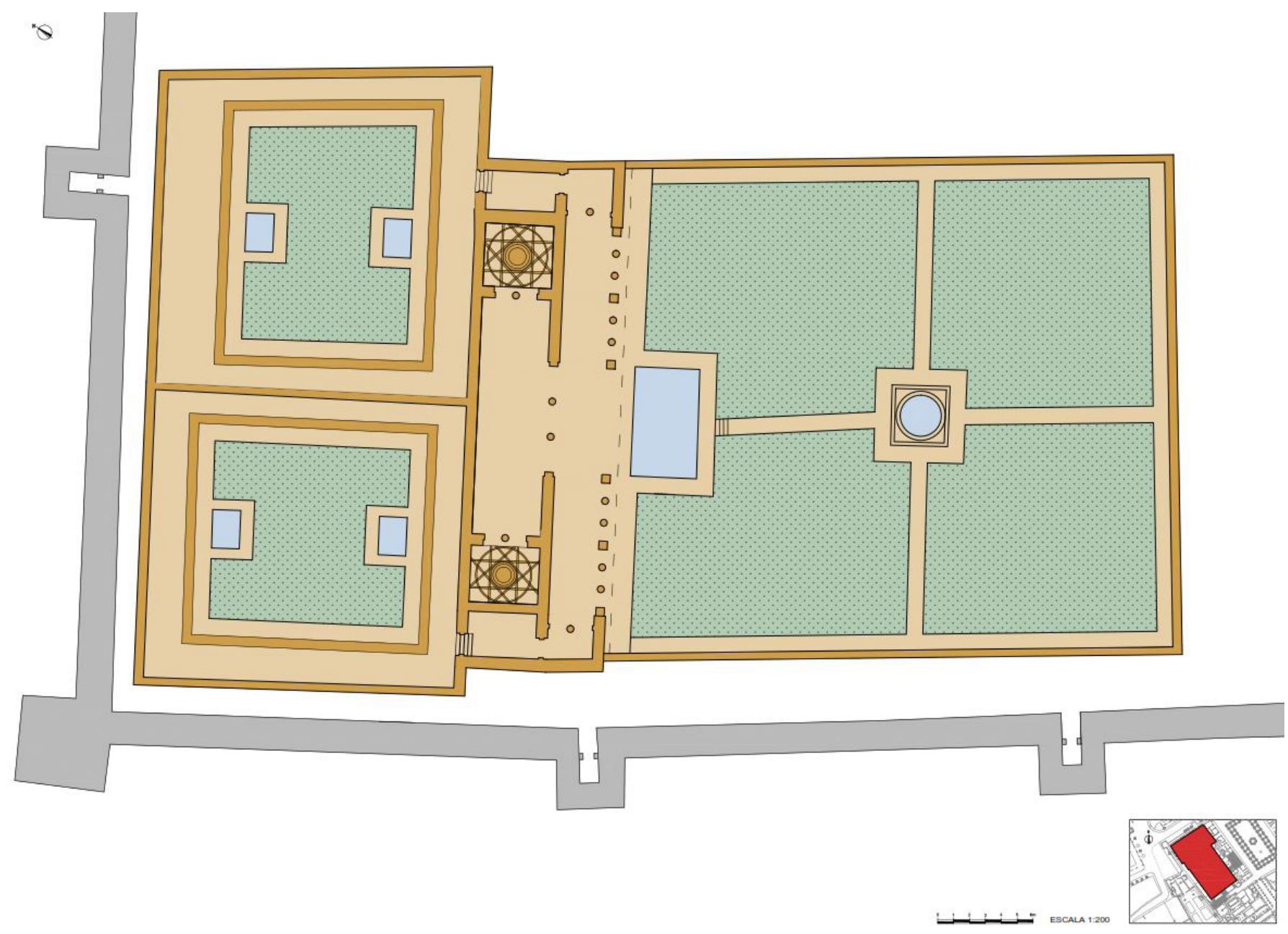

Figura 12. Planta hipotética del palacio islámico. Dibujo de Jesús García Carpallo a partir de Miguel Ángel Tabales Rodríguez y Cristina Vargas Lorenzo. Escala 1/200. 


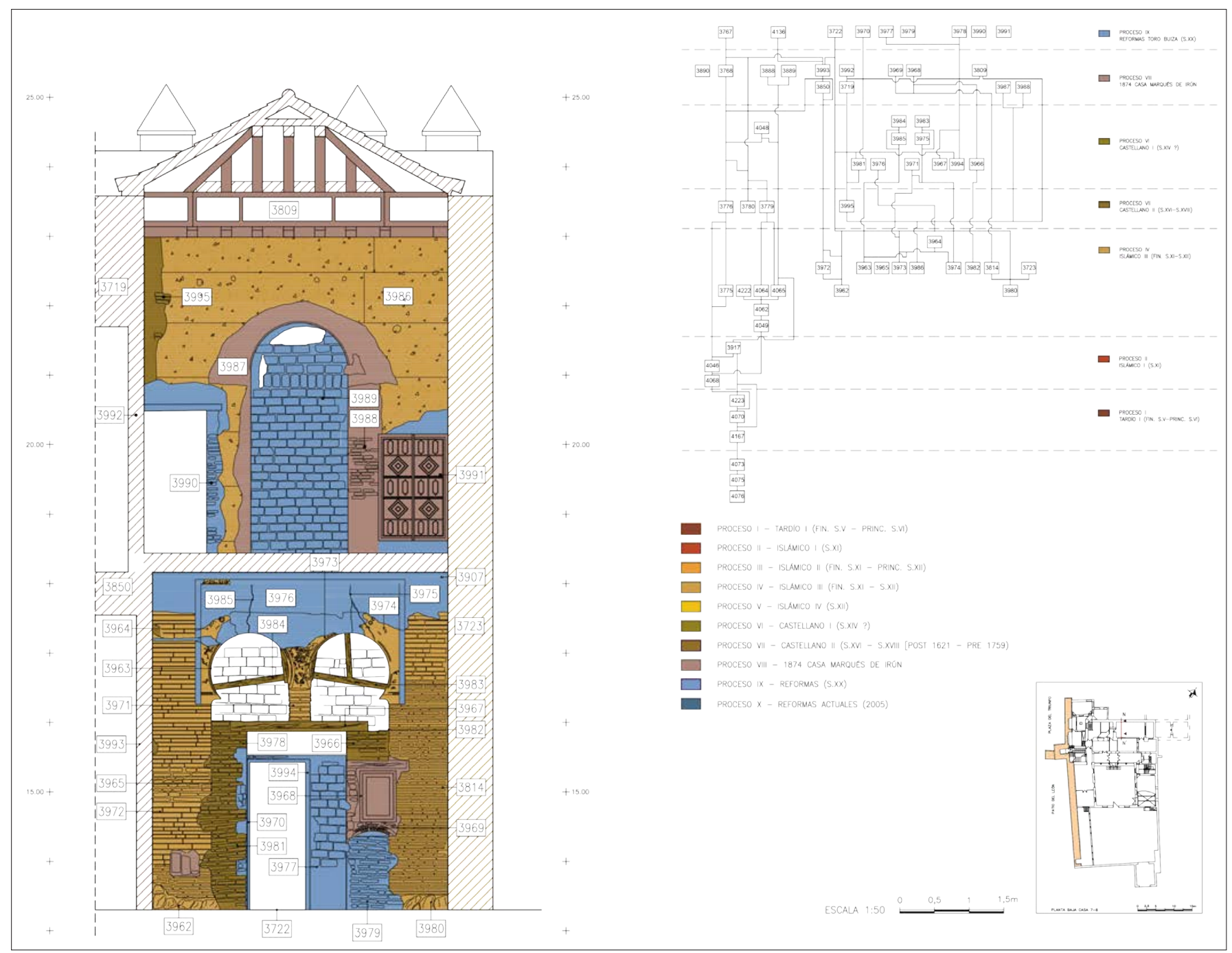

Figura 13. Análisis de paramentos. Sección E-E’. Estudio estratigráfico. Escala 1/50. Dibujo de Miguel Ángel Tabales Rodríguez.

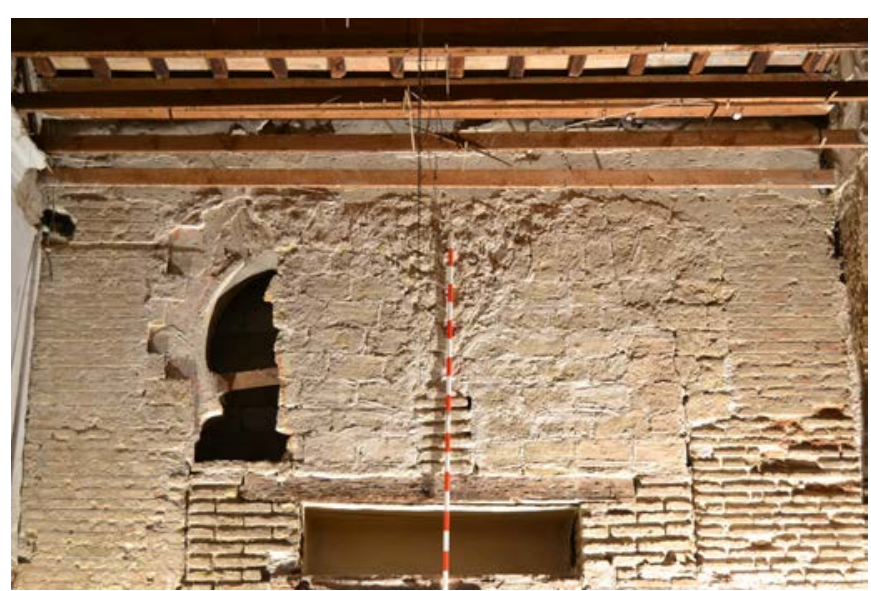

Figura 14. Descubrimiento del arco geminado perteneciente a la alcoba oeste del palacio islámico en el inmueble no 7-8 del Patio de Banderas. rehabilitación un resultado "científicamente irreprochable, así como una adecuación respetuosa pero funcional al nuevo uso" (Tabales 2002a: 248). Por desgracia, la buena sintonía entre ambos profesionales, aunque con excepciones como esta y según en qué comunidades, no solo no ha prosperado en los últimos años sino que se ha polarizado por dos cuestiones: por un lado, sigue sin existir una figura legal que otorgue al arqueólogo un papel de mayor responsabilidad en la obra más allá de la Vigilancia Arqueológica y, por otro, a pesar del impulso que adquirió la disciplina en nuestro país a finales de la década de los 90, es común que en algunos ámbitos se continúe vinculando al arqueólogo únicamente con el subsuelo siendo, por tanto, esta una carencia en la que hay que seguir insistiendo. 


\section{EL PRIMER PALACIO DEL ALCÁZAR}

El análisis arqueológico de los restos integrados en el inmueble n. ${ }^{\circ}$ 7-8 y, parcialmente, los del n. ${ }^{\circ} 2$, han permitido generar una hipótesis sobre sus trazas originales, dimensiones totales y funcionalidad de sus espacios, dando como resultado un modelo de palacio que excede los límites de ambas viviendas. El conjunto, ubicado en el sector más noroccidental del Patio de Banderas, queda delimitado por el norte y oeste con los lienzos de la muralla del primer recinto del Alcázar, por el este con las estancias más occidentales de las casas n. ${ }^{\circ} 2,3,4,5$ y, por el sur, con un callejón que separa las viviendas n. ${ }^{\circ}$ 6, 7-8, 9 y el Patio del Yeso, respectivamente. Sus muros carecen de contacto directo con los lienzos de muralla, pues el espacio intermedio entre ambos estuvo ocupado en origen por un paseo de ronda, fosilizado en el lado norte por un pasaje de 1,40 $\mathrm{m}$ de ancho, a través del cual se accede a la casa $n .^{\circ} 1$. En el lado oeste no se advierte dicha fosilización, pues los muros modernos y contemporáneos colmataron la estructura e invadieron el espacio hasta el punto de, en este caso sí, entestar directamente con la muralla. No obstante, sí se pudo documentar en el corte XXV, alcanzando en este punto una anchura de 1,70 m (Fig. 15).

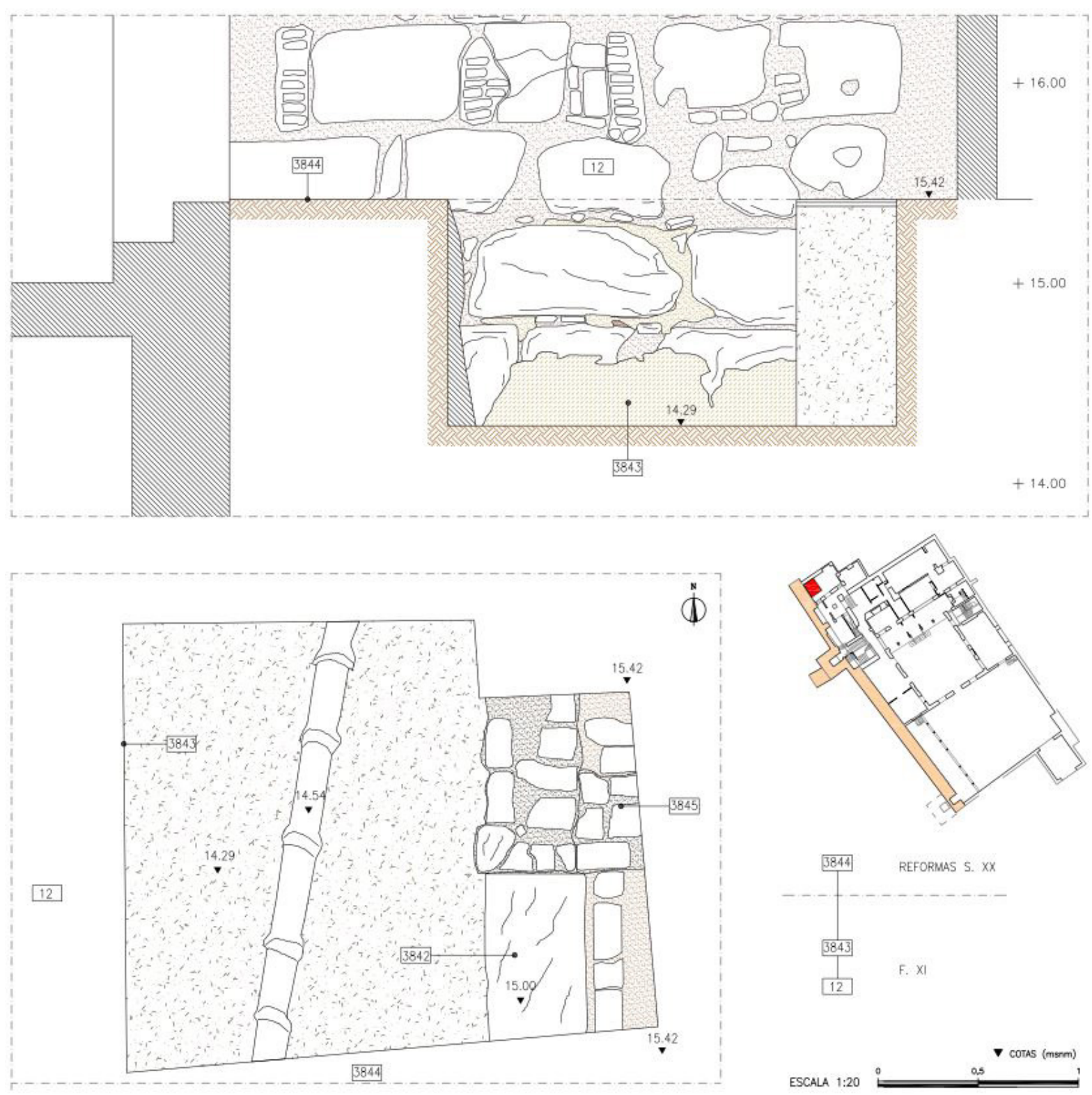

Figura 15. Dibujo del sondeo estratigráfico en el que se hallaron los restos pertenecientes al paseo de ronda del palacio islámico. Escala 1/20. Dibujo de Miguel Ángel Tabales Rodríguez. 
En resumen, el palacio se oculta bajo los muros y cimientos de las 9 casas que actualmente ocupan el flanco noroccidental del Patio de Banderas. De ellas, el inmueble 7-8 es uno de los más extensos, con una superficie de $813 \mathrm{~m}^{2}$. Esta circunstancia posibilitó una distribución de catas paramentales y sondeos, antes descritos, lo suficientemente eficiente como para obtener sus trazas fundamentales a través de los restos rescatados.

Así, bajo el extenso patio que precede a la casa decimonónica, pudo hallarse en su extremo nororiental los restos de la fuente islámica central que servía de eje vertebrador de 4 cuadrantes ajardinados y deprimidos, cuyos andenes afloraron en el lado opuesto del patio. En la esquina nororiental de su segundo patio se documentó parte de la alberca que articulaba el ingreso al palacio desde el jardín. Los pilares en cimentación hallados bajo el subsuelo de la primera crujía, permitieron obtener una cadencia de arcos cuyo patrón parecía responder a la fachada del edificio. La investigación de la segunda y tercera crujías deparó restos en subsuelo y alzado en un excelente grado de conservación, reconociendo una estancia principal de formato rectangular dividida en tres partes, la central más larga que las dos laterales, denominadas alcobas, simétricas y de formato cuadrangular. El paramento norte de esta pieza, medianero con la vivienda $n^{\circ}{ }^{\circ}$, resultó ser original hasta el nivel de forjado de su cubierta, así como el muro de acceso a la alcoba oeste, con el arco geminado policromado simétrico al de la alcoba de la casa . $^{\circ} 2$. De esta manera se pudo reconstruir el sector occidental perteneciente a la nave norte del palacio, concebida como zona de representación. Las comunicaciones halladas con los inmuebles situados a la espalda del muro medianero fueron interpretadas como accesos a un área complementaria a la zona noble y funcionalmente destinada a uso doméstico, extremo no constatado de momento al no haber sido analizadas arqueológicamente (Fig. 16).

Teniendo en cuenta la zona privada, el resultado es un palacio de $2.212 \mathrm{~m}^{2}$, ocupando el $26 \%$ del espacio total del primer recinto, de casi una hectárea de dimensión $\left(8.450 \mathrm{~m}^{2}\right)$. Si nos atenemos exclusivamente a los ámbitos constatados, esto es, área palatina y patio, el conjunto ofrece paralelos evidentes en cuanto a esquema organizativo, forma y dimensiones con otros palacios del Alcázar como el de la Contratación, y en menor medida, el del Yeso; atendiendo a la primera característica, los tres edificios comparten la misma distribución y orientación de su zona noble, con una estancia tripartita compuesta por una sala central de formato rectangular y dos alcobas cuadrangulares y simétricas. A nivel formal, la Contratación y el

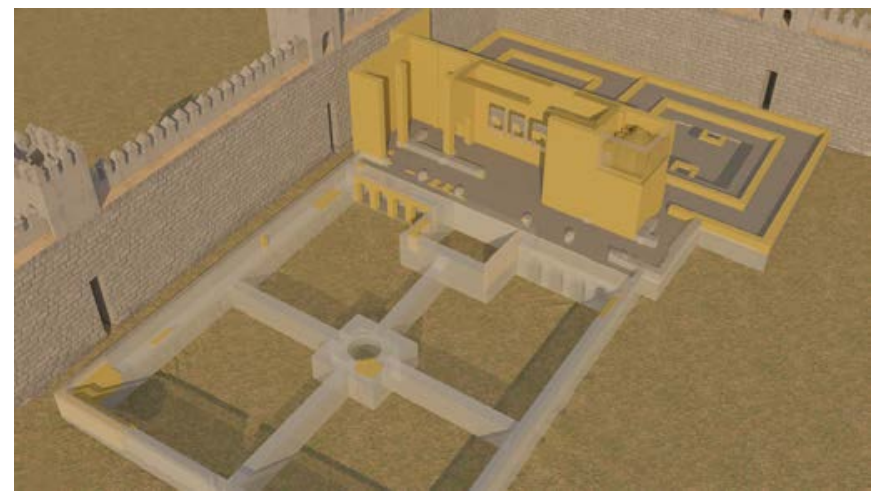

Figura 16. Reconstrucción virtual de los restos excavados perteneciente al palacio islámico. Reconstrucción virtual de Jesús García Carpallo a partir de Miguel Ángel Tabales Rodríguez y Cristina Vargas Lorenzo.

palacio fundacional son casi idénticos, con una fachada conformada por cinco tramos, el central más ancho que los dos laterales al ser este concebido como el acceso principal, colocado a eje respecto del ingreso a la nave norte a través de un triple arco o trífora. Difieren en la ordenación de cada uno de sus tramos laterales, pues en el caso de la Contratación se compartimentan en dos arcos, mientras que en el palacio son tres, característica que, en este caso, comparte con el Palacio del Yeso. En cuanto a dimensiones, de nuevo es el conjunto de Contratación el que presenta una métrica similar, pues ambos cuentan con una anchura total de 100 pies islámicos y 30 si nos referimos únicamente a la suma de la estancia principal, de $18^{12}$ pies, y galería, de 12. El patio del palacio fundacional es algo mayor en longitud, con 110 pies, mientras que el de Contratación tiene 96. No obstante, presenta el mismo formato de crucero, con cuatro parterres ajardinados a bajo nivel (Fig. 17).

La diferencia más notable respecto a estos palacios, en particular, y otros del siglo XI y XII, en general, es la ausencia de indicios que demuestren la existencia de otra nave simétrica en el frente sur. Este hecho puede deberse a tres motivos: porque la sobreexcavación del terreno en el punto donde debieran aflorar las estructuras haya borrado huella de su presencia, porque el proyecto no contemplara su construcción, o bien porque la obra quedara inconclusa. De la misma manera, la existencia de la zona privada compartimentada en dos piezas casi simétricas e interconectadas con la zona pública es una peculiaridad que aún no podemos constatar, pero tampoco descartar, siendo ambas cuestiones objeto de investigaciones que puedan derivarse de proyectos futuros.

\footnotetext{
Se ha tenido en cuenta el espesor de sus muros.
} 


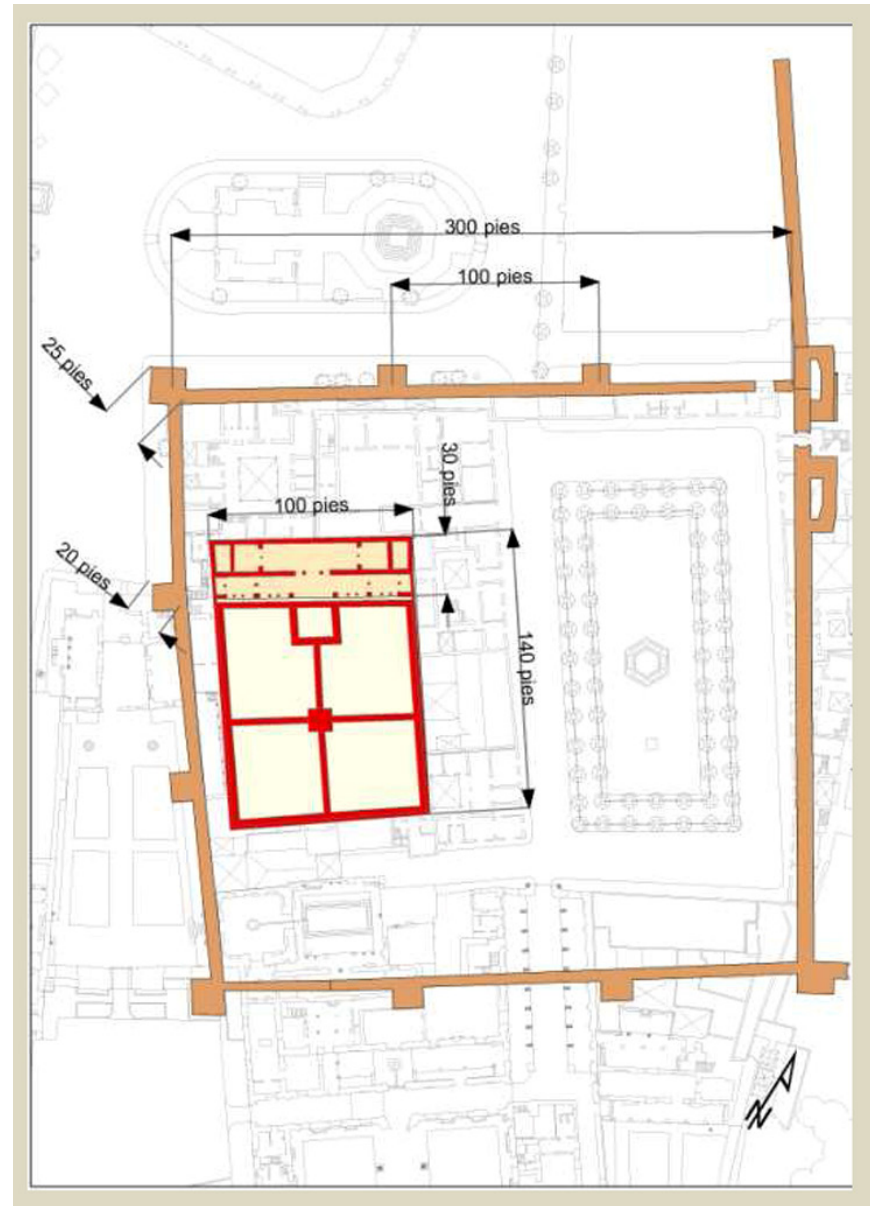

Figura 17. Análisis métrico del palacio islámico en el contexto del primer recinto del Alcázar. Dibujo y análisis de Alejandro Jiménez Hernández.

Centrándonos ya en la descripción arqueológica y constructiva de los restos exclusivamente documentados, tanto a nivel de cimientos como de alzados, comenzaremos por la construcción del edificio principal. En su planificación hubo de tenerse muy en cuenta los condicionantes geomorfológicos del terreno. Ya hemos advertido en líneas precedentes el desnivel existente en sentido norte-sur que afecta a todo el sector, incluido el Patio de Banderas, de modo que muchas estructuras pertenecientes a las mismas fases históricas pueden causar un desfase de más de un metro en sus cotas de uso. Esta circunstancia también la apreciamos al analizar los fundamentos del palacio, algunos muy bien conservados, al menos, dentro de los límites del actual inmueble al haber sido reaprovechados para la construcción del sótano de la casa en el s. XIX.

A la casuística natural también hay que añadir, en esta ocasión, una intencionalidad propagandística y de representación, ya que el palacio se sitúa a la cota 13,86 m s. n. m., esto es, muy por encima del paisaje urbano circundante, otorgándole una situación privilegiada y dominante propia de un edificio que interpretamos como oficial, al estar incluido en el interior del primer recinto amurallado del alcázar islámico.

Para lograr tal efecto, se construyó un muro de sillares isódomos de $30 \mathrm{~m}$ de $\operatorname{largo}{ }^{13}, 1,50$ de espesor y 1,50 de altura, apurando sus cimientos a la cota 11,75 m s. n. m. La cara sur presentaba los sillares bien regularizados mediante cuñas de ladrillo de formato romano, mientras que la cara norte (SE XXIV) estaba retacada con ladrillos y reforzada por una secuencia de pilares, hechos también en ladrillo, sobre una losa corrida de tierra compactada de 1,04 m de profundidad. Su funcionalidad era acoger los diferentes arcos pertenecientes a su fachada principal, cuya posición ha quedado fosilizada gracias a la utilización de estos mismos cimientos para construir la actual galería decimonónica. Los restos conservados nos permiten dibujar una primera crujía de una sola altura de $2,80 \mathrm{~m}$ de luz por $32 \mathrm{~m}$ de largo, cuyo frente estaría conformado por cinco tramos divididos a su vez en tres calles constituidas por tres arcos salvo el tramo central, más grande que los laterales y libre de la citada tripartición (Figs. 18, 19 y 20).

El espacio de esta galería quedaba delimitado por el norte mediante un muro que servía de medianera con la segunda crujía del palacio o nave principal, cuyos fundamentos se documentaron en una de las estancias occidentales de la vivienda actual (SE XXVII). Para su construcción, se abrió una fosa sobre la que se dispuso un cimiento de medio metro de profundidad a la cota $11,95 \mathrm{~m} \mathrm{~s}$. n. m. de tierra compactada, sobre el que se labró a su vez un muro hecho mediante ladrillo fino $(0,27 \times 0,13 \times 0,035 \mathrm{~m})$ dispuesto a soga. En este caso la cota de asiento del cimiento es menor respecto a la del muro sur de la galería, pues no actúa como soporte para salvar el desnivel, sino que se interpreta como muro de carga. En este punto, el paramento aparecía trabado con una mocheta de ladrillo fino a soga y tizón en su base y coronado por un sillar vertical de $0,52 \mathrm{~m}$ de altura, sobresaliendo del plano frontal de la alineación $0,09 \mathrm{~m}$.

\footnotetext{
13 De estos $30 \mathrm{~m}$ de largo, hemos podido documentar 19,20, ya que los metros restantes trascienden la propiedad de la vivienda que nos ocupa, quedando incluidos en el interior del inmueble $n .^{\circ} 2$ del Patio de Banderas.
} 


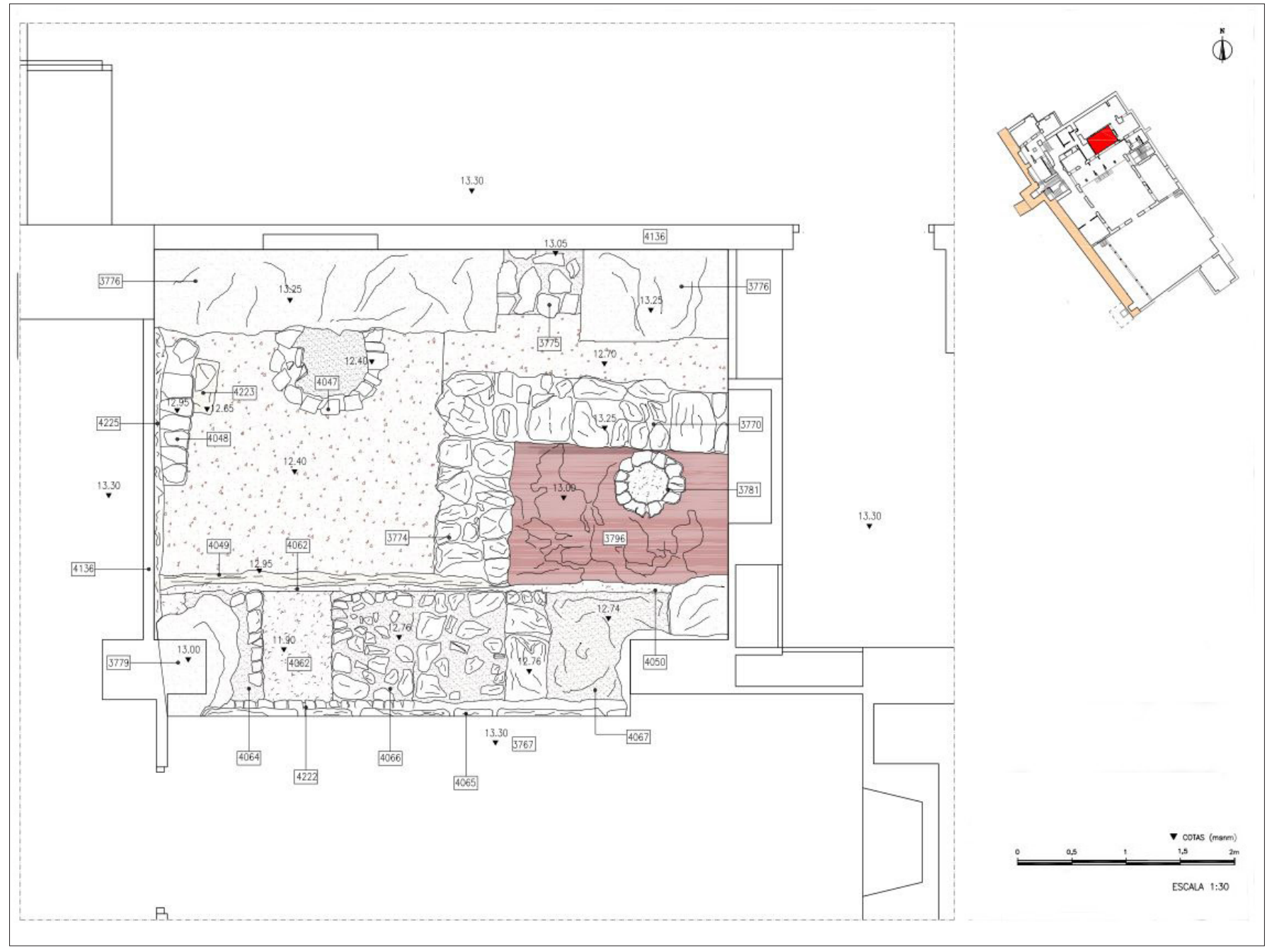

Figura 18. Dibujo del sondeo estratigráfico de los restos de una de las viviendas perteneciente al arrabal islámico fechado en el siglo XI anulados por la cimentación del palacio. Escala 1/30. Dibujo de Miguel Ángel Tabales Rodríguez.

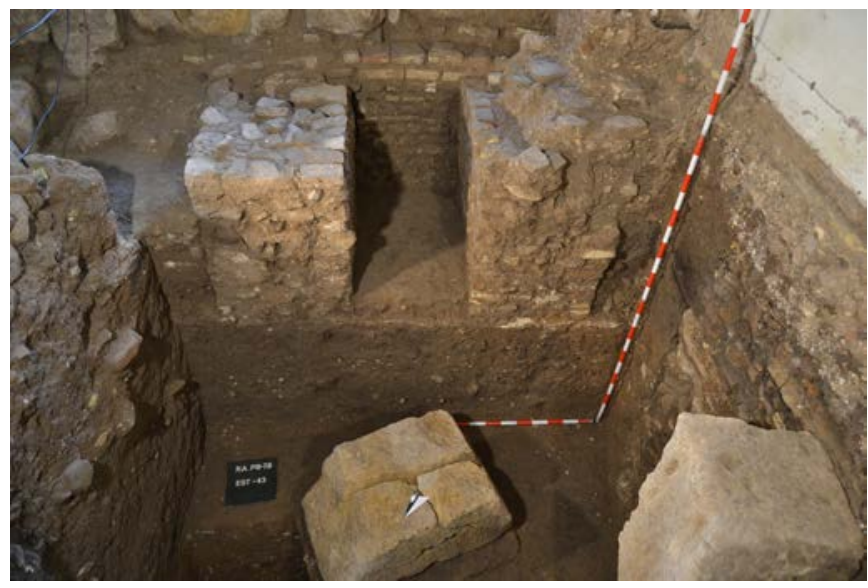

Figura 19. Cimentación de los pilares pertenecientes a los arcos que sustentaban la fachada del palacio islámico.

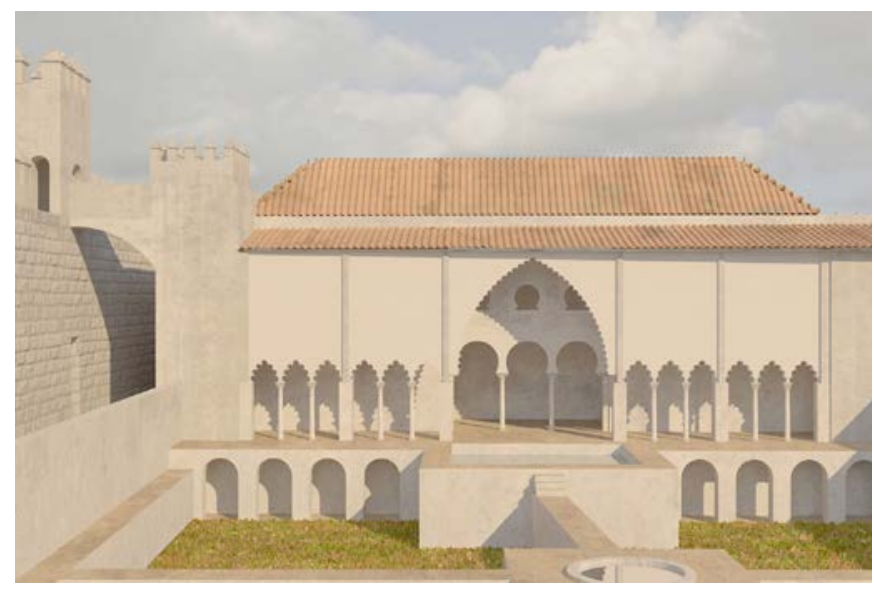

Figura 20. Reconstrucción hipotética del palacio islámico. Visión frontal. Reconstrucción de Jesús García Carpallo a partir de Miguel Ángel Tabales Rodríguez y Cristina Vargas Lorenzo. 
La prolongación del muro hacia el este se encontró en muy mal estado de conservación al haber sido arrasado por las obras posteriores, por lo que solo pudo documentarse una fábrica de mampostería ordinaria a nivel de cimentación cortando los restos del antiguo arrabal islámico, que en ningún caso reaprovechan y tampoco conservan sus orientaciones. A eje respecto de la mocheta se documentó un pilar cuadrangular en estado de cimentación, con unas dimensiones completas de 0,51 ×0,51 ×0,67 $\mathrm{m}$, labrado mediante ladrillo regular en sus esquinas e irregular en el centro. El lado opuesto, es decir, el extremo occidental del muro sur, estaba alterado por la presencia de cimentaciones recientes; no obstante, pudo advertirse la fábrica de sillares perteneciente al muro de corrección del desnivel topográfico con la misma tipología de ladrillo fino, evidenciando que en aquellos puntos donde estaban previstas zonas de paso se introducían ladrillos para recoger los apoyos de los vanos. Estos restos permitieron interpretar la existencia de una alcoba ubicada en el extremo occidental de la galería, a la que se accedería mediante un arco geminado, teniendo con casi toda seguridad su correspondencia en el extremo oriental.

En el punto medio del muro medianero de separación entre el espacio que conforma la galería y la nave principal, se localizó el acceso hacia el interior de esta, de 6,65 m de luz, gracias al hallazgo de sus machones; el occidental a nivel de cimientos, mientras que el oriental, aunque en muy mal estado de conservación, se encontraba en alzado enmascarado bajo los muros de la casa del siglo XIX. Asimismo, el descubrimiento de un pilar a $2 \mathrm{~m}$ respecto del machón oeste, sirvió de base para interpretar que nos encontrábamos ante una puerta de tres vanos, seguramente resueltos mediante arcos de herradura, como sucede en la nave norte del vecino Patio del Yeso. El hallazgo de los restos de un pequeño ventanuco con pequeños fragmentos de yeserías descubierto a eje sobre la trífora, hizo suponer que cada arco quedaría rematado con una celosía, aportando ventilación y algo de luz al interior de la estancia.

Llegamos así al interior de la nave septentrional, también de una sola altura, con unas medidas de 22,96 $\mathrm{m}$ de largo por 4,30 $\mathrm{m}$ de ancho. Sorprende el buen estado de conservación generalizado de las estructuras que conforman el espacio, sobre todo del muro norte, pues a pesar de presentar transformaciones fruto de reformas posteriores, mantiene la altura completa hasta su nivel de coronación, coincidente con el arranque de la cubierta actual. Es importante señalar que parte de sus fundamentos se encuentran por encima del nivel de suelo actual $(+13,30 \mathrm{~m})$ debido a la sobreexcavación contemporánea de $0,40 \mathrm{~m}$ de profundidad que arrasó por completo cualquier vestigio de pavimentación antigua. En este sentido, en el sondeo XXIII, ubicado a los pies del paramento, se documentó la potencia de la cimentación, obtenida mediante tierra mejorada con cal de $0,90 \mathrm{~m}$ de profundidad sobre la que se apoya un pie de agua de más de metro y medio de altura, hecho mediante una fábrica mixta de ladrillo fino aparejada con mampuestos de mediano calibre, sobre la que finalmente asienta una fábrica de tapial simple con cajones de 0,75 $\mathrm{m}$ de altura. Se advierte una notable reparación en el paramento a través de dos actividades constructivas que se resumen en, por un lado, la reparación del tapial simple islámico mediante un parcheado de ladrillo grueso visible a lo largo de buena parte de su superficie y por otro, la reconstrucción completa del extremo occidental del edificio. El punto de unión de ambas edificaciones se encuentra presente en una discontinuidad localizada en el paramento norte, perceptible en las estancias más noroccidentales de la vivienda, en la que se reconoce perfectamente la adaptación del tapial nuevo al antiguo mediante una masa de ladrillo a modo de grapa que va cosiendo el edificio longitudinalmente. La fábrica nueva es un tipo de tapial encadenado en ladrillo grueso con mechinales de sección cuadrada protegidos con remate latericio, con cajones de $0,85 / 0,87 \mathrm{~m}$, sustentada sobre un fundamento de tierra mejorada con cal de más de un metro de profundidad (cuya composición es muy similar a la cimentación del tapial simple islámico) y zapata en resalte de dos hiladas de ladrillo. La esquina suroccidental fue también reconstruida, pero en este caso se hizo mediante una fábrica de ladrillos con una métrica y aparejo idénticos a los empleados para reconstruir las cadenas y pie de aguja del tapial nuevo, considerando, por tanto, ambas fábricas coetáneas. La exclusividad del ladrillo en este caso puede deberse a la utilización de este espacio como ámbito de una escalera de comunicación con las plantas superiores, cuyo uso se mantuvo hasta la construcción de la casa actual.

Con independencia de las reformas y reparaciones lógicas fruto del uso continuado de la vivienda, los datos expuestos sumados a la ausencia total de restos de la bóveda de crucería idéntica a la de la casa 2 , sugiere la posibilidad de que se sucediera en el pasado un episodio natural lo suficientemente violento como para provocar la desaparición de este sector del antiguo palacio y de 
su urgente reparación, quizás el terremoto con epicentro en el Cabo de San Vicente ocurrido el 24 de Agosto de 1356. En cualquier caso, como se tratará más adelante, la ocupación cristiana está certificada por la alteración parcial de las pinturas que decoran los arcos geminados, cuyas albanegas lucen sendos leones rampantes y un castillo en la enjuta, todos ellos, emblemas indiscutibles de la corona de castellana.

Por último, la terminación que presenta la fábrica de tapial en el extremo oeste del muro norte hace suponer la existencia de un acceso en el mismo punto en el que ahora se encuentra un vano contemporáneo, ejecutado en el contexto de la vivienda de 1874 y que bien podría tratarse de una fosilización, interpretada como una posible conexión entre la zona palatina y la doméstica.

Este espacio estaba compartimentado en origen en tres estancias, siendo la central más grande que las dos laterales, ambas simétricas, de modo que la primera alcanza una longitud total de $15,02 \mathrm{~m}$ y las dos alcobas $3,97 \mathrm{~m}$, respectivamente. El ingreso a cada una de ellas ha supuesto uno de los hallazgos más relevantes de la intervención, pues se realizaba a través de un arco doble de herradura cuyas dovelas presentan una rica decoración con pinturas al temple. La alcoba oriental era conocida desde siglos atrás como ya se ha advertido, mientras que la occidental, al igual que la bóveda, se creía perdida al existir en su lugar una citara de ladrillo de factura muy reciente.

Sin embargo, el picado del tabique reveló tras recientes capas de yeso sus restos en un aceptable estado de conservación, pues el tabicado no fragmentó los elementos, sino que los enmascaró, respetando sus machones originales fabricados en ladrillo, así como la doble rosca completa y enmarcada en un alfiz. El único elemento perdido es la columna central que sí se conserva en la casa $n .{ }^{\circ} 2$, entendiendo que fue eliminada en el transcurso de las obras del s. XIX al reducirse el acceso a un modesto paso adintelado con carpintería de madera pintada en color blanco.

El paramento presenta unas características técnicas muy variadas, pues en su factura se mezclan hasta tres tipos de materiales diferentes, a saber, mampuesto, ladrillo y tapial.

El mampuesto se empleó en la cimentación, para la cual se ejecutó en primer lugar una zanja corrida rellena posteriormente de tierra compactada sobre la que se asentaron dos hiladas de mampuestos irregulares de mediano tamaño, conformando un cimiento de $0,50 \mathrm{~m}$ de profundidad total. A continuación, se labraron los machones donde irían enmarcados los arcos geminados, realizados en ladrillo fino de 0,26-0,27 × 0,12-0,13 $\times 0,02-0,03 \mathrm{~m}$ dispuesto a soga y tizón con restos reconocibles en algunos puntos del avitolado primitivo rehundido a media caña, técnica que muy posiblemente se empleó a modo de mortero de agarre para acoger la capa pictórica final.

El resalte de la moldura superior del alfiz marca el inicio del segundo cuerpo del paramento hasta su nivel de coronación, realizado en el mismo tapial monolítico que el muro de cierre de la estancia por el norte, muy afectado en este caso por retoques recientes.

Resulta significativa la ausencia casi total de restos de revestimientos originales. Es razonable pensar que el uso continuado del edificio en épocas posteriores así como el rebaje de la cota de uso islámica en 0,40 $\mathrm{m}$ hayan sido las principales responsables de tal desaparición, pero lo cierto es que las remociones de tierra fruto de las obras de restauración tampoco han sacado a la luz ningún resto decorativo vinculado al palacio a excepción de la decoración pictórica del arco geminado, lo cual resulta en cualquier caso extraordinario dada la escasez de estructuras en alzado relativas al siglo XI. La superficie frontal y el intradós presentan policromía. No así su trasdós, que estaba revestido únicamente con un enfoscado fino de cal de color blanco.

En este sentido, el conjunto está enmarcado por un alfiz rectangular rehundido unos $2 \mathrm{~cm}$, con unas dimensiones totales de 1,90 m de altura, 3,04 de ancho y 0,32 de profundidad, acompañado de una inscripción en negro sobre blanco que contrasta con los vivos colores rojos, ocres, naranjas, verdes turquesa y negros que señalan el despiece de las distintas dovelas de los arcos. Estas están decoradas con motivos vegetales y roleos florales que se intercalan con motivos en zig-zag en color negro sobre blanco. El zizagueado también se observa en el intradós de cada arco y en la cenefa perimetral que recorre el espacio resultante entre las roscas de ambos arcos (señalada con un trazo en color naranja) y la arquivolta, combinando trazos negros con otros en tonos anaranjados. Unas pequeñas ovas rematan la circunferencia inferior de la arquería, subrayada arriba y abajo por la misma línea rojiza que observamos en la zona superior. Cada una de las albanegas está decorada con la representación pictórica de un león rampante en tonos rojizos sobre fondo blanco de raigambre claramente castellana, así como la enjuta, enriquecida con un castillo de tres torres definido por trazos negros sobre un fondo de color anaranjado (Fig. 21). 


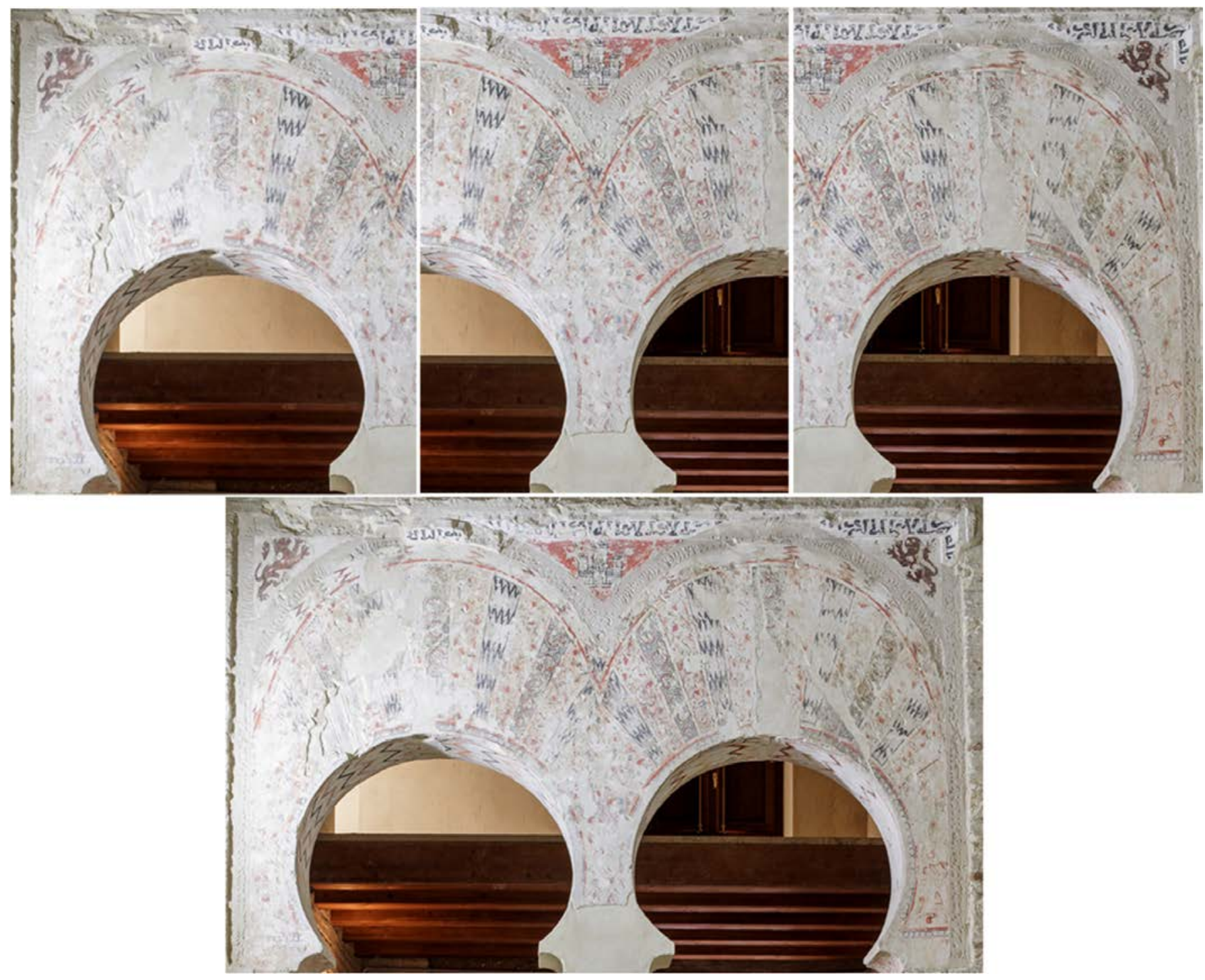

Figura 21. Decoración pictórica de los arcos geminados pertenecientes a la alcoba occidental del palacio islámico descubierta en el inmueble no 7-8 del Patio de Banderas. Fotografía de Fernando Alda editada por Cristina Vargas Lorenzo.

También ha sido posible conocer y, en algún caso, recuperar las soluciones constructivas diseñadas para cubrir la nave principal. En el caso de las dos alcobas laterales, ya hemos señalado que la única que se conserva en la actualidad es la oriental. Gestoso en el siglo XIX la analizó en profundidad, describiéndola como una bóveda que arranca de un anillo de escocia lisa con doce lados, la cual se apoya a su vez en un dodecágono de nervaduras entrecruzadas componiendo una lacería. En su centro hay una especie de linterna cuya clave está formada por una estrella de seis puntas. La sala fue retocada para hacer una entreplanta en su tercio superior. Los arranques de las nervaduras originales eran más prolongados, hallándose ocultos detrás de una imposta de ladrillo y yeso que rodea los cuatros muros, la cual se ve adornada por recuadros ejecutados en el s. XVI, o posteriormente. Estima que la cúpula es almohade por el sistema de bovedillas estalactíticas, estableciendo un paralelo con la Ermita del Cristo de la Luz (Gestoso 1889, 324-325) (Fig. 22).

La revisión y posterior interpretación que hace Antonio Almagro en 2011 del análisis de Gestoso, queda plasmada en un alzado en el que prolonga los nervios seccionados, presentando así su hipótesis de trazado original, con la que coincidimos. No determina su adscripción almohade, sin embargo, las similitudes que presenta con los palacios que considera de tal cronología, como el del Yeso, Contratación y Crucero, hace que se incline por ese periodo. Como ya hemos apuntado, su última revisión, en 2015, la efectúa tras conocer los 


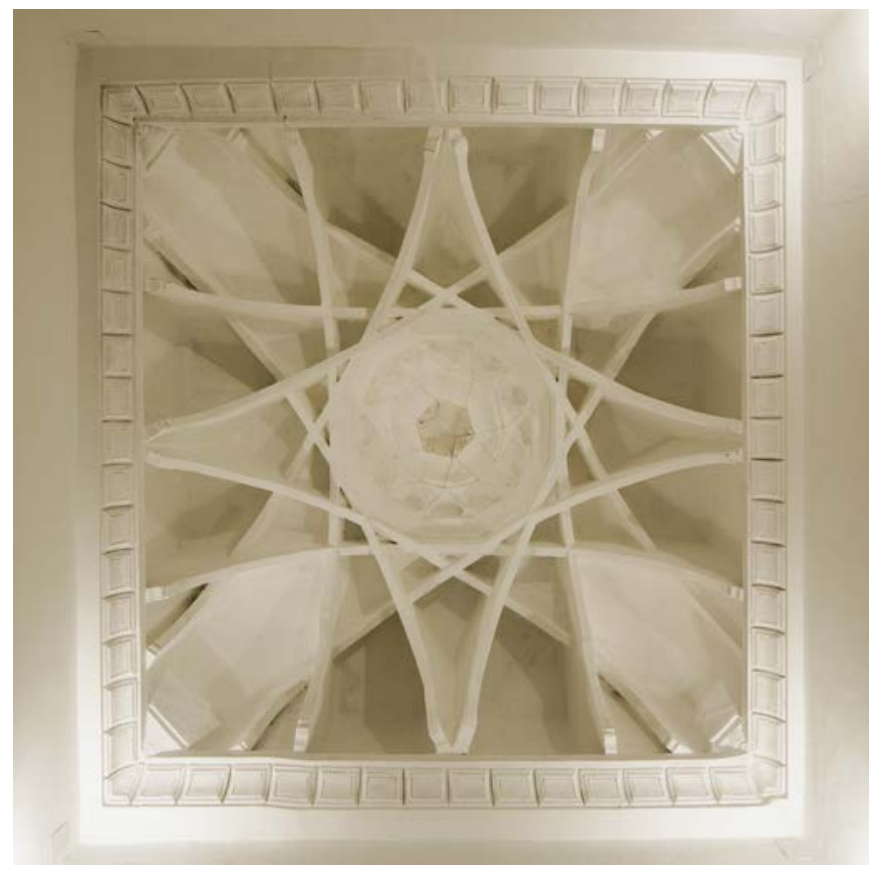

Figura 22. Bóveda de nervaduras de la alcoba oriental perteneciente al palacio islámico conservada en el inmueble no 2 del Patio de Banderas. Fotografía de Fernando Alda.

hallazgos fruto del análisis arqueológico (Tabales y Vargas 2014: 9-41), arrojando una posible adscripción almorávide sin renunciar a su cronología previamente planteada.

La techumbre perteneciente al espacio central de la nave se ha podido recuperar en su formato original. No así en su totalidad, pues como ya avanzamos, el fenómeno de segregación que sufrió el palacio a partir del siglo XVIII provocó que la zona oriental de la sala principal pasara a ser propiedad de la casa $n .^{\circ} 2$. Como consecuencia de ello, cada espacio evolucionó según el gusto de sus residentes; en el caso del inmueble n. ${ }^{\circ} 2$, se respetaron las estructuras originales incluyendo bóveda y parte del alfarje de la pieza central. No así en la casa $7-8$, donde no queda rastro alguno de la bóveda y el alfarje fue progresivamente alterado hasta convertirse en una armadura de lima bordón par de tres paños y cuatro vertientes, respetándose tan solo las ménsulas sobre las que descansaba un sencillo arrocabe decimonónico.

La recuperación del tramo de alfarje primitivo inserto en la propiedad 7-8 permitió reconstruir su proceso constructivo. En este sentido, la primera operación fue componer el asiento de la techumbre, la cual se logró mediante la colocación de unos elementos transversales de madera embutidos en la coronación de cada uno de los cuatro muros de tapial que conforman la estancia, denominados nudillos, de entre 0,30 y $0,45 \mathrm{~m}$ de longitud, separados entre sí una distancia media de 0,60 m. Sobre ellos, y en sentido perpendicular, se colocó un elemento longitudinal, también de madera, conformando la solera. Esta plataforma se empleó como base de apoyo de los canes, creando un sistema de cámaras de aire que garantizaba su correcta ventilación y, por tanto, conservación. Cada ménsula, de 1,20 ×0,09 ×0,115 m aproximadamente, quedaría embutida en el muro una profundidad de $0,55 \mathrm{~m}$, quedando $0,65 \mathrm{~m}$ en voladizo. Como es tradicional en este tipo de armadura de cubierta, las ménsulas soportarían la carga de los tirantes, de 0,09 m de escuadría, con el objeto de ampliar la base de apoyo de estos y ayudar a transmitir los esfuerzos y disminuir el riesgo de sufrir humedades ${ }^{14}$. Entre tirantes y canes no habría contacto directo, existiendo entre ambos una delgada tablazón llamada tocadura, sobre la que se colocaría un sistema de tablas continuas y perpendiculares a los canes cubriéndolos horizontalmente.

Los espacios vacíos entre tirantes quedarían resueltos con unas sencillas tablas de madera, al igual que los canes. Asimismo, el arrocabe estaría compuesto por un conjunto de tablillas llamadas tabicas, insertas mediante calos practicados en cada uno de los planos verticales de ménsulas y tirantes (Fig. 23).

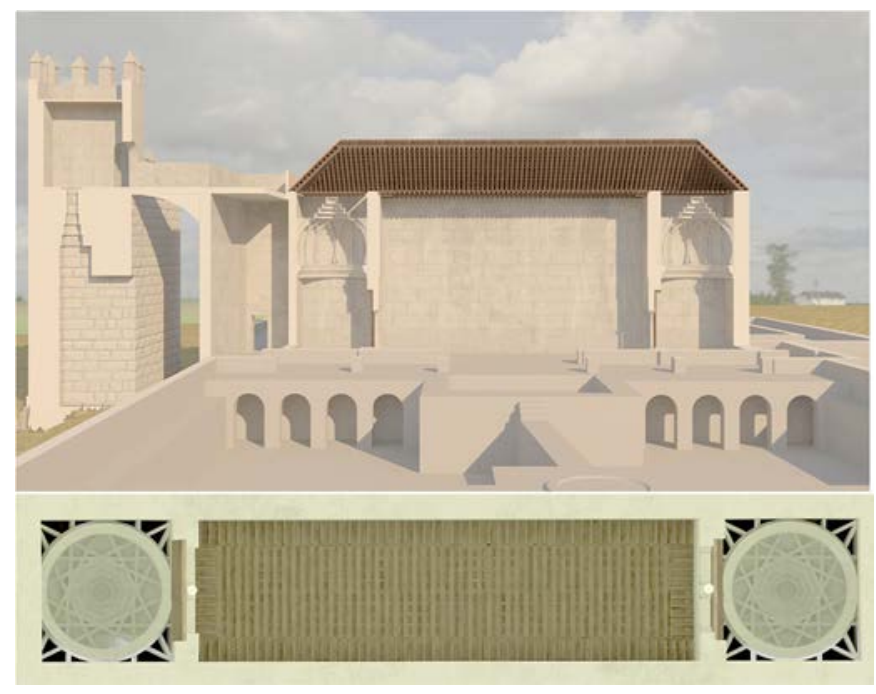

Figura 23. Reconstrucción hipotética del alfarje y cubierta exterior de la nave septentrional del palacio islámico. Sección oeste-este y abajo, representación de su sistema de cubierta. Reconstrucción virtual de Jesús García Carpallo a partir de Miguel Ángel Tabales Rodríguez y Cristina Vargas Lorenzo.

\footnotetext{
14 Análisis de la armadura efectuado por la doctora Cecilia Cañas Palop para la redacción de la Memoria Final de la Actividad Arqueológica Preventiva denominada "Control Arqueológico de Movimiento de Tierras en Patio de Banderas n. ${ }^{\circ}$ 7-8" (Memoria Final inédita).
} 

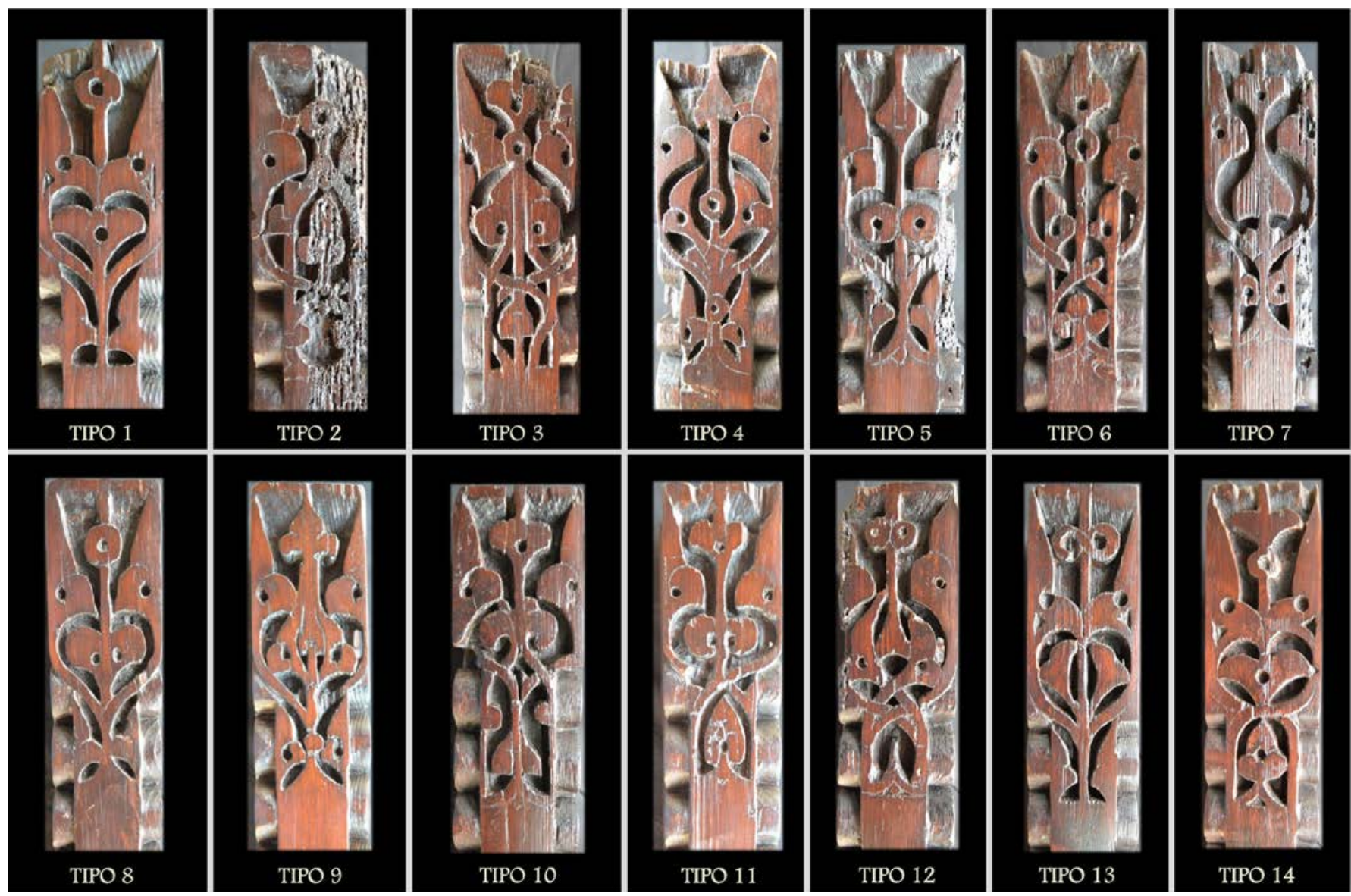

Figura 24. Sistematización tipológica de los canes pertenecientes al alfarje original del palacio islámico.

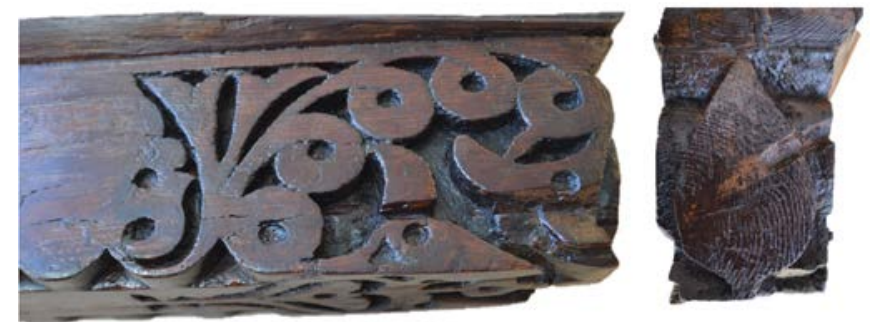

Figura 25. Detalle de la decoración de uno de los canes pertenecientes al alfarje original del palacio islámico (visión lateral y frontal).

Aproximadamente la mitad de cada can expuesto presenta decoración en todos sus planos visibles. Los laterales cuentan con una talla a bajo relieve que reproducen unos modelos decorativos muy similares a los característicos de época taifa, basados en roleos y tallos florales entrelazados formando una curva, motivo muy repetitivo en las yeserías del Palacio de la Aljafería de Zaragoza y también en los modillones de lóbulo de la Mezquita de Córdoba. El plano inferior dibuja un tallo del que irrumpen hojas de envoltura a ambos lados, distinguiendo hasta 14 tipos. El extremo se remata con un círculo del que sale una línea que se prolonga hacia la testa, conectando con el plano que conforma la cabeza de cada uno de los canes. Estas también están talladas, en este caso, dibujando una gran hoja simple, ovada y peciolada (Figs. 24 y 25).

Lo habitual es que estas piezas se decoraran con policromías, sin embargo, las catas realizadas en algunas de ellas no han sacado ningún resto pictórico previo. De existir, es posible que se hayan eliminado progresivamente como consecuencia de las decapaciones y repintes posteriores.

Los procesos continuos de transformación del palacio, por no hablar de los terremotos que sufriría la ciudad de Sevilla $(1356,1755)$, han hecho imposible la conservación de resto alguno de sus sistemas de cubierta exterior. A esta cuestión se suma la segregación del palacio, afectando igualmente a su cubrición, de modo que, en la actualidad, ambos inmuebles cuentan con soluciones constructivas independientes y distintas en su tipología, alteradas por las constantes reparaciones, siendo las últimas constatadas en el s. XX. 

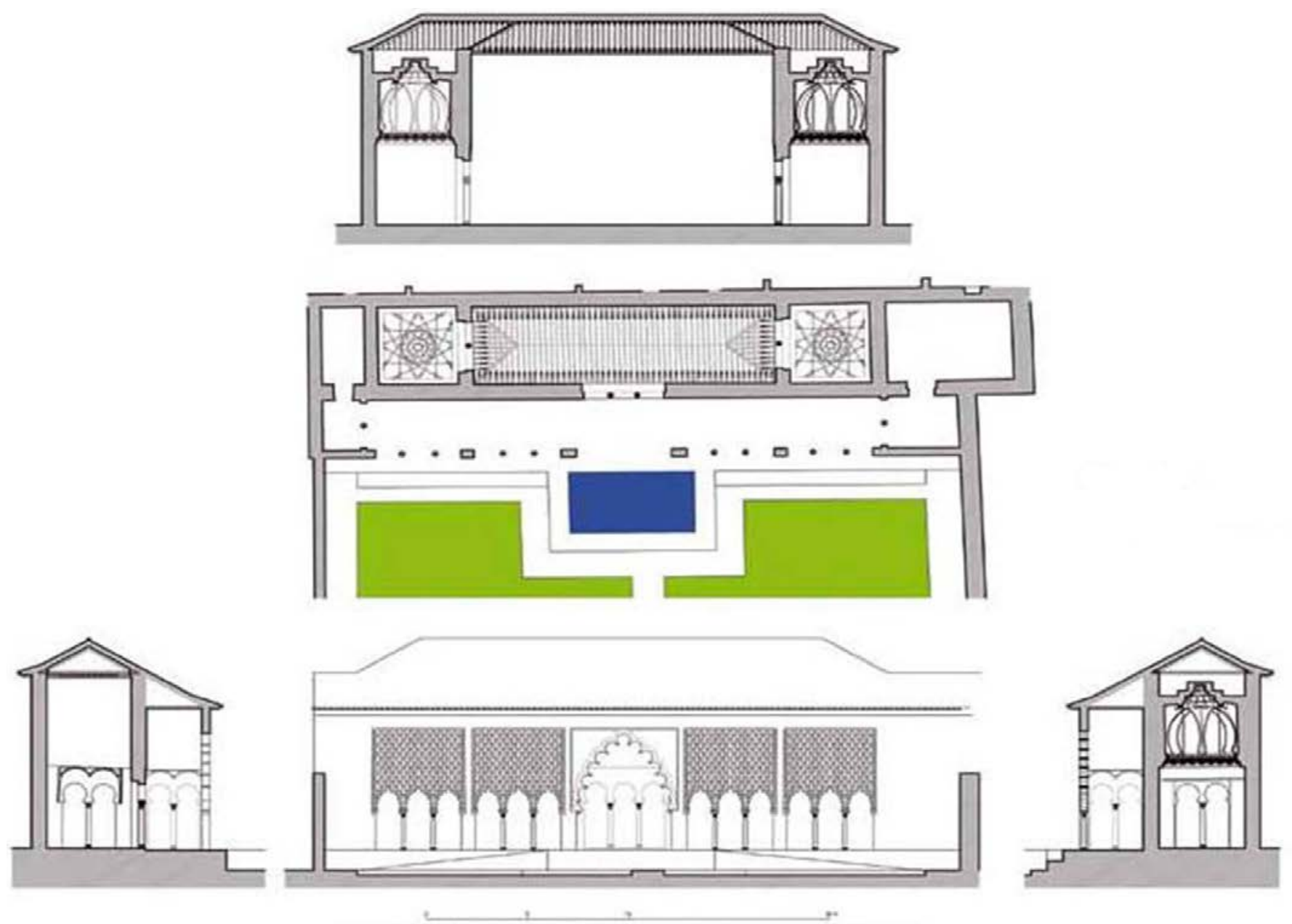

Figura 26. Reconstrucción hipotética del palacio islámico según Antonio Almagro (2015).

En este sentido, las certezas que poseemos sobre las techumbres interiores del edificio nos lleva a plantearnos la hipótesis de que la cubrición exterior fuera probablemente a cuatro aguas, acogiendo únicamente el ámbito de la nave norte, resolviéndose por tanto el espacio de la galería mediante un único faldón a un agua.

Antonio Almagro propuso una hipótesis según la cual la cubierta sería a cuatro aguas, pero el faldón que vierte hacia el patio del palacio sería continuo (Almagro 2015b: 12), difiriendo respecto a nuestra hipótesis en ese aspecto. En cualquier caso, creemos acertada su idealización en cuanto a la disposición, pendiente y vuelo de la cubierta de la nave principal (Fig. 26).

El palacio que acabamos de describir no tendría sentido sin la existencia de un gran patio deprimido a sus pies. El conocimiento de su configuración y dimensiones totales fue posible gracias al hallazgo de los restos pertenecientes a la tapia de cierre por sus extremos occidental y meridional respectivamente, así como de una alberca presidiendo la entrada al palacio con una fuente central a eje respecto de esta, marcando la simetría de la otra mitad del patio. El muro oeste (sondeo XXXV), de $0,55 \mathrm{~m}$ de largo $\times 0,48$ de ancho y labrado mediante mampuestos sin carear de tamaño mediano hundía sus cimientos a la cota $11,15 \mathrm{~m} \mathrm{~s}$. n. m., quedando su enlucido (presente en ambas caras) por debajo de las cotas de las alineaciones modernas. La esquina suroccidental fue documentada en el corte XXII, muy alterada por las construcciones recientes pero reconocible a través de su vinculación material con la tapia anterior. Los restos de la alberca que presidía el patio se hallaron en el sondeo XXXI. Su estructura exterior estaba realizada mediante dos hojas de sillares alcorizos idénticos a los de la muralla, con un relleno interior de tierra anaranjada y compactada, alcanzando unas dimensiones totales de $11 \times 7 \mathrm{~m}$. Finalmente, en el punto medio del lado oriental del primer patio actual (corte XXVIII), se documentaron los restos de una plataforma de formato cuadrangular de un pie realizado en ladrillo 
fragmentado sobre la que se dispuso un estanque circular de 2,59 m de diámetro interior revestido con dos capas de cal hidráulica. En el extremo sur se advirtió la presencia de un canalillo de riego o rebosadero que trascendía rosca y plataforma, sugiriendo de ese modo que esta fuente surtía de agua la vegetación de los jardines deprimidos. No se han localizado restos de andenes dada la potencia de las intrusiones de época moderna. No obstante, la distribución de las estructuras documentadas, con la presencia de la alberca y la fuente en el centro del jardín deprimido, dibujan un esquema que solo resulta coherente colocando un sistema de andenes que, en sentido norte-sur y esteoeste, dividan el jardín en cuatro cuadrantes, permitiendo de ese modo el tránsito con el andén perimetral.

La conexión entre patio y palacio ha sido una de las últimas novedades que ha deparado la investigación. En un primer momento, siguiendo los modelos de patios de crucero cercanos, se pensó en la existencia de rampas o escaleras apoyadas en los lados cortos de la alberca. Esta

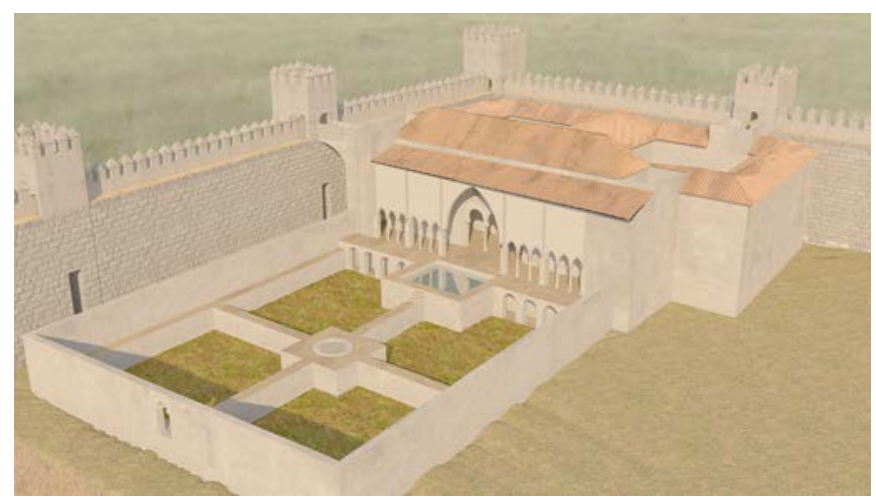

Figura 27. Reconstrucción hipotética del palacio islámico. Visión lateral general. Reconstrucción virtual de Jesús García Carpallo a partir de Miguel Ángel Tabales Rodríguez y Cristina Vargas Lorenzo.

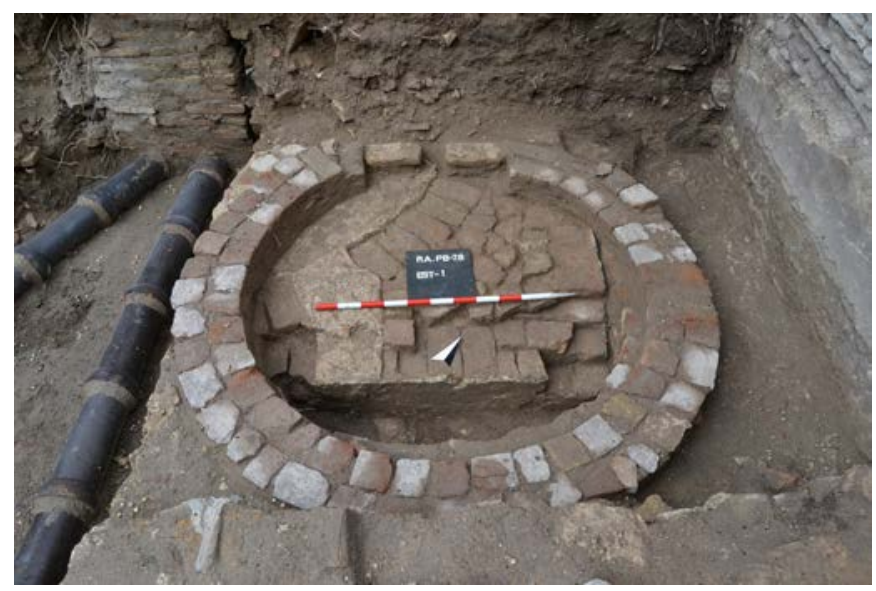

Figura 28. Fuente central original perteneciente al jardín deprimido del palacio islámico anulada por los restos de otra fuente, en este caso, correspondiente al patio de época moderna. hipótesis fue eliminada con el hallazgo de una arquería enmascarada tras el paramento norte que sustenta el andén de la galería de fachada, de modo que la cota de suelo de la arquería, situada a $+10,79 \mathrm{~m}$, quedaba dos metros y medio por debajo del nivel de uso del andén del palacio, a $+13,30 \mathrm{~m}$. Dicha arquería estaría compuesta por una secuencia de cuatro arcos de medio punto labrados con ladrillo de $0,05 \mathrm{~m}$ de grosor y tomados con mortero de tierra y cal, quedando interrumpido por el encuentro con la alberca. Salvado el espacio de la alberca, continuaría con una segunda secuencia de otros cuatro arcos hasta alcanzar el cierre del muro del patio por su esquina nororiental. Su funcionalidad sería únicamente estética, pues no hemos encontrado accesos desde la galería semisoterrada al interior del palacio, siendo el único ingreso posible a través de los andenes perimetrales, o bien desde el central, rodeando la alberca. No existen, al menos que sepamos de momento, paralelos claros de esta solución aplicada a patios de época islámica a excepción del Palacio del Crucero. En este último caso, los arcos serían de mayores dimensiones para salvar los 4,70 $\mathrm{m}$ de desnivel existente entre la cota de uso de los andenes del edificio y la de la galería, así como la cadencia de las arquerías, repitiéndose en sus cuatro frentes. Sea como fuere, interpretamos que el modelo de patio de la casa 7-8 podría haber servido de inspiración para la construcción del patio de crucero almohade. Paralelos de patio de crucero tenemos en el mismo Alcázar; nos referimos al Palacio de la Contratación (ss. XII-XIV), Crucero (s. XII-XIII) y Montería (s. XI-XII). Fuera de Sevilla hay buenos ejemplos como el palacio de Monteagudo (s. XII) o Dar as-Sugrá (ss. XII-XIII) con la diferencia de la ausencia de otra alberca situada en el frente menor opuesto (Figs. 27, 28 y 29).

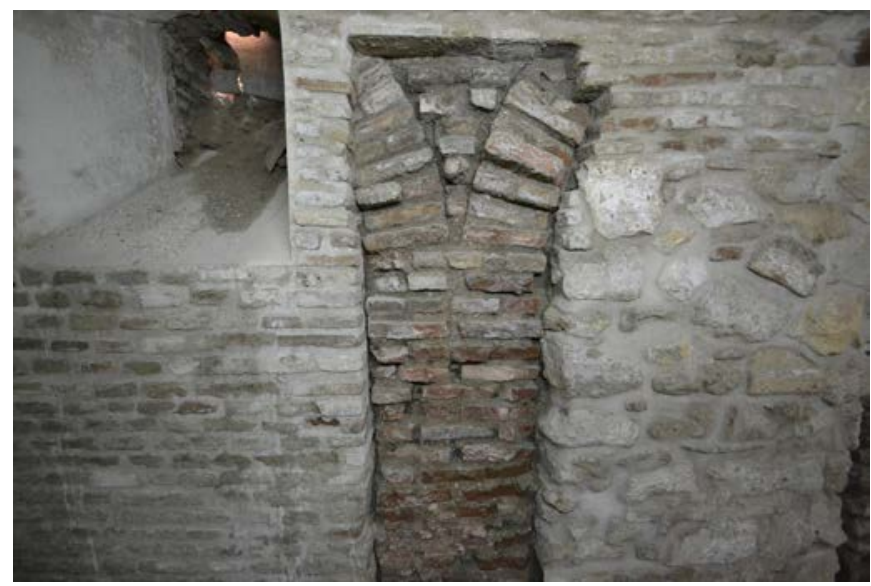

Figura 29. Restos de la arquería del patio islámico enmascarada tras uno de los muros del sótano. 


\section{Fundamentos para la datación}

La datación de la muralla del primer recinto y su palacio fundacional se ha obtenido mediante la aplicación de los métodos tradicionales basados en la estratigrafía y cronología de sus materiales en combinación con otros sistemas analíticos más novedosos como Carbono 14 y termoluminiscencia, siendo esta última técnica de gran precisión ya que determina el tiempo transcurrido desde el momento en el que un material cerámico ha sido fabricado mediante el proceso de cocción ${ }^{15}$.

En el caso de la muralla, los trabajos desarrollados desde el año 1997 en múltiples puntos del Alcázar (Tabales 2000, 2001, 2002b, 2010, 2012, 2013) permitieron establecer una cronología que oscila entre finales del s. XI y principios del XII. Estas fechas se han contrastado recientemente con los resultados derivados de un programa de muestreos tomados en lienzos, torres y cimentaciones de la muralla con el objeto de someterlos a análisis de Carbono $14 \mathrm{y}$ termoluminiscencia ${ }^{16}$. A pesar de los intervalos de incertidumbre que se presuponen en este tipo de ensayos, las conclusiones no solo corroboran la datación relativa fruto de los trabajos arqueológicos, sino que también vienen a cerrar la horquilla cronológica con altos niveles de certeza con unos valores medios que oscilan entre los años 1060 y 1062 (Jiménez e. p.).

Este mismo protocolo de datación ha sido aplicado al palacio primitivo, efectuándose en primer lugar el preceptivo análisis de estructuras para determinar sus relaciones físicas y caracterización de materiales arqueológicos para, en un segundo momento, someterse a análisis radiocarbónicos y termoluminiscentes.

Ya hemos analizado en líneas precedentes la secuencia evolutiva de la muralla y su palacio, advirtiendo cómo su proceso constructivo implicó, en primer lugar, la anulación del barrio taifa previo, al menos en este sector, y, en segundo lugar, la adaptación del palacio a lienzos y torres del primer recinto.

Los rellenos de cimentación vinculados con el palacio, registrados entre las cotas $+13,20 \mathrm{y}+11,70 \mathrm{~m}$ s. n. m., teniendo en cuenta el escaso volumen de material y lo poco representativo en cuanto a tipología, se

\footnotetext{
15 También se puede aplicar en materiales como sílex y otros restos arqueológicos como tejas, ladrillos, etc.

16 Programa de muestreos englobado en el Proyecto de Investigación "Análisis Estratigráfico y Cronotipológico de los Recintos Fortificados del Alcázar de Sevilla. Procedimientos, Sistemas y Aplicaciones desde su Vertiente Constructiva" (P12-TEP-1843), financiado por la Consejería de Economía, Innovación y Ciencia de la Junta de Andalucía.
}

fecharían a fines del siglo XI, sin descartar una cronología más avanzada, ya que no aparece ningún fragmento con características exclusivas del siglo XII.

Piezas como los ataifores esmaltados registrados podrían encuadrarse en producciones de fines del siglo XI con pervivencia hasta principios del XII, como así lo indican los estudios realizados en el Real Alcázar de Sevilla; Patio de las Doncellas (Huarte 2016: 349) y Patio de Banderas (Huarte 2015: 198, 215, 216), Madinat Qurtuba (Salinas 2012: 543-544) y Mértola (Gómez 2004: 229). Lo mismo ocurre con las bases de cangilones similares a las del Castillo de San Jorge, Sevilla (Vera y López 2005: 109), las jarritas con asas estriadas y los jarros con pitorro vertedor.

Estas piezas suelen fecharse a principios del siglo XII, por considerarlas ligeramente evolucionadas con respecto a las clásicas del periodo taifa, pero actualmente no hay argumentos que puedan probar que esta producción alfarera sea de ese momento, ya que el resto de analíticas de $\mathrm{C} 14$ o termoluminiscencia nos hace pensar que no es una fabricación exclusiva de época almorávide.

En definitiva, el estudio de la cerámica establece una evolución en las características técnicas de las piezas documentadas, cuyos inicios se remontan a las primeras alfarerías taifas hasta alcanzar formas más evolucionadas. ¿Es posible que el palacio comenzara a edificarse en los últimos momentos del periodo taifa y se finalizara tras la conquista almorávide?

Dicho planteamiento podría explicar las propuestas de Almagro y Gestoso, que abogan por una datación almorávide basada en la tipología de la bóveda de nervaduras que corona la alcoba de la casa ${ }^{\circ}{ }^{\circ} 2$, así como la precipitación visible en el acabado de las pinturas que decoran los arcos de ingreso a sendas habitaciones, realizados con trazos gruesos y toscos, poco habituales dada la riqueza ornamental propia de edificios de factura taifa. La bóveda no ha podido ser analizada al estar la propiedad que la acoge fuera del ámbito de actuación de la obra. Por el contrario, fue posible caracterizar y fechar mediante dataciones absolutas los elementos arquitectónicos y artísticos del palacio recuperados en el transcurso de los trabajos, tales como los arcos geminados, el muro de tapial y los canes que sustentaban el alfarje de la estancia principal y la galería perteneciente al patio ajardinado.

El muro de ladrillo avitolado donde se inserta el arco geminado presenta una relación de adosamiento respecto al muro de tapial perteneciente al cierre del 
palacio por su lado norte. Del primero se tomó una muestra de ladrillo y mortero de cal asociado para datarlo mediante termoluminiscencia, mientras que del segundo, se tomó una muestra del carbón empleado para la fabricación del tapial. Ambos, dieron unos resultados coherentes con los estudios estratigráficos y muy cercanos entre sí, arrojando una fecha que oscila entre 1098 y 1194 para el muro del arco, y de entre 1027 y 1170 para el tapial.

Las pinturas que enriquecen los arcos también han sido analizadas desde varias perspectivas. Un primer acercamiento al análisis de su programa decorativo nos aproximó a un periodo de transición taifa-almorávide, pues los motivos ornamentales reconocidos son afines a esquemas decorativos propios de otros palacios del s. XI-XII como los restos pictóricos de la alberca hallada bajo el Patio de la Montería en el Alcázar de Sevilla (Tabales 2000: 24), o la pintura mural localizada in situ en el zócalo de una alberca perteneciente a un palacio también del siglo XI, en la calle San Julián 2-4 (Tabales y Vargas 2014: 30). Fuera de Sevilla los escasos ejemplos publicados se corresponden con las pinturas parietales de la Aljafería de Zaragoza (s. XI), el Oratorio del Alcázar Mayor (Murcia) y el Palacio Dar as-sugrà, localizado bajo el antiguo refectorio del monasterio de Santa Clara la Real (s. XII) (Navarro y Jiménez 2012: 235, 314, 315, 323).

Los resultados de esta primera inspección visual fueron contrastados con los análisis derivados de la consolidación estructural de los arcos, realizados antes de comenzar la obra de rehabilitación de la vivienda. En este sentido, los análisis de los pigmentos ${ }^{17}$ utilizados para decorar ambos programas decorativos (arcos de tradición islámica y enjutas con motivos castellanos) establecieron que en los dos casos se habían usado pigmentos de naturaleza animal o vegetal, llamados comúnmente pigmentos históricos al no existir un procesado de carácter industrial susceptible de arrojar una cronología más o menos ajustada en el tiempo. En cambio, las observaciones artísticas y técnicas realizadas en el transcurso de su consolidación, mostraron evidencias lo suficientemente sólidas como para plantear, al menos, otras posibilidades a tener en cuenta ${ }^{18}$.

\footnotetext{
17 Caracterización de materiales y análisis de la técnica de ejecución realizado por la doctora Ana García Bueno para la redacción de la Memoria Final de la Actividad Arqueológica Preventiva denominada "Control Arqueológico de Movimiento de Tierras en Patio de Banderas n. ${ }^{\circ}$ 7-8" (Memoria Final inédita). 18 Informe sobre la limpieza y consolidación de las pinturas murales del arco geminado efectuado por la restauradora M. ${ }^{\mathrm{a}}$ Isabel Baceiredo Rodríguez para la redacción de la Memoria Final de la Actividad Arqueológica Preventiva denominada "Control Arqueológico de Movimiento de Tierras en Patio de Banderas n. ${ }^{\circ}$ 7-8" (Memoria Final inédita).
}

En primer lugar, dado que los motivos heráldicos establecen una clara relación de posterioridad respecto a la estructura del arco, se efectuó una microcata bajo la figura del león rampante de la albanega derecha, con el objeto de encontrar pigmentos subyacentes. Los resultados fueron negativos, es más, el temple blanco de cola animal detectado era en apariencia similar al del resto de la composición pictórica. Tampoco se encontraron escalonamientos que evidenciaran que la pintura original hubiera sido raspada y sustituida por otra. Dicho de otro modo, el conjunto pictórico es homogéneo y presenta idénticos estratos compositivos tanto en el programa decorativo de los arcos como en la heráldica; la estructura de ladrillos que conforman las roscas presenta un tratamiento inicial de estuco calizo avitolado en las llagas a media caña, por encima del cual se aplicó una capa de enfoscado de nivelación de entre 4 y $6 \mathrm{~mm}$ de grosor, hecho con yeso, tierra y algo de cal. El siguiente paso fue aplicar el enlucido, realizado mediante una capa de mortero de yeso de terminación lisa de entre 1-1,5 cm de grosor. A continuación, se utilizó una brocha para efectuar la imprimación mediante 2 o 3 capas de temple de yeso de entre 0,3 y $0,5 \mathrm{~mm}$, siendo muy evidentes los trazos al no haber seguido un orden en su aplicación. El objeto de esta última capa era preparar la superficie para que la decoración pictórica penetrara de una manera homogénea y regular. Por último, se acometió la tarea de la decoración pictórica, la cual se hizo con temple magro de cola animal en dos pasos, a saber, el trazo de los contornos principales (dovelas, alfiz, etc.) y el rellenado de los mismos con formas florales y geométricas.

Otra evidencia muy a tener en cuenta fue la observación de cuñas de madera usadas para sellar grietas que se encontraban ocultas bajo la propia pintura, cuyo desmonte estuvo justificado por la presencia de fracturas naturales. En concreto, nos referimos a un calzo introducido en una grieta localizada en el salmer central, con unas dimensiones superiores a la de la abertura, por lo que parece imposible haberla colocado después de revestir el muro. Con este dato resulta obligado preguntarse en qué momento el arco fue revestido y pintado, pues las grietas sugieren que entre la fecha de su construcción y la de su decoración transcurrió el tiempo suficiente como para que este comenzara a sufrir patologías de carácter estructural de cierta gravedad.

Existen varias interpretaciones que explicarían el fenómeno observado. Es posible que el avitolado sea original y el revestido de una época posterior, sugiriendo de este modo que el palacio quedara inconcluso, al 
menos, en cuanto a acabados se refiere. Así se justificaría el desplazamiento que advertimos en el despiece de las dovelas del avitolado respecto de las decoradas, la similitud de los avitolados de machones y arcos, así como la homogeneidad de estratos que presenta la decoración de tradición islámica y castellana. El terremoto de 1356 pudo provocar el agrietamiento y pérdida casi total de los revestimientos, hecho que causara la eliminación de la pintura hasta el nivel del avitolado, sustituyendo de este modo las pinturas originales por una copia más tosca y precipitada como esta, incorporándole siglos más tarde la heráldica de leones y castillos. La inscripción del alfiz está mal ejecutada y resulta ilegible, por lo que parece evidente que se trata de una operación de reparación de la escritura original realizada por algún maestro ignorante del significado de la epigrafía que estaba restaurando, quizás un alarife mudéjar.

Otra posibilidad es que avitolado, revestimientos y decoración pertenezcan a la misma fase medieval cristiana, lo cual explicaría la ausencia completa de huellas pertenecientes a picados posteriores sobre el avitolado de agarre. El terremoto de 1356 también pudo ser el causante, provocando tal destrucción que hiciera necesaria una reparación urgente. Así se justificaría también la incorporación de las cuñas de madera, colocadas en otros puntos de la estructura, así como los revocos de fibra vegetal y tierra detectados sobre los revestimientos de yeso localizados en las albanegas.

Por último, cabe la probabilidad de que estructura y conjunto pictórico (salvo heráldica y epigrafía) se hicieran en el mismo momento histórico, pero en diferentes procesos constructivos, efectuándose el programa decorativo en una de las últimas fases de la obra y de una manera precipitada. Así se explicaría la brusquedad con la que se aplicaron las capas previas de preparación, con brochas gruesas y trazos desordenados e irregulares. Cuesta creer que para ese momento la estructura ya presentara grietas de envergadura como las documentadas, pero tampoco es descartable dado los plazos necesarios para construir un palacio de estas características con los condicionantes y problemáticas constructivas lógicas de la época. Siguiendo esta interpretación, las albanegas y enjuta originales presentarían una terminación blanca lisa, superficie que luego sería aprovechada para alterar el arco tras la ocupación cristiana.

Con el objeto de arrojar más certezas sobre dicha cuestión, se tomó una muestra de la cuña de madera inserta en el salmer central para ser analizada mediante Carbono 14, comparando sus resultados con el análisis, también por C14, de la viga de madera embutida en la trasera del arco y cuya función era acoger el empotramiento de los goznes de una puerta doble que abría al espacio de la alcoba. Ambos resultados fueron prácticamente coincidentes, arrojando unas fechas entre 1022 y 1156 para el primer caso y de 1023 a 1163 para el segundo, o de 1089 y 1093 respectivamente si tomamos los valores medios. En otras palabras; o bien la reforma del arco mediante la introducción de la cuña de madera y acabado pictórico final se efectuó en siglos posteriores reutilizando materiales originales del palacio, o bien se llevó a cabo en uno de los últimos procesos próximos a su finalización.

La comparativa con la decoración de los arcos de la casa $n^{\circ} 2$ es otro argumento que invita a la reflexión, pues ambos presentan el mismo esquema decorativo, pero con diferencias visibles que conviene señalar. No entramos a valorar la desafortunada restauración que se realizó en los arcos de la casa $n^{\circ} 2$ en época reciente y que desvirtuó por completo la policromía, otorgándole una pátina amarillenta que falsea sus tonalidades originales y enturbia las formas decorativas.

En cambio, llama la atención la desproporción que ambos arcos guardan tanto en el falso despiece de su dovelaje como en su alternancia decorativa. Respecto a la primera cuestión, mientras que en la casa n. $.^{\circ} 7-8$ cada arco cuenta con un falso despiece de 14 dovelas, en la casa 2 el número se reduce a 12 , causando por tanto un ensanchamiento de las dovelas que provoca una sensación visual de achatamiento del conjunto. Asimismo, la cadencia decorativa también presenta variaciones, pues en la casa . $^{\circ}$ 7-8 el esquema más repetido y que marca la pauta es el de hojas de envoltura, con una secuencia que se inicia desde el exterior del arco izquierdo por una dovela con hojas de envoltura, otra en zig-zag, de nuevo hojas de envoltura, y otra con roleos. Este patrón se repite dos veces más en el mismo orden, finalizando con otra dovela de hojas de envoltura y una última con motivos en zig-zag. La decoración del arco derecho es idéntica al izquierdo, de modo que si pudiéramos plegar ambas roscas por su eje central los motivos coincidirían a la perfección. El esquema ornamental de los arcos de la casa . $^{\circ} 2$ también se repite en el mismo orden en sendas roscas, pero muestra un patrón diferente respecto al de los arcos de la casa 7-8, pues en este caso, el motivo que marca la pauta es el de los roleos, además de advertir una repetición del esquema de hojas de envoltura en las dos dovelas centrales obedeciendo a la siguiente secuencia: roleos-hojas de envoltura-roleos-zigzag-roleos-hojas de envoltura-hojas de envoltura-roleoszig-zag-roleos-hojas de envoltura-roleos (Fig. 30). 


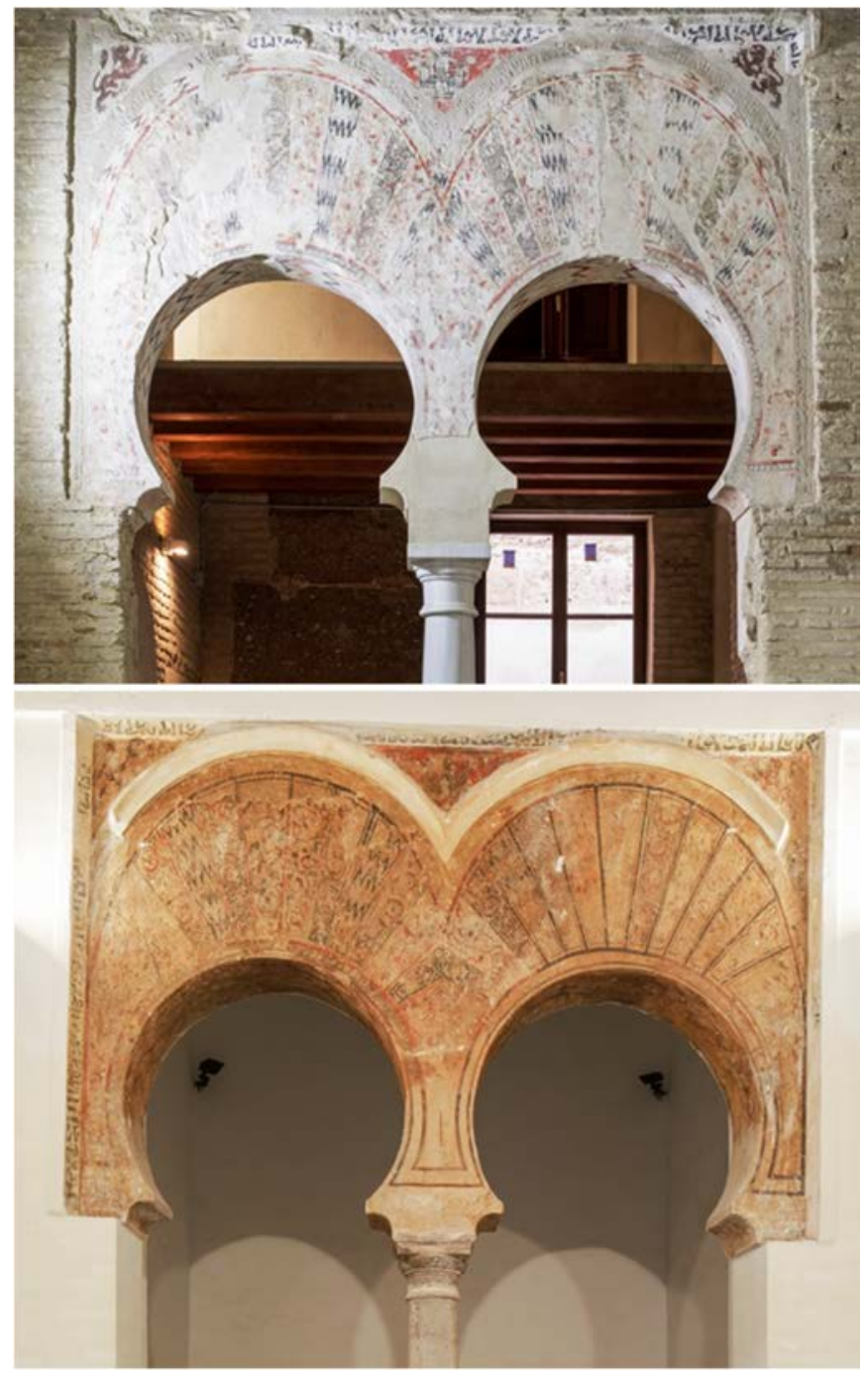

Figura 30. Diferencias visibles en el patrón decorativo del dovelaje del arco geminado del inmueble no 7-8 respecto al del inmueble no 2 . Fotografías de Fernando Alda.

Desconocemos si existieron trabajos de remozamiento de la estructura a excepción de la reciente restauración de las pinturas de los arcos de la casa n. ${ }^{\circ} 2$. Es posible que esta no solo consolidara la policromía, sino que alterara los motivos originales que posiblemente estuvieran muy perdidos por su exposición continuada a los agentes externos, falseando por tanto la relación de simetría que consideramos deberían guardar entre ellos, pero, por otro lado, no se puede asegurar tal extremo al no lograr, de momento, analizar estos arcos suficientemente.

El alfarje de la estancia central, cuya prolongación se conserva en su estado original en la casa n. ${ }^{0} 2$, también fue analizado desde varias perspectivas. Los análisis estratigráficos confirmaron la coetaneidad de alfarje y canes respecto al edificio islámico. Esta relación sincrónica quedó verificada por el hallazgo de los empotramientos de los canes en el muro de tapial del palacio, no ofreciendo dudas al ser esas las únicas huellas que se advierten en el paramento. El estudio estilístico de la decoración realizado por Bernabé Cabañero (e. p.) fue revelador, pues además de certificar la inexistencia total de policromías, incluso en los intersticios de las formas talladas, algo inconcebible en el arte islámico, hizo tres observaciones determinantes para la cronología. La primera fue la relación de inmediata posterioridad entre estos canes y los documentados en el Palacio de la Aljafería de Zaragoza, levantado entre 1039 y 1075 y considerado como uno de los principales modelos del periodo de los reinos de taifas por su alto nivel de conservación. Estos reinos, herederos del Califato Cordobés, necesitaban legitimar su poder a través del profeta, o en todo caso, del califa. La taifa sevillana lo hizo a través de la figura de Hišām II, mientras que la zaragozana, no solo acogió en sus dominios al último califa omeya, Hišām III, sino que también emprendió la labor de construir el Palacio de la Aljafería, decorado en su interior con elementos arquitectónicos y artísticos similares a la Gran Mezquita de Córdoba. Así, obtuvieron los dos objetivos perseguidos, a saber; certificar su autoridad y convertirse en transmisores de la cultura omeya. A partir de este momento, encontramos paralelos decorativos indiscutibles en diferentes edificios de nuestro país y fuera de él: el Palacio del Temple en Toledo (1085-1114, Cabañero y Herrera 2000: 221), la Iglesia de San Millán en Segovia (1106-1114, Cabañero y Herrera 1999: 227), o la Mezquita de Tremecén (1082-1136, Almagro 2015a: fig. $22 \mathrm{~s} / \mathrm{n}$ ) son algunos de los ejemplos, a los que viene a sumarse el palacio de la casa 7-8, cuyo alfarje y decoración participan de esos mismos principios básicos recibidos del califato.

La segunda observación es el uso de plantilla para trazar la decoración de los costados, pues los motivos de rizos de rollos que se repiten entre sí apenas presentan minúsculas variaciones que no comprometen el homogéneo resultado final. Esta indagación le lleva a la tercera y última, pues advierte la presencia de partes que se encuentran sin tallar, mostrando solo el trazado de base sobre el que comenzar a trabajar.

Todo ello le hace afirmar sin ninguna duda que los canes de la casa 7-8 beben directamente de la influencia recibida del Palacio de la Aljafería de Zaragoza entre 1065 a 1075 así como del Palacete de Balaguer, fechado en torno a 1075-1080, arrojando una posible fecha de construcción del palacio del Alcázar que oscila entre 
1086 y 1091. Asimismo, la certeza de que estas piezas quedaran inconclusas podría explicarse por los trágicos hechos históricos que determinaron el final de la taifa sevillana y que se sucedieron precisamente en esa última década del siglo XI.

Para la datación por Carbono 14 del alfarje se tomaron tres muestras en total: de la madera de los empotramientos pertenecientes a dos canes de la techumbre de la casa 7-8 se obtuvieron dos, siendo la tercera muestra extraída de uno de los tirantes del alfarje de la casa $n .^{\circ} 2$. Los resultados arrojaron unas fechas coherentes con los análisis anteriores, a saber, entre 1032 a 1186 y 1031 a 1170 para los canes, y $1117 \pm 30$ para el tirante, sugiriendo, por tanto, un momento de transición taifa-almorávide.

Por último, las muestras de Carbono 14 de la galería de arcos situada frente al patio ajardinado dieron como resultado unos valores de $1126 \pm 28$ años, igualmente razonables en el contexto de los intervalos expuestos.

\section{Perduración y amortización}

El palacio continuaría en uso tras la ocupación cristiana, experimentando una reforma en su sector occidental como consecuencia de una necesidad urgente de reparar sus muros. El argumento material en el que nos apoyamos para hacer esta interpretación está en una discontinuidad próxima al extremo oeste del paramento norte, antes descrita, punto en el que se aprecia la conexión del muro de tapial islámico con otro de diferente tipología. Las características de este tapial, de menos calidad que el original, nos acerca a un periodo inicial cristiano $^{19}$, inmediato a la conquista.

El frente meridional de la crujía norte del palacio fue eliminado hasta sus cimientos, aprovechando sus fundamentos para levantar en su lugar un muro de ladrillos cuya métrica y aparejo son los mismos que los empleados para construir las cadenas y pie de aguja del tapial castellano, considerando ambas fábricas coetáneas. La exclusividad del ladrillo en este caso puede deberse a la utilización de este espacio como ámbito

\footnotetext{
19 Siguiendo la clasificación de Graciani y Tabales (2008) el tapial que se utiliza para la reforma del palacio responde a la tipología 4.2, cuyo uso se extiende desde época almohade hasta la edad moderna. Asimismo, la métrica de los cajones, de $0,90 \mathrm{~m}$, de sus piezas latericias $(0,30 \times 0,15 \times 0,005 \mathrm{~m})$ así como su aparejo, a soga y tizón moviendo la soga, nos acercan a un momento encuadrable en época cristiana.
}

de una escalera de comunicación con las plantas superiores, cuyo uso se mantuvo hasta la construcción de la casa actual.

Tal y como avanzábamos en líneas previas, relacionamos esta reforma con los desastres que debieron producirse tras el terremoto documentado en 1356, vinculando también este fenómeno con la destrucción de la bóveda y la reparación pictórica de los arcos geminados, otorgándoles una nueva pátina castellana lograda a través de la representación de las figuras de leones y castillos, motivos que se repiten con frecuencia en el interior del Alcázar, sobre todo en el Palacio de Pedro I (Figs. 31 y 32).

El edificio iría degradándose con el paso de los siglos, sufriendo importantes alteraciones como consecuencia de las nuevas ordenaciones en el caserío urbano. No obstante, la entidad del enclave fue respetada, pues se fijaría como residencia del Alcaide del Alcázar, cargo de máximo prestigio durante época moderna.

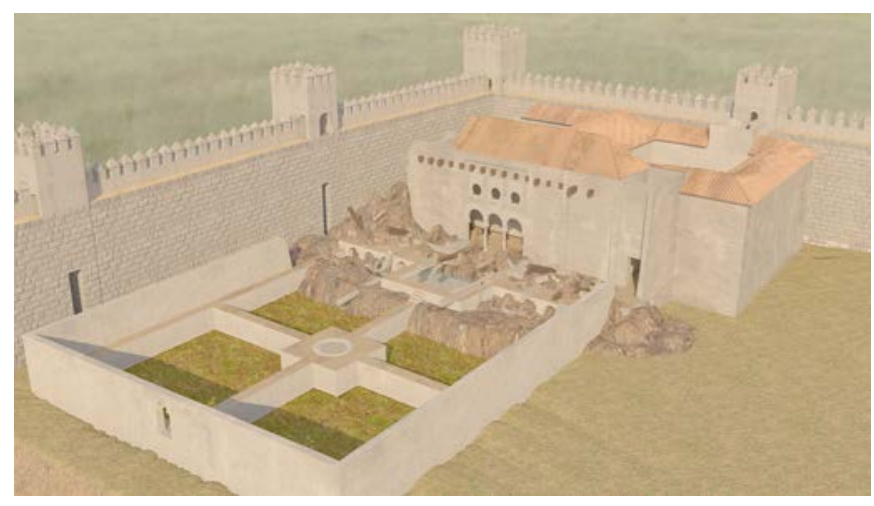

Figura 31. Reconstrucción hipotética de la transformación del palacio islámico durante el siglo XIV. Reconstrucción virtual de Jesús García Carpallo a partir de Miguel Ángel Tabales Rodríguez y Cristina Vargas Lorenzo.

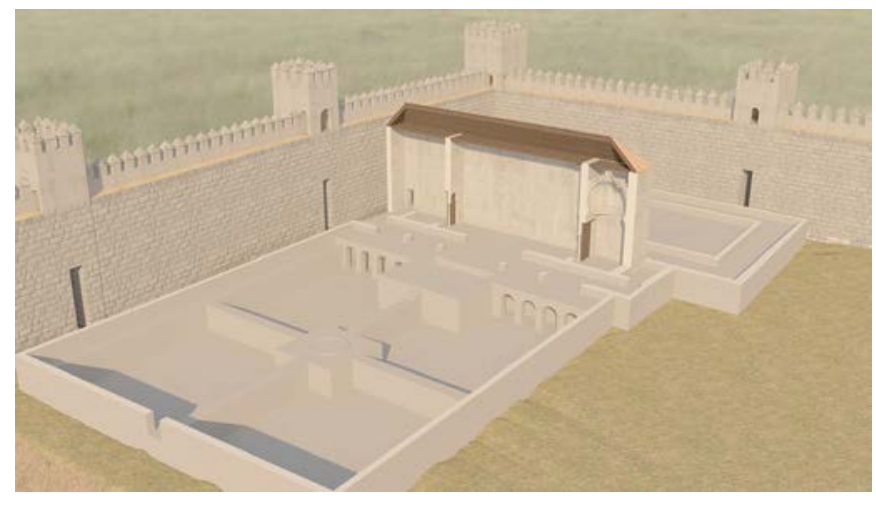

Figura 32. Reconstrucción hipotética del aspecto del palacio tras el terremoto de 1356. Reconstrucción virtual de Jesús García Carpallo a partir de Miguel Ángel Tabales Rodríguez y Cristina Vargas Lorenzo. 
El siglo XIX supuso para el antiguo palacio un notable punto de inflexión, pues la parcela quedó segregada en 9 inmuebles diferentes, afrontando su última gran transformación en 1874, año en el que se construye el edificio actual a petición del I marqués de Irún, cuyo sucesor, Fernando de la Serna Zuleta (II marqués de Irún) se convertiría en Administrador del Alcázar en el año de 1892 (Márquez 2010: 119). A partir de ese momento, el inmueble se consolidó como residencia del marqués y su familia, que continuó arrendando la casa al Patronato a cambio del pago de una cuota hasta 1931, año en el que se instaura la II República, pasando el Alcázar a ser propiedad de Patrimonio del Estado. La situación cambió con el Decreto de 22 de abril de 1931, según el cual el Conjunto Monumental volvería a pasar al Consistorio, pero no así las casas, que resultaban beneficiosas para el Estado por las rentas que producían. Estas circunstancias se han mantenido hasta la actualidad, siendo sus últimos inquilinos parientes lejanos del II marqués de Irún. Nos referimos a la señora Magdalena Delgado, esposa del emblemático Luis Toro Buiza, uno de los principales responsables de la Sociedad de Bibliófilos Sevillanos y Director del Archivo Hispalense, cargo que aceptó en 1943 (Fig. 33).

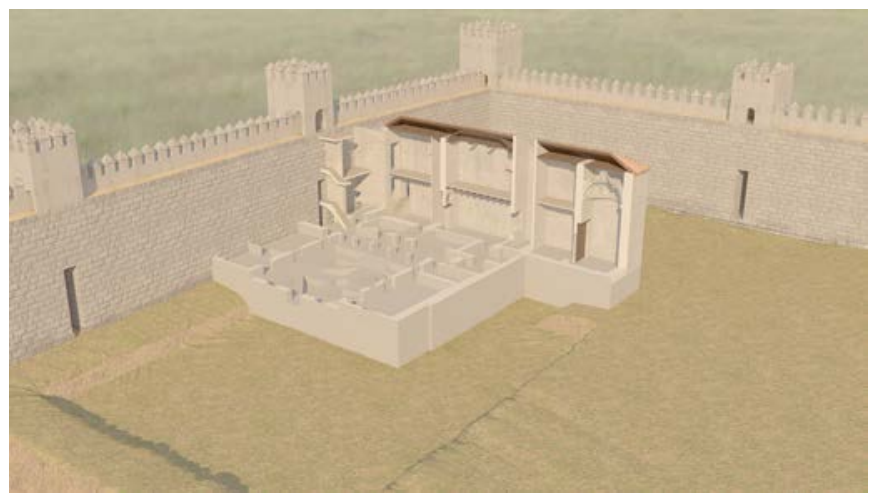

Figura 33. Reconstrucción hipotética de la transformación del palacio islámico en el siglo XIX tras la construcción de la vivienda actual. Reconstrucción virtual de Jesús García Carpallo a partir de Miguel Ángel Tabales Rodríguez y Cristina Vargas Lorenzo.

\section{LA RECUPERACIÓN DEL PALACIO Y PLANTEAMIENTOS DE FUTURO}

Los trabajos, asumidos en el Control Arqueológico de Obras, consistieron en supervisar todas aquellas actividades reflejadas en el Proyecto Arquitectónico de consolidación del inmueble que implicaran una alteración de estructuras preexistentes, tanto en alzado como en subsuelo, poniendo especial atención a las recomendaciones para la conservación de los restos del palacio. Asimismo, en el transcurso de los trabajos surgieron problemáticas no previstas en un principio y que derivaron en nuevas propuestas que fueron aceptadas e incorporadas al proyecto.

Todas las actuaciones encaminadas a consolidar y poner en valor los restos arqueológicos recuperados, se efectuaron de acuerdo a los criterios establecidos en los Planes Especiales de Protección del Conjunto Histórico de Sevilla, los documentos internacionales y las leyes de patrimonio donde se exige el cumplimiento de unos requisitos mínimos, garantizando así cuestiones como la total distinción entre las partes antiguas y las nuevas o limitar un posible exceso en el grado de intervención.

\section{Control arqueológico de las tareas de consolidación de estructuras y elementos arquitectónicos derivadas de las recomendaciones para la conservación}

El trazado de la muralla integrado en la propiedad fue intervenido al completo mediante un picado de los revestimientos contemporáneos, llagueado de juntas con especial cuidado de no eliminar sus ripios originales, cepillado y limpieza de sillares, contemplando la reconstrucción volumétrica de todos los que estuvieran afectados por pérdida de masa muraria mediante morteros de cal y arena, consolidación de revestimientos originales y tratamiento final contra insectos xilófagos.

En la Torre del León se contempló la demolición de un castillete contemporáneo de escalera adosado a la cara oriental de la torre, así como de forjados y tabiques, también contemporáneos, ubicados en su interior. Tras dicha operación, se llevó a cabo el picado de los revestimientos recientes, interiores y exteriores, limpieza de su fábrica original, reconstrucción volumétrica de los sillares pertenecientes a la bóveda por aproximación de hiladas, reconstrucción del acceso original al interior de la torre y puesta en valor mediante iluminación para potenciar la visión de su cámara.

En la nave norte perteneciente al palacio, se recuperaron los paramentos originales de acceso a la alcoba occidental mediante picado de revestimientos contemporáneos, manteniendo su avitolado primitivo, reconstrucción con ladrillo macizo de pérdidas de masa muraria e incorporación de la columna central de la bífora similar 
a la de la casa n. $^{\circ} 2$ sobre peana de ladrillos para indicar la cota del palacio, así como limpieza y consolidación de los muros de tapial de los siglos XI y XIV respectivamente previa protección mediante enfoscado de morteros de cal y arena.

En el sótano, se llevó a cabo la limpieza y consolidación del muro de cimentación del palacio islámico localizado en planta baja, así como el picado de revestimientos contemporáneos, llagueado de juntas y limpieza de las bóvedas del sótano.

Los restos en subsuelo de los sondeos estratigráficos realizados entre los años 2013 y 2014, fueron protegidos mediante malla geotextil y posterior enterramiento con arena lavada a excepción del XXIV, perteneciente al arrabal de época taifa previo a la construcción del Alcázar.

\section{Control arqueológico de actuaciones incorporadas al proyecto arquitectónico en el transcurso de la obra}

Con el objeto de la mejora e introducción de nuevos saneamientos en el sótano, salieron a la luz restos de la cimentación del lienzo occidental de la muralla del Alcázar. El elemento, una vez analizado y contextualizado, fue incorporado visualmente al edificio. Para ello, se procedió a una limpieza de las dos hiladas de sillares recuperadas, reconstruyendo sus partes perdidas con morteros de cal y arena y delimitando su contorno con grava de pequeño calibre para facilitar su comprensión y mejor entendimiento.

En el área central del sótano, durante los trabajos de limpieza y resanado del paramento que se halla enfrentado al muro de fachada del palacio, salieron a la luz los restos de la arquería perteneciente al jardín deprimido, situada a ambos lados de la alberca. Tras el preceptivo análisis estratigráfico y tipológico, se propuso la posibilidad de consolidar sus restos y dejarlos a la vista dada su singularidad y valor histórico, siendo la propuesta finalmente aceptada.

Respecto a las actuaciones en planta baja, expresamos la voluntad de ampliar la continuidad visual de la muralla hacia el interior de la vivienda mediante la apertura en la nave occidental de dos huecos de formato rectangular protegidos con sendos vidrios. La propuesta fue elevada a la propiedad y resuelta favorablemente, aplicando además ese mismo criterio de respeto y sensibilidad en todas aquellas dependencias por las que esta discurriera. En este sentido, el forjado intermedio situado en el ala oeste de la vivienda fue desmantelado y sustituido por otro de nueva factura anclado a la muralla en tan solo dos puntos, dejando a la vista el lienzo completo hasta el nivel de su adarve. Un criterio similar se aplicó en la estancia principal perteneciente al antiguo palacio, cuyo forjado intermedio de factura reciente fue demolido y, en este caso, no repuesto, dejando la estancia diáfana de acuerdo con su fisonomía original. Además, el muro de tapial correspondiente al cierre de la estancia por su lado norte fue consolidado, dejando a la vista una muestra sin revestir con el objeto de exponer su fábrica primitiva.

El ámbito de la Torre de la León también fue objeto de una profunda remodelación respecto al planteamiento establecido en proyecto. En principio, este contemplaba la sustitución de la escalera decimonónica anclada en la masa muraria de muralla y torre por otra de semejante factura. En su lugar, se dispuso una escalera metálica más ligera, cuyos anclajes se desviaron a muros recientes, logrando así los dos objetivos propuestos, estos son, no agredir su materialidad a la par que respetar y señalar sus valores históricos.

En la planta superior, y durante el transcurso del picado y limpieza de sus paramentos, emergió el fragmento perteneciente a una de las tres celosías que originalmente coronaban cada uno de los arcos de la trífora de acceso a la nave principal. El fragmento, tras su análisis y contextualización, fue sometido a limpieza y consolidación con la finalidad de incorporarlo visualmente al edificio.

Por último, durante los trabajos de revisión del estado de aquellos forjados no contemplados en proyecto, se descubrió el acusado deterioro del artesonado que cubría la nave principal del palacio. La gravedad de los daños en la estructura requirió de una intervención urgente no planificada inicialmente, consistente en analizar sus soluciones constructivas en primera instancia para plantear, en segundo lugar, una propuesta de rehabilitación y puesta en valor. Dicha propuesta contempló la recuperación del formato original del alfarje según el modelo conservado en el inmueble $n .^{\circ} 2$, respetando las piezas conservadas (canes), y reproduciendo los elementos desaparecidos con criterio diferenciador (vigas y tablazones). Su estructura exterior se recuperaría según la altura y pendientes a cuatro aguas propios del edificio islámico, modelo conocido y propuesto por Antonio Almagro (2015b: 20), con el que coincidimos, siendo el objetivo último conseguir la unificación de la 
estancia completa, actualmente dividida por un pequeño patinillo. Así, en un futuro, de lograrse la unificación, se actuaría en la casa $n .^{\circ} 2$ de tal modo que la techumbre islámica original sería recuperada al completo por extensión de la ya construida en la casa 7-8.

Los trabajos arqueológicos, una vez autorizados por la Comisión Provincial de Patrimonio, consistieron en supervisar el desmontaje tanto de la cubierta decimonónica como de los canes del antiguo alfarje, su proceso de restauración, así como el asesoramiento sobre la reproducción del formato de techumbre siguiendo el modelo original. Para esta última tarea fue imprescindible la investigación arqueológica previa y, sobre todo, la realizada durante la vigilancia del desmontaje citado, pues gracias a ello pudimos certificar el formato primitivo de la techumbre, diferenciando sus partes antiguas de las recientes, conocer y recuperar sus cotas históricas (situadas a $7 \mathrm{~cm}$ por debajo de los niveles en los que se apoyaba el artesonado contemporáneo) y analizar en profundidad sus canes cronotipológicamente.

Desde el mismo planteamiento del Proyecto Arquitectónico hasta el final de la obra de rehabilitación, el respeto y cuidado de los valores patrimoniales ha primado sobre el resto de intereses. Para ello, ha sido imprescindible el buen entendimiento entre el equipo de arquitectos y aparejadores, encargados de la obra, y los investigadores del edificio, responsables de su análisis arqueológico. Ambos agentes, conscientes de la responsabilidad que suponía afrontar su recuperación dado el valor del enclave y sus implicaciones, aunaron esfuerzos en la obtención de un doble objetivo común: efectuar, por un lado, las tareas necesarias para revertir el deterioro del inmueble, y por otro, anticiparse a un más que posible cambio de uso, pasando de ser un edificio administrativo, como estaba planteado inicialmente, a un edificio histórico de función patrimonial.

Como hecho más relevante se debe destacar la confirmación de la existencia en la tercera crujía del inmueble de los restos del palacio más antiguo del recinto primitivo del Alcázar. Esta evidencia nos ha hecho insistir durante todo el desarrollo del proyecto en la necesidad de unificar en un futuro próximo la sala principal del palacio, así como las dos alcobas anexas, recuperando en una de ellas su forma original (la cúpula existente en la casa n. $^{\circ} 2$ ), y recreando de forma virtual la ya desaparecida. Para ello, se ha previsto el espacio necesario, eliminando el forjado intermedio de la sala, de factura reciente, y colocando el alfarje tal y como estuvo dispuesto en el siglo XI.

En este sentido, los trabajos futuros como consecuencia del cambio de uso del inmueble deberían abordar ciertas actividades en materia de conservación no llevadas a cabo durante el desarrollo de la obra por falta de presupuesto. Nos referimos a tareas como la restauración de la decoración pictórica del arco geminado, únicamente consolidado, la restauración y consolidación de los restos arqueológicos mantenidos en la galería del palacio, la recuperación del estanque central localizado en las excavaciones de 2013, reconstrucción del patio decimonónico a fin de que no acabe siendo destinado a aparcamiento después del esfuerzo realizado en reparar la muralla, y la consolidación de los arcos inferiores del patio islámico localizados en el sótano frontal.

La unificación de la estancia principal del palacio islámico se lograría previa demolición del patinillo de separación entre las casas 7-8 y 2 , seguido de la prolongación de la techumbre de la casa 7-8 recién recuperada hacia la casa $n^{\circ}{ }^{\circ} 2$, siguiendo el mismo proceso de ejecución, a saber: eliminación de alfarje intermedio, reposición y ajuste del alfarje primitivo, reconstrucción de la techumbre superior en la casa 2, ajuste de cotas para homologar los espacios, reconstrucción con materiales ligeros de la bóveda occidental y, finalmente, unificación de ambas cubiertas inclinadas de tejas.

Dichas operaciones, si bien aún no están autorizadas, confiamos en que lo estén en un futuro próximo, pues resultan claves para la reconstrucción de esta etapa histórica del Alcázar (Fig. 34).

\section{CONCLUSIONES}

El análisis realizado mediante las herramientas que proporciona la Arqueología de la Arquitectura ha permitido afrontar el estudio y análisis de una construcción histórica compleja en rehabilitación: la aplicación de la estrategia de intervención basada en el método estratigráfico supuso el punto de partida desde el que comenzar a trabajar, obteniendo de ese modo una primera hipótesis evolutiva fundamentada en dataciones relativas, obtenidas a través del análisis arqueológico de paramentos y subsuelo, para, en una segunda fase, convertir en absolutas esas cronologías preliminares a través de las ciencias auxiliares. En este punto, la participación de un extenso equipo multidisciplinar ha sido fundamental para lograr los objetivos perseguidos, estos son: la caracterización de sus elementos estructurales, constructivos, patológicos, artísticos, etc., y su posterior datación a través de analíticas químicas. 

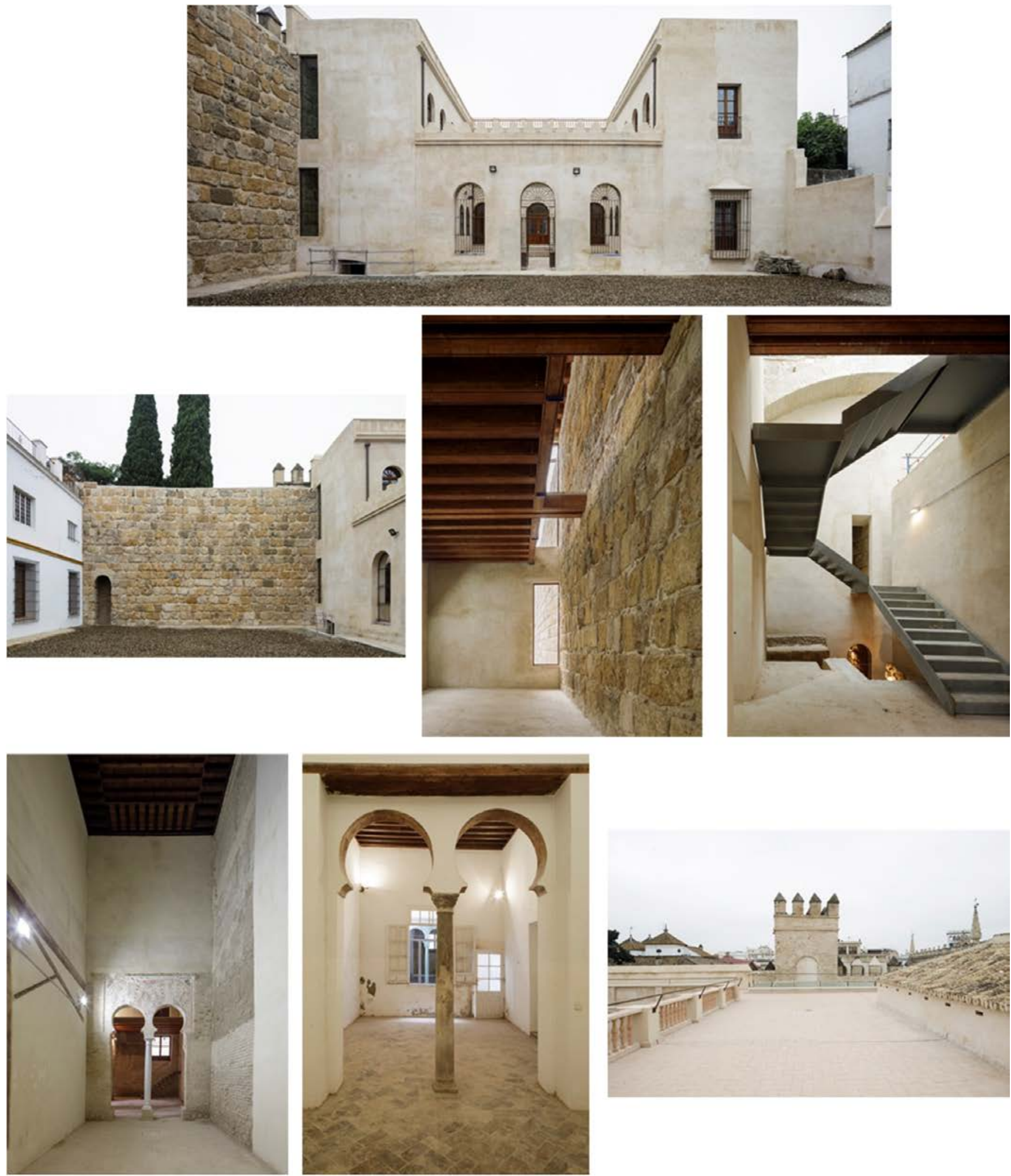

Figura 34. Estado de la vivienda tras la ejecución de las obras de restauración con los restos de la muralla y palacio recuperados. Fotografías de Fernando Alda. 
En este sentido, el estudio estratigráfico permite esbozar con altos niveles de certeza las trazas de un edificio de corte palacial fechado por sus materiales entre mediados del siglo XI y primeras décadas del siglo XII, esto es, años centrales de los reinados de al-Mu'tadid y al-Mu'tamid, respectivamente, y principios del mandato de Yūsuf ibn Tāšifīn. Descartamos una cronología más avanzada al constatar la total ausencia de materiales más evolucionados, así como la conformidad con la constatación de la secuencia general del Alcázar de Sevilla, que atribuye la construcción de nuevos palacios vinculados a la ampliación del recinto fundacional a partir del siglo XII (Tabales 2010: 18-21).

Los estudios de los restos artísticos conservados (policromías de los arcos geminados y canes del alfarje) han caracterizado la composición de sus elementos con altísimo rigor además de proporcionar nuevas evidencias sobre las que reflexionar, estas son: la incertidumbre sobre la cronología del programa pictórico de las roscas de los arcos respecto de la heráldica presente en sus enjutas, así como la posibilidad de que el palacio quedara inconcluso si tenemos en cuenta la ausencia de talla de algunas partes de los canes.

Por último, las analíticas de Carbono 14 y termoluminiscencia han servido para convertir en absolutas las dataciones relativas obtenidas a partir del análisis estratigráfico. El modelo bayesiano aplicado es rotundo a ese respecto; los resultados muestran que la muralla del primer recinto se construyó en un momento inmediatamente anterior al palacio, contemplándose para ese último dos posibilidades más o menos ajustadas en función de los sigmas aplicados: entre 1054 y 1143 con $2 \sigma(95,4 \%)$ y $1065-1140$ con $1 \sigma$, es decir, época de transición taifa-almorávide (Jiménez e. p.).

Teniendo en cuenta todo lo anterior, y aunque no podemos aportar datos cuantificables que certifiquen que el palacio quedara inconcluso, nos inclinamos por seguir trabajando sobre esta hipótesis. A favor de ella, y recapitulando, la inexistencia de otra nave opuesta al frente norte, la completa ausencia de restos pictóricos en la totalidad de los rellenos excavados, la composición pictórica de dudosa adscripción, o la seguridad de que parte de los canes quedaron sin tallar, suponen evidencias lo suficientemente sólidas como para no desestimarlas. Dicha teoría resulta coherente considerando el momento histórico que envuelve la construcción del primer alcázar y su palacio, marcado por una precipitada caída en desgracia de al-Mu'tamid al confiar en el emir almorávide Yūsuf ibn Tāšifīn para que lo ayudara a conquistar la fortaleza de Aledo tras su victoria en Sagrajas contra los castellanos en el año 1086. Así, en el año 1091 los almorávides tomaron la ciudad, usurpando todas las posesiones que durante casi medio siglo la dinastía abbadí se había preocupado por erigir, incluido el palacio de Sevilla, quizás sin finalizar debido a la repentina sucesión de los acontecimientos.

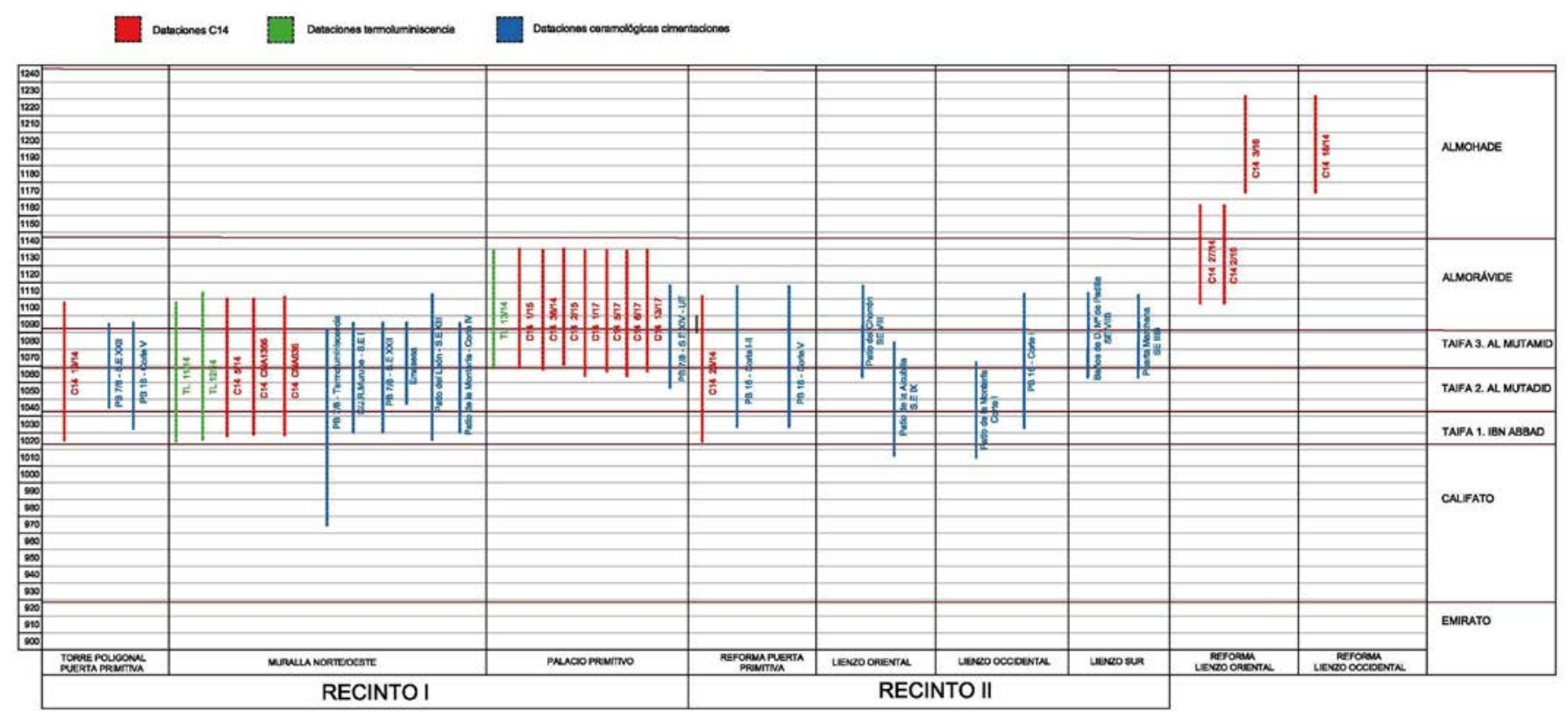

Figura 35. Tabla comparada de dataciones de los recintos primitivos del Alcázar y su palacio (según Miguel Ángel Tabales Rodríguez). 


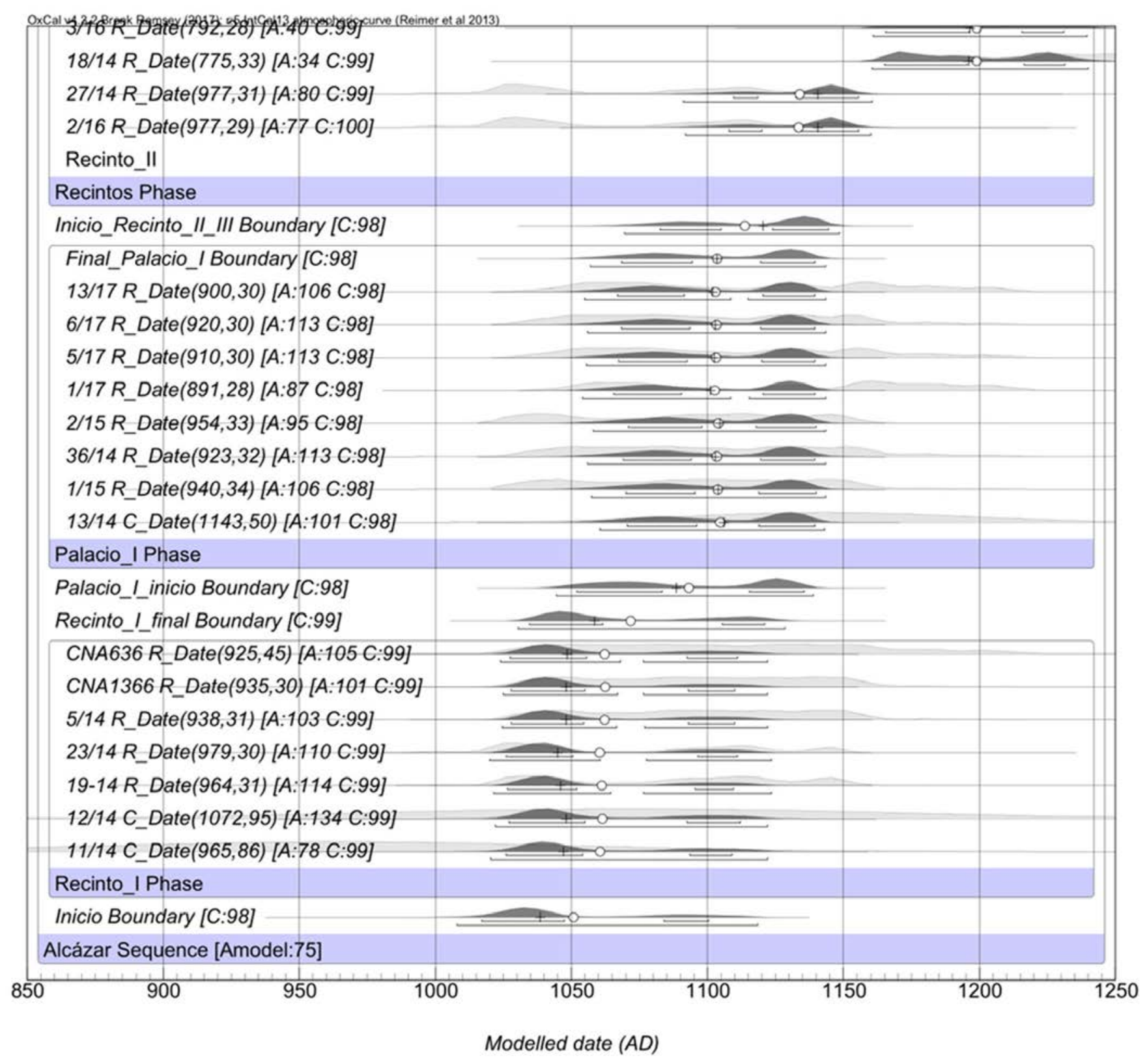

Figura 36. Modelado bayesiano de las muestras radiocarbónicas y luminiscentes del recinto I y el palacio. Las muestras en sombreado de color claro indican el rango de fechas sin modelar y en color oscuro la probabilidad ya modelada. El punto blanco representa la muestra media y la cruz indica la mediana. Modelado bayesiano, comentarios y gráfico efectuado por Alejandro Jiménez Hernández.

En definitiva, los restos recuperados permiten definir las trazas de un palacio ubicado en alto, compartimentado en dos grandes áreas, una de representación, decorada con ricas policromías, y otra doméstica, con un patio de crucero a sus pies organizado en torno a dos puntos de captación de agua: una alberca en el frente menor y una fuente, en el centro.

Esta solución formal y artística no es aislada, responde a un esquema heredado de los principios básicos arquitectónicos y decorativos concebidos durante el califato cordobés, continuado con la construcción del Palacio de la Aljafería y asumido a posteriori por la cultura andalusí. El análisis de los escasos ejemplos de edificios del s. XI documentados en nuestro país, estos son: la Aljafería de Zaragoza, la casa del Temple en Toledo, el palacete de Balaguer, o la Iglesia de San Millán en Segovia, efectuado por el profesor Cabañero Subiza, constata la existencia de una corriente de influencias cuyo origen se sitúa en las tablas decorativas halladas en el Cortijo del Alcaide, en Córdoba (960-981), generando un patrón 
que fue asimilado durante el Califato de Córdoba y reproducido mecánicamente en edificios islámicos posteriores con el objeto de legitimar el poder allí donde los mandatarios no estuvieran directamente vinculados con la familia del profeta ni con ninguna otra figura de autoridad. Así sucedió en la taifa de Zaragoza, mediante la construcción de un palacio que reproduce con minuciosidad el interior de la Gran Mezquita de Córdoba, modelo que sabemos con certeza siguieron otras ciudades como Toledo, Lérida y Segovia, teniendo en cuenta los casos investigados (Cabañero 2018: 360, 365).

A todos ellos viene a sumarse ahora el palacio de Sevilla, con unas soluciones formales y decorativas tomadas de esos focos fundamentales y que, a su vez, participa de esa misma tradición trasmisora, pues resulta lógico pensar que sirviera como prototipo de otros palacios del Alcázar inmediatamente posteriores, como el del Yeso, Crucero y Contratación, dadas las semejanzas que guarda con todos ellos.

Nos encontramos, por tanto, ante un paradigmático caso de estudio, con las incógnitas esenciales ya despejadas, pero con otras por resolver, como es la constatación de la existencia de su ámbito doméstico o el análisis arqueológico del sector oriental de la estancia principal. Ambas problemáticas esperamos resolverlas en el desarrollo de cualquier proyecto futuro que nos permita continuar con su investigación, pues sus resultados serán claves en la reconstrucción de esta etapa histórica del Alcázar.

Entendemos que la vinculación investigación-restauración ha funcionado, en este caso, aceptablemente. $\mathrm{Al}$ análisis previo para generar una hipótesis de partida, le ha seguido el desarrollo de una investigación preventiva, así como la asunción por el proyecto de ejecución de nuestras recomendaciones; un proyecto ejecutado junto con un exhaustivo control arqueológico de obras $\mathrm{y}$, finalmente, una coherente recuperación de los restos islámicos originales y una adecuación de los espacios para futuras incorporaciones de elementos del complejo palatino en las casas colindantes.

\section{AGRADECIMIENTOS}

Agradecemos a Patrimonio del Estado la buena sintonía y el respeto por la investigación mantenida durante todo el proceso, así como a los arquitectos Javier Ochoa y Gabriel Ocaña.
Las fotos correspondientes a los planos de Vermondo Resta y Sebastián Van der Borcht fueron efectuadas con el permiso del Archivo General de Simancas y Archivo General de Palacio, respectivamente.

La autoría de figuras consta en sus pies, excepto en aquellas que son de la autora del texto.

\section{FICHA TÉCNICA}

- PROPIEDAD: Patrimonio del Estado. Ministerio de Hacienda y Función Pública.

- ARQUITECTO DIRECTOR DE OBRA: Gabriel Ocaña Gómez. Patrimonio del Estado. Ministerio de Hacienda y Función Pública.

- DIRECTOR DE EJECUCIÓN DE OBRA: Juan Antonio Cuenca García. Ingeniero de Edificación. Ministerio de Hacienda y Función Pública.

- ARQUITECTO REDACTOR DEL PROYECTO: Javier Ochoa Casteleiro. OC Arquitectura y Urbanismo.

- EMPRESA CONSTRUCTORA: TRAGSA Empresa de Transformación Agraria S.A.

- COORDINACIÓN INTERVENCIÓN ARQUEOLÓGICA: Miguel Ángel Tabales Rodríguez (Universidad de Sevilla).

- DIRECCIÓN INTERVENCIÓN ARQUEOLÓGICA: Cristina Vargas Lorenzo (Arqueóloga).

- PLANIMETRÍA, DELINEACIÓN: Jesús García Carpallo (Ingeniero de Edificación).

- BASE DE DATOS, ESTUdIO METROLÓGICO Y MODELADO BAYESIANO DE LOS ELEMENTOS RADIOCARBÓNICOS Y TERMOLUMINISCENTES: Alejandro Jiménez Hernández (Doctor Arqueólogo).

- REGISTRO Y CONTROL DE MATERIALES: Ana Durán Jerez (Arqueóloga).

\section{ANEXO: ARCHIVO COMPLEMENTARIO}

En la versión en línea (menú Herramientas del artículo) se acompaña un archivo complementario en formato vídeo MP4: Reconstrucción virtual del palacio primitivo del Alcázar de Sevilla. Autor Jesús García Carpallo según hipótesis de Miguel Ángel Tabales Rodríguez y Cristina Vargas Lorenzo. 


\section{FUENTES PRIMARIAS}

Baceiredo Rodríguez, M. I. 2019: "Intervención de urgencia. Limpieza y consolidación de las pinturas murales de un arco geminado prealmohade. Inmueble 7 y 8 del Patio de Banderas de Sevilla", en C. Vargas Lorenzo, Control Arqueológico de Movimiento de Tierras en la Casa 7-8 del Patio de Banderas (Memoria Final inédita).

Cabañero Subiza, B. en prensa: "Análisis cronológico de la estructura y de los elementos decorativos del palacio del primer recinto", en M. Á. Tabales Rodríguez (coord.), El origen del Alcázar de Sevilla. Estudios arqueológicos y constructivos. Junta de Andalucía, Consejería de Cultura.

Cañas Palop, C. 2019: "Estudio de la armadura de cubierta que cubre la estancia principal de lacasa 7-8 del Patio de Banderas", en C. Vargas Lorenzo, Control Arqueológico de Movimiento de Tierras en la Casa 7-8 del Patio de Banderas (Memoria Final inédita).

García Bueno, A. 2019: "Caracterización de materiales y técnica de ejecución. Arco geminado del inmueble n. ${ }^{\circ}$ 7-8 del Patio de Banderas. Real Alcázar de Sevilla", en C. Vargas Lorenzo, Control Arqueológico de Movimiento de Tierras en la Casa 7-8 del Patio de Banderas (Memoria Final inédita).

Jiménez Hernández, A. en prensa: "Modelado bayesiano de las dataciones radiocarbónicas y luminiscentes", en M. Á. Tabales Rodríguez (coord.), El origen del Alcázar de Sevilla. Estudios arqueológicos y constructivos. Junta de Andalucía, Consejería de Cultura.

Tabales Rodríguez, M. Á. en prensa: "La construcción de las murallas del primer recinto", en M. Á. Tabales Rodríguez (coord.), El origen del Alcázar de Sevilla. Estudios arqueológicos y constructivos. Junta de Andalucía, Consejería de Cultura.

\section{BIBLIOGRAFÍA}

Almagro Gorbea, A. 2011: "Sistemas constructivos almohades: estudio de dos bóvedas de arcos entrecruzados", en S. Huerta, I. Gil Crespo, S. García y M. Taín (eds.), Actas del Séptimo Congreso Nacional de Historia de la Construcción, Santiago 26-29 octubre 2011, pp. 44-53. Instituto Juan de Herrera, Madrid.

Almagro Gorbea, A. 2015a: "La mezquita mayor de Tremecén y la cúpula de su maqsūra", Al-Qantara-Revista de estudios árabes, 36 (1), pp. 199-257. https://doi.org/10.3989/alqantara.2015.007

Almagro Gorbea, A. 2015b: "Los jardines andalusíes y mudéjares del Alcázar de Sevilla”, en A. Marín y C. Plaza (eds.), Los jardines del Real Alcázar de Sevilla. Historia y Arquitectura desde el medievo islámico al s. XX, pp. 1-39. Patronato del Real Alcázar de Sevilla y de la Casa Consistorial, Sevilla.

Caballero Zoreda, L. 1996: "El análisis estratigráfico de construcciones históricas", en L. Caballero Zoreda y C. Escribano Velasco (eds.), Arqueología de la Arquitectura. El método arqueológico aplicado al proceso de estudio y de intervención en edificios históricos, pp. 55-74. Junta de Castilla y León.

Cabañero Subiza, B. 2018: "La aportación del Palacio Aljafería de Zaragoza al arte del Islam Occidental de los siglos XII al XV”, en M. Marcos (dir. y coord.), al-Murābițūn (los almorávides): un Imperio islámico occidental. Estudios en memoria del Profesor Henri Terrasse, pp. 345-373. Junta de Andalucía, Consejería de Cultura, Patronato de la Alhambra y Generalife.

Cabañero Subiza, B. y Herrera Ontañón, V. 1999: "La techumbre mudéjar de la iglesia de San Millán de Segovia. Estudio de una obra maestra del arte taifal digna de ser recuperada", Artigrama, 14, pp. 207-240.

Cabañero Subiza, B. y Herrera Ontañón, V. 2000: "La Casa palacio del Temple de Toledo. Un monumento taifa recientemente recuperado", Artigrama, 15, pp. 177-230.
Fernández Aguilera, S., Prada Machuca, M. A. y Gelo Pérez, R. 2017: "El Patrimonio Artístico del Real Alcázar de Sevilla, a través de sus inventarios históricos", Apuntes del Alcázar 18.

Francovich, R. y Parenti, R. (eds.) 1988: Archeologia e restauro dei monumenti: I Ciclo di lezioni sulla Ricerca applicata in Archeologia, Certosa di Pontignano, Siena, 28 settembre-10 ottobre 1987, pp. 157-195. Firenze: All'Insegna del Giglio.

Gestoso Pérez, J. 1889: Sevilla monumental y artística. Historia y descripción de todos los edificios notables, (vol. I). Oficina tipográfica de El Conservador, Sevilla.

Gestoso Pérez, J. 1897: Guía artística de Sevilla. Historia y descripción de sus principales monumentos religiosos y civiles y noticia de las preciosidades artístico-arqueológicas que en ellos se conservan. Oficina de la Andalucía Moderna, Sevilla.

Gómez Martínez, S. 2004: La cerámica islámica de Mértola: producción y comercio. Tesis doctoral. Universidad Complutense de Madrid, Madrid.

Graciani García, A. y Tabales Rodríguez, M. Á. 2008: "El tapial en el área sevillana. Avance cronotipológico estructural", Arqueología de la Arquitectura, 5, pp. 135-158. https://doi.org/10.3989/arq.arqt.2008.93

Huarte Cambra, R. 2015: "Estudio de materiales cerámicos islámicos", en M. Á. Tabales Rodríguez, Excavaciones arqueológicas en el Patio de Banderas del Alcázar de Sevilla. Memoria de Investigación 2009-2014, pp. 141-280. Patronato del Real Alcázar y de la Casa Consistorial, Sevilla.

Huarte Cambra, R. 2016: "Analítica de las producciones cerámicas medievales: de la taifa abadí a la corona castellana”, en M. Á. Tabales Rodríguez, Excavaciones arqueológicas en el Patio de las Doncellas del Palacio de Pedro I. Memoria de Investigación 2002-2005, pp. 307-382. Patronato del Real Alcázar y de la Casa Consistorial, Sevilla.

Manzano Martos, R. 1995: "El alcázar almohade", en M. Valor (coord.), El último siglo de la Sevilla islámica (1147-1248), exposición Real Alcázar de Sevilla, 5 de diciembre 95-14 Enero 96, pp. 99-124. Universidad de Sevilla y Gerencia Municipal de Urbanismo del Ayuntamiento de Sevilla, Sevilla.

Márquez Redondo, Ana G. 2010: Los Alcaides del Alcázar de Sevilla. Patronato del Real Alcázar de Sevilla, Sevilla.

Navarro Palazón, J. y Jiménez Castillo, P. 2012: "La arquitectura de Ibn Mardanîsh: revisión y nuevas aportaciones", en G. M. Borrás y B. Cabañero (coords.), La Aljafería y el Arte del Islam Occidental en el siglo XI, Actas del Seminario Internacional celebrado en Zaragoza los días 1, 2 y 3 de diciembre de 2004, pp. 291-350. Instituto Fernando el Católico (CSIC), Excma. Diputación de Zaragoza, Zaragoza.

Salinas Pleguezuelo, M. ${ }^{a}$ E. 2012: La Cerámica Islámica de Madinat Qurtuba de 1031 a 1236: cronotipología y centros de producción. Tesis doctoral. Universidad de Córdoba, Córdoba.

Tabales Rodríguez, M. Á. 2000: "Investigaciones Arqueológicas en el Real Alcázar de Sevilla. Notas sobre su evolución constructiva y espacial", Apuntes del Alcázar de Sevilla, 1, pp. 12-45.

Tabales Rodríguez, M. Á. 2001: "Las murallas del Alcázar de Sevilla. Investigaciones arqueológicas en los recintos islámicos", Apuntes del Alcázar, 2, pp. 6-35

Tabales Rodríguez, M. Á. 2002a: Sistema de Análisis Arqueológico de Edificios Históricos. Universidad de Sevilla, Instituto Universitario de Ciencias de la Construcción, Sevilla.

Tabales Rodríguez, M. Á. 2002b: La primitiva puerta del Alcázar de Sevilla: memoria arqueológica. Parques Nacionales, Madrid.

Tabales Rodríguez, M. Á. 2010: El Alcázar de Sevilla. Reflexiones sobre su origen y transformación durante la Edad Media. Memoria de Investigación Arqueológica, 2000- 2005. Junta de Andalucía, Consejería de Cultura, Sevilla.

Tabales Rodríguez, M. Á. 2012: "El subsuelo del Patio de Banderas entre los siglos IX a.C. y XII d.C.”, Apuntes del Alcázar, 13, pp. 8-53.

Tabales Rodríguez, M. Á. 2013: "Origen y Alcázar islámico", Apuntes del Alcázar de Sevilla, 14, pp. 94-117.

Tabales Rodríguez, M. Á. 2015: Excavaciones arqueológicas en el Patio de Banderas del Alcázar de Sevilla. Memoria de Investigación 2009-2014. Patronato del Real Alcázar y de la Casa Consistorial, Sevilla. 
Tabales Rodríguez, M. Á. y Vargas Lorenzo, C. 2014: “La arqueología en el Alcázar de Sevilla. Nuevos estudios en el recinto primitivo e investigaciones derivadas de hallazgos casuales (2012-2014)”, Apuntes del Alcázar de Sevilla, 15, pp. 9-60.

Torres Balbás, L. 1949: Ars Hispaniae: Arte almohade; Arte nazarí; Arte mudéjar, Vol. IV. Plus Ultra, Madrid.

Vargas Lorenzo, C. 2013: "Reflexiones sobre cronotipologías en Arqueología de la Arquitectura. Métodos y sistemas de análisis”,
Arqueología de la Arquitectura, 10, e001. https://doi.org/10.3989 arq.arqt.2013.001

Vera Reina, M. y López Torres, P. 2005: La cerámica medieval sevillana (siglos XII al XIV): La producción trianera. BAR International Series 1403. The Basingstoke Press, Oxford.

VV. AA. 2002: Arqueología de la Arquitectura, 1. https://doi.org/10.3989/ arqarqt.2002.i1 